JORDI GALÍ

\title{
The Optimal Inflation Target and the Natural Rate of Interest
}

ABSTRACT We study how changes in the steady-state real interest rate (henceforth $r^{*}$ ) affect the optimal inflation target in a New Keynesian dynamic stochastic general equilibrium (DSGE) model with trend inflation and a lower bound on the nominal interest rate. In this setup, a lower $r^{*}$ increases the probability of hitting the lower bound. That effect can be counteracted by an increase in the inflation target, but the resulting higher steady-state inflation has a welfare cost in and of itself. We use an estimated DSGE model to quantify that trade-off and determine the implied optimal inflation target, conditional on the monetary policy rule in place before the financial crisis. The relation between $r^{*}$ and the optimal inflation target is downward sloping. While the increase in the optimal inflation rate is in general smaller than the decline in $r^{*}$, in the currently empirically relevant region the slope of the relation is found to be close to -1 . That slope is robust to allowing for parameter uncertainty. Under

Conflict of Interest Disclosure: Philippe Andrade is a senior economist and policy adviser at the Federal Reserve Bank of Boston; Jordi Galí is a senior researcher at the Centre de Recerca en Economia Internacional (CREI), a professor at Universitat Pompeu Fabra, and a research professor at the Barcelona Graduate School of Economics, as well as an academic consultant to Sveriges Riksbank and a member of the Research Council of the Deutsche Bundesbank; Hervé Le Bihan is Deputy Director for the Directorate of Monetary and Financial Studies at the Banque de France; Julien Matheron is a senior research adviser for the Directorate of Monetary and Financial Studies at the Banque de France. Beyond these affiliations, the authors did not receive financial support from any firm or person for this paper or from any firm or person with a financial or political interest in this paper. None of the authors are currently officers, directors, or board members of any organization with an interest in this paper. No outside party had the right to review this paper before circulation. The views expressed in this paper are those of the authors, and do not necessarily reflect those of the aforementioned institutions affiliated with the authors. 
makeup strategies such as price level targeting, the optimal inflation target is significantly lower and less sensitive to $r^{*}$.

A recent but sizable literature has pointed to a permanent—or at least very persistent-decline in the natural rate of interest in advanced economies (Holston, Laubach, and Williams 2017; Laubach and Williams 2016). Various likely sources of that decline have been discussed, including a lower trend growth rate of productivity (Gordon 2015), demographic factors (Eggertsson, Mehrotra, and Robbins 2019), or an enhanced preference for safe and liquid assets (Caballero and Farhi 2018; Del Negro and others 2017; Summers 2014).

A lower steady-state real interest rate matters for monetary policy. Given average inflation, a lower steady-state real interest rate will cause the nominal interest rate to hit its zero lower bound (ZLB) more frequently, hampering the ability of monetary policy to stabilize the economy, bringing about more frequent (and potentially protracted) episodes of recession and below-target inflation. The low interest rate environment is a key factor behind the Federal Reserve's current review of its monetary policy (Clarida 2019; Fuhrer and others 2018). ${ }^{1}$

In the face of that risk several prominent economists have forcefully argued in favor of raising the inflation target. ${ }^{2}$ Since a lower natural rate of interest is conducive to a higher ZLB incidence, one would expect a higher inflation target to be desirable as, other things being equal, a higher inflation target increases the steady-state nominal interest rate and reduces the ZLB incidence. But the answer to the practical question of how much should the target be increased is not obvious. Indeed, the benefit of providing a better hedge against hitting the ZLB, which is an infrequent event, comes at the cost of higher steady-state inflation which induces permanent costs, as recently argued by Bernanke (2016), among others. The answer to this question thus requires us to assess how the trade-off between the incidence of the ZLB and the welfare cost induced by steady-state inflation is modified when the natural rate of interest decreases. While the decrease in the natural rate of interest has been emphasized in the recent literature, such assessment has received surprisingly little attention.

1. Note that the numerical value of the inflation target is not part of that review.

2. See, among others, Ball (2014), Blanchard, Dell'Ariccia, and Mauro (2010), and, with qualifications, Williams (2016). 
The present paper contributes to this debate by asking four questions. First, to what extent does a lower steady-state real interest rate $\left(r^{*}\right)$ call for a higher optimal inflation target $\left(\pi^{*}\right)$ ? Second, does the source of decline in $r^{*}$ matter? Third, how does parameter uncertainty affect the $\left(r^{*}, \pi^{*}\right)$ curve? Fourth, to what extent do the strategy and rules followed by the central bank alter the relation between $r^{*}$ and $\pi^{*}$ ? We focus on the U.S. economy but the issues we investigate equally apply to other advanced economiesin particular the euro area-because the decline in $r^{*}$ appears to be a global phenomenon (Brand, Bielecki, and Penalver 2019; Del Negro and others 2019; Rachel and Summers 2019). ${ }^{3}$

We provide answers to these questions using a structural, empirically estimated, macroeconomic model. Our main findings can be summarized as follows: (1) The relation between $r^{*}$ and $\pi^{*}$ is downward sloping, but not necessarily, in general, one-for-one. (2) In the vicinity of the pre-crisis values for $r^{*}$, the slope of the $\left(r^{*}, \pi^{*}\right)$ locus is close to -1 , though slightly below in absolute value; the relation is largely robust to the underlying source of variation in $r^{*}$ for a plausible range of $r^{*}$ values. (3) The slope of the $\left(r^{*}, \pi^{*}\right)$ locus remains close to -1 when the central bank is uncertain about the parameters of the model characterizing the economy, including $r^{*}$. (4) The slope of the curve is also robust to various alteration of the monetary policy rule but not to the adoption of rules such as price level targeting, which involve a credible commitment to making up for past deviations from the inflation target.

Our results are obtained from extensive simulations of a New Keynesian dynamic stochastic general equilibrium (DSGE) model estimated for the United States over a Great Moderation sample. ${ }^{4}$ The framework features: (1) price stickiness and partial indexation of prices to trend inflation, (2) wage stickiness and partial indexation of wages to both inflation and productivity, and (3) a ZLB constraint on the nominal interest rate. The first two features imply the presence of potentially substantial costs associated with nonzero steady-state inflation. The third feature warrants a strictly positive inflation rate in order to mitigate the incidence and adverse effects of the ZLB. To our knowledge, these three features have not been jointly taken into account in previous analyses of optimal inflation.

3. We will provide a comparable analysis for the euro area in a work in progress, "Should the ECB Adjust Its Strategy in the Face of a Lower Natural Rate of Interest?"

4. In Andrade, Le Bihan, Galí, and Matheron (2020), we show that very similar results obtain in a model estimated with euro area data. 
Our analysis focuses on the trade-off between the costs attached to the probability of hitting the ZLB and the costs induced by a positive steadystate inflation rate for a given monetary policy strategy. In the baseline, monetary policy follows an inertial interest rate rule estimated using pre-crisis data. Importantly, the specification of the policy rule implies that interest rates remain low for long after the end of a ZLB episode and that private agents expect the central bank to do so. This implies that some monetary accommodation can be provided despite the ZLB constraint. This specification can thus be seen as a parsimonious way to factor in the effects of nonconventional policies that the Fed implemented during the ZLB period in our analysis.

According to our simulations, the optimal inflation target obtained when the policymaker is assumed to know the economy's parameters with certainty (and taken to correspond to the mean of the posterior distribution) is around 2 percent (in annual terms). This result is obtained in an environment with a relatively low probability — around 6 percent—of hitting the ZLB when the target for the inflation rate is set at the historical mean of inflation and given the size of the shocks estimated on our Great Moderation sample. Our simulations also show that a 100 basis point drop of $r^{*}$ from its estimated 2.5 percent pre-crisis level will almost double the probability of hitting the ZLB if the monetary authority keeps its inflation target unchanged. The optimal reaction of the central bank is to increase the inflation target by about 99 basis points. This optimal reaction limits the increase in the probability of hitting the ZLB to a mere half of a percentage point.

This optimal adjustment is robust to a set of alternative scenarios. It does not depend on the cause (productivity, demography, or safe assets) underlying such a structural decline. It also remains close to one for one when we consider alternative assumptions regarding key structural parameters: structural shocks with higher variance, alternative markups in the goods and labor market, and different degrees of indexation to trend inflation. Strikingly, while the level of the locus can be significantly affected by those changes - these alternative scenarios call for an optimal inflation target that would have been close to or above 2 percent before the crisis-overall the slope of the $\left(r^{*}, \pi^{*}\right)$ relation remains close to -1 in the vicinity of the pre-crisis parameter region.

More generally, one may wonder how a central bank should adjust its optimal inflation target when it is uncertain about the true values of structural parameters describing the economy. A notable feature of our approach is that we perform a full-blown Bayesian estimation of the model. This 
allows us not only to assess the uncertainty surrounding $\pi^{*}$ but also to derive an optimal inflation target taking into account the parameter uncertainty facing the policymaker, including uncertainty with regard to the determinants of the steady-state real interest rate. When that parameter uncertainty is allowed for, the optimal inflation target value increases significantly, to 2.4 percent. The higher optimal target under parameter uncertainty reflects the fact that the loss function is asymmetric, so that choosing an inflation target that is lower than the optimal one is more costly than choosing an inflation target that is above. In spite of the higher level, it remains true that a Bayesian-theoretic optimal inflation target rises by about 90 basis points in response to a downward shift of the distribution in $r^{*}$ by 100 basis points.

Finally, we study how potential changes in the monetary policy rule or strategy affect the $\left(r^{*}, \pi^{*}\right)$ relation. We consider a number of different cases: (1) defining the inflation target in terms of average realized inflation as opposed to a parameter in the rule; (2) a central bank constrained by an effective lower bound on the policy rate that can be below zero; (3) a central bank with a lower or higher smoothing parameter in the interest rate policy rule; (4) a monetary policy rule with a smoothing component that involves the lagged actual policy rate instead of the lagged shadow rate; and (5) a central bank targeting the price level rather than the inflation rate. All these changes have an impact on the level of $\pi^{*}$ for any given level of $r^{*}$. Yet only in the case of higher interest rate smoothing and price level targeting do we find a noticeable change in the slope of the $\left(r^{*}, \pi^{*}\right)$ relation. In these two cases, the relation is much less steep, illustrating the strength of makeup strategies to overturn the ZLB. However, as we discuss in the conclusion, an important caveat is that this result is obtained under the joint assumption of rational expectations, perfect information, and full credibility of the commitment.

The remainder of the paper is organized as follows. Section I describes our baseline model. Section II discusses how the model is estimated and simulated, as well as how the welfare-based optimal inflation target is computed. Section III is devoted to the analysis of the $\left(r^{*}, \pi^{*}\right)$ relation under the baseline estimates as well as for a set of alternative parameters. Section IV presents and discusses this locus under parameter uncertainty. Section $\mathrm{V}$ investigates the $\left(r^{*}, \pi^{*}\right)$ under alternative monetary policy rules and strategies. Finally section VI summarizes and concludes.

RELATED LITERATURE To our knowledge no paper has systematically investigated the $\left(r^{*}, \pi^{*}\right)$ relation. Coibion, Gorodnichenko, and Wieland (2012), followed up by Dordal-i-Carreras and others (2016), and Kiley and Roberts (2017), are the papers most closely related to ours, as they study 
optimal inflation in quantitative setups that account for the ZLB. However, the analyses by Coibion, Gorodnichenko, and Wieland (2012) assume a constant steady-state natural rate of interest, so a key difference is our focus on eliciting the relation between the steady-state real interest rate and optimal inflation. Other differences are that we estimate, rather than calibrate, the model, and that we allow for wage rigidity in the form of infrequent, staggered, wage adjustments. A distinctive feature with respect to Kiley and Roberts (2017) is that we use a model-consistent, micro-founded loss function to compute optimal inflation.

A series of papers assessed the probability that the U.S. economy hit the ZLB for a given inflation target. Interestingly, our own assessment of this pre-crisis ZLB incidence falls in the ballpark of available estimates, for example, Chung and others (2012). As we show, when the inflation target is not adjusted, but allowing for post-Great Moderation shocks, we also get post-crisis probability of hitting the ZLB that is comparable to the ones obtained in recent related studies such as Chung and others (2019).

In the New Keynesian setup that we consider, agents have rational expectations and make decisions that are forward-looking: they fully understand that the central bank's inability to lower the policy further will lead to a deflation which magnifies the contractionary demand shocks that were responsible for driving the economy to the ZLB in the first place. One concern may be that this framework makes the ZLB too destabilizing, hence overweighing the benefits of a positive inflation target. However, this is partially offset by the fact that rational expectations and forwardlooking decisions also make the lower for longer monetary policies that we consider at the end of the trap very effective, which limits the length and width of ZLB episodes. Chung and others (2019) illustrate that ZLB episodes can also be very costly in setups featuring agents that are less forward-looking, such as the FRB/US model (one of the Federal Reserve's models of the U.S. economy).

Our assessment of the (welfare) cost of inflation also critically relies on our assumptions of a Calvo mechanism for price and wage setting. Among the recent papers on ZLB, Blanco (forthcoming) studies optimal inflation in a state-dependent pricing model, that is, a menu cost model. In this setup, optimal inflation is typically positive and higher than with timedependent pricing. Indeed, as in our analysis, positive inflation hedges the economy against the detrimental effects of the ZLB. ${ }^{5}$ In addition, as shown

5. By contrast, see Burstein and Hellwig (2008) for a similar exercise under menu costs without ZLB, which leads to negative optimal inflation rate. 
by Nakamura and others (2018), the presence of state-dependent pricing weakens considerably the positive relationship between inflation and price dispersion, thus reducing the costs of inflation. Nakamura and others (2018) further argue that menu costs are a more plausible mechanism for pricing frictions. ${ }^{6}$ Two points are, however, worth making. First, in the range of values for the inflation target that we consider, the difference between the welfare cost in a Calvo model and in a menu cost model is less dramatic than with a 10 percent or higher inflation rate, as documented by Nakamura and others (2018). Second, most recent empirical analyses of price setting show that there is a mass of small price changes in the data that cannot be rationalized by a menu cost model. To fit the micro data, much of this recent literature typically introduces a random opportunity of price change, hence a Calvo component, in the menu cost model (Alvarez, Le Bihan, and Lippi 2016). In such an augmented menu cost model, the distinction with the assessment taken from the Calvo model is bound to be attenuated.

Our paper is also connected to the voluminous literature on monetary policy under uncertainty (Levin and others 2006; Williams 2013), although to our knowledge this literature has not investigated the impact of uncertainty on the determination of the optimal inflation target.

Other relevant references, albeit ones that put little or no emphasis on the ZLB, are the following. An early literature focuses on sticky prices and monetary frictions. In such a context, as shown by Khan, King, and Wolman (2003) and Schmitt-Grohé and Uribe (2010), the optimal rate of inflation should be slightly negative. Similarly, a negative optimal inflation would result from an environment with trend productivity growth and prices and wages both sticky, as shown by Amano and others (2009). In this kind of environment, moving from a 2 percent to a 4 percent inflation target would be extremely costly, as suggested by Ascari, Phaneuf, and Sims (2018). By contrast, adding search and matching frictions to the setup, Carlsson and Westermark (2016) show that optimal inflation can be positive. Bilbiie, Fujiwara, and Ghironi (2014) find positive optimal inflation can be an outcome in a sticky-price model with endogenous entry and product variety. Somewhat related, Adam and Weber (2019) show that, even without any ZLB concern, optimal inflation might be positive in the context of a model with heterogeneous firms and systematic firm-level productivity trends.

6. They document that the cross-sector dispersion in the size of price changes is similar in the current low inflation period as in the high inflation period of the late 1970s. If Calvo were the relevant pricing frictions, the dispersion in size of price changes should have been much larger in the high inflation period than today. 
Finally, Lepetit (2018) shows that optimal inflation can be different from zero when profits and utility flows are discounted at different rates, as is generally the case in overlapping generation models. In a parameterized example of the latter, he shows the optimal steady-state inflation is significantly above zero.

\section{The Model}

We use a relatively standard medium-scale New Keynesian model as a framework of reference. Crucially, the model features elements that generate a cost to inflation: (1) nominal rigidities, in the form of staggered price and wage setting; (2) less than perfect price (and wage) indexation to past or trend inflation; and (3) trend productivity growth, to which wages are imperfectly indexed.

As is well known, staggered price setting generates a positive relation between deviations from zero inflation and price dispersion (with the resulting inefficient allocation of resources). Also, and ceteris paribus, price inflation induces (nominal) wage inflation, which in turn triggers inefficient wage dispersion in the presence of staggered wage setting. Partial indexation also magnifies the costs of nonzero price (or wage) inflation as compared to a setup where price and wages fully catch up with trend inflation (Ascari and Sbordone 2014). Finally the lack of a systematic indexation of wages to productivity also induces an inefficient wage dispersion.

At the same time, there are benefits associated to a positive inflation rate, as interest rates are subject to a ZLB constraint. In particular, and given the steady-state real interest rate, the incidence of binding ZLB episodes and the associated macroeconomic volatility should decline with the average rate of inflation.

Overall, the model we use, and the implied trade-off between costs and benefits of steady-state inflation, are close to those considered by Coibion, Gorodnichenko, and Wieland (2012). However we assume Calvo-style sticky wages, in addition to sticky prices. ${ }^{7}$

\section{I.A. Households}

The economy is inhabited by a continuum of measure one of infinitely lived, identical households. The representative household is composed of a

7. In their robustness analysis, Coibion, Gorodnichenko, and Wieland (2012) consider downward nominal wage rigidity, which entails different mechanisms than with Calvo-style rigidities. 
continuum of workers, each specialized in a particular labor type indexed by $h \in[0,1]$. The representative household's objective is to maximize an intertemporal welfare function

$$
\mathbb{E}_{t} \sum_{s=0}^{\infty} \beta_{s}^{s}\left\{\mathrm{e}^{\zeta_{s+t+}} \log \left(C_{t+s}-\eta C_{t+s-1}\right)-\frac{\chi}{1+v} \int_{0}^{1} N_{t+s}(h)^{1+v} \mathrm{~d} h\right\},
$$

where $\beta \equiv \mathrm{e}^{-\rho}$ is the discount factor ( $\rho$ being the discount rate), $\mathbb{E}_{t}\{\cdot\}$ is the expectation operator conditional on information available at time $t$, $C_{t}$ is consumption, and $N_{t}(h)$ is the supply of labor of type $h$. The utility function features habit formation, with degree of habits $h$. The inverse Frisch elasticity of labor supply is $v$, and $\chi$ is a scale parameter for labor disutility. The utility derived from consumption is subject to a preference shock $\zeta_{g, t}$.

The representative household maximizes equation (1) subject to the sequence of constraints

$$
P_{t} C_{t}+\mathrm{e}^{\zeta_{t} t} Q_{t} B_{t} \leq \int_{0}^{1} W_{t}(h) N_{t}(h) \mathrm{d} h+B_{t-1}-T_{t}+D_{t},
$$

where $P_{t}$ is the aggregate price level, $W_{t}(h)$ is the nominal wage rate associated with labor of type $h, \mathrm{e}^{\zeta_{h, t}} Q_{t}$ is the price at $\mathrm{t}$ of a one-period nominal bond paying one unit of currency in the next period, where $\zeta_{q, t}$ is a "risk-premium" shock, $B_{t}$ is the quantity of such bonds acquired at $t$, $T_{t}$ denotes lump-sum taxes, and $D_{t}$ stands for the dividends rebated to the households by monopolistic firms.

\section{I.B. Firms and Price Setting}

The final good is produced by perfectly competitive firms according to the Dixit-Stiglitz production function

$$
Y_{t}=\left(\int_{0}^{1} Y_{t}(f)^{\left(\theta_{p}-1\right) / \theta_{p}} \mathrm{~d} f\right)^{\theta_{p} /\left(\theta_{p}-1\right)},
$$

where $Y_{t}$ is the quantity of final good produced at $t, Y_{t}(f)$ is the input of intermediate good $f$, and $\theta_{p}$ the elasticity of substitution between any two intermediate goods. The zero-profit condition yields the relation

$$
P_{t}=\left(\int_{0}^{1} P_{t}(f)^{1-\theta_{p}} \mathrm{~d} f\right)^{1 /\left(1-\theta_{p}\right)} .
$$


Intermediate goods are produced by monopolistic firms, each specialized in a particular good $f \in[0,1]$. Firm $f$ has technology

$$
Y_{t}(f)=Z_{t} L_{t}(f)^{1 / \phi},
$$

where $L_{t}(f)$ is the input of aggregate labor, $1 / \phi$ is the elasticity of production with respect to aggregate labor, and $Z_{t}$ is an index of aggregate productivity. The latter evolves according to

$$
Z_{t}=Z_{t-1} \mathrm{e}^{\mu_{z}+\zeta_{2, t}}
$$

where $\mu_{z}$ is the average growth rate of productivity. Thus, technology is characterized by a unit root in the model.

Intermediate goods producers are subject to nominal rigidities à la Calvo. Formally, firms face a constant probability $\alpha_{p}$ of not being able to reoptimize prices. In the event that firm $f$ is not drawn to reoptimize at $t$, it rescales its price according to the indexation rule

$$
P_{t}(f)=\left(\Pi_{t-1}\right)^{\gamma_{p}} P_{t-1}(f),
$$

where $\Pi_{t} \equiv P_{t} / P_{t-1}, \Pi$ is the associated steady-state value and $0 \leq \gamma_{p}<1$. Thus, in case firm $f$ is not drawn to reoptimize, it mechanically rescales its price by past inflation. Importantly, however, we assume that the degree of indexation is less than perfect since $\gamma_{p}<1$. One obvious drawback of the Calvo setup is that the probability of price reoptimization is assumed to be invariant, inter alia to the long-run inflation rate. Drawing from the logic of menu cost models, the Calvo parameter of price stickiness could be expected to endogenously decrease when trend inflation rises. However, in the range of values for trend inflation that we will consider, available microeconomic evidence, such as that summarized in Golosov and Lucas (2007), suggests there is no significant correlation between the frequency of price change and trend inflation.

If drawn to reoptimize in period $t$, a firm chooses $P_{t}^{*}$ in order to maximize

$$
\mathbb{E}_{t} \sum_{s=0}^{\infty}\left(\beta \alpha_{p}\right)^{s} \Lambda_{t+s}\left\{\left(1+\tau_{p, t+s}\right) \frac{V_{t, t+s}^{p} P_{t}^{*}}{P_{t+s}} Y_{t, t+s}-\frac{W_{t+s}}{P_{t+s}}\left(\frac{Y_{t, t+s}}{Z_{t+s}}\right)^{\phi}\right\},
$$

where $\Lambda_{t}$ denotes the marginal utility of wealth, $\tau_{p, t}$ is a sales subsidy paid to firms and financed via a lump-sum tax on households, and $Y_{t, t+s}$ is the 
demand function that a monopolist who last revised its price at $t$ faces at $t+s$. It obeys

$$
Y_{t, t+s}=\left(\frac{V_{t, t+s}^{p} P_{t}^{*}}{P_{t+s}^{*}}\right)^{-\theta_{p}} Y_{t+s},
$$

where $V_{t, t+s}^{p}$ reflects the compounded effects of price indexation to past inflation

$$
V_{t, t+s}^{p}=\prod_{j=t}^{t+s-1}\left(\Pi_{j}\right)^{\gamma_{p}}
$$

We further assume that

$$
1+\tau_{p, t}=\left(1+\tau_{p}\right) e^{-\zeta_{h, t},}
$$

with $\zeta_{u, t}$ appearing in the system as a cost-push shock. Furthermore, we set $\tau_{p}$ so as to neutralize the steady-state distortion induced by price markups.

\section{I.C. Aggregate Labor and Wage Setting}

There is a continuum of perfectly competitive labor-aggregating firms that mix the specialized labor types according to the CES technology

$$
N_{t}=\left(\int_{0}^{1} N_{t}(h)^{\left(\theta_{w}-1\right) / \theta_{w}} \mathrm{~d} h\right)^{\theta_{w} /\left(\theta_{w}-1\right)},
$$

where $N_{t}$ is the quantity of aggregate labor and $N_{t}(h)$ is the input of labor of type $h$, and where $\theta_{w}$ denotes the elasticity of substitution between any two labor types. Aggregate labor $N_{t}$ is then used as an input in the production of intermediate goods. Equilibrium in the labor market thus requires

$$
N_{t}=\int_{0}^{1} L_{t}(f) \mathrm{d} f .
$$

Here, it is important to notice the difference between $L_{t}(f)$, the demand for aggregate labor emanating from firm $f$, and $N_{t}(h)$, the supply of labor of type $h$ by the representative household.

The zero-profit condition yields the relation

$$
W_{t}=\left(\int_{0}^{1} W_{t}(h)^{1-\theta_{w}} \mathrm{~d} h\right)^{1 /\left(1-\theta_{w}\right)},
$$


where $W_{t}$ is the nominal wage paid to aggregate labor while $W_{t}(h)$ is the nominal wage paid to labor of type $h$.

Mirroring prices, we assume that wages are subject to nominal rigidities, à la Calvo, in the manner of Erceg, Henderson, and Levin (2000). Formally, unions face a constant probability $\alpha_{w}$ of not being able to reoptimize wages. In the event that union $h$ is not drawn to reoptimize at $t$, it rescales its wage according to the indexation rule

$$
W_{t}(h)=\mathrm{e}^{\gamma_{z} \mu_{z}}\left(\Pi_{t-1}\right)^{\gamma_{w}} W_{t-1}(h),
$$

where, as before, wages are indexed to past inflation. However, we assume that the degree of indexation is here, too, less than perfect by imposing $0 \leq \gamma_{w}<1$. In addition, nominal wages are also indexed to average productivity growth with indexation degree $0 \leq \gamma_{z}<1$.

If drawn to reoptimize in period $t$, a union chooses $W_{t}^{*}$ in order to maximize

$$
\mathbb{E}_{t} \sum_{s=0}^{\infty}\left(\beta \alpha_{w}\right)^{s}\left\{\left(1+\tau_{w}\right) \Lambda_{t+s} \frac{V_{t, t+s}^{w} W_{t}^{*}}{P_{t+s}} N_{t, t+s}-\frac{\chi}{1+v} N_{t, t+s}^{1+v}\right\},
$$

where the demand function at $t+s$ facing a union who last revised its wage at $t$ obeys

$$
N_{t, t+s}=\left(\frac{V_{t, t+s}^{w} W_{t}^{*}}{W_{t+s}}\right)^{-\theta_{w}} N_{t+s}
$$

and where $V_{t, t+s}^{w}$ reflects the compounded effects of wage indexation to past inflation and average productivity growth

$$
V_{t, t+s}^{w}=\mathrm{e}^{\gamma_{z} \mu_{z}(t+s)} \prod_{j=t}^{t+s-1}\left(\Pi_{j}\right)^{\gamma_{w}} .
$$

Furthermore, we set $\tau_{w}$ so as to neutralize the steady-state distortion induced by wage markups.

\section{I.D. Monetary Policy and the ZLB}

Monetary policy in so-called normal times is assumed to be given by an inertial Taylor-like interest rate rule 


$$
\hat{\imath}_{t}=\rho_{i} \hat{l}_{t-1}+\left(1-\rho_{i}\right)\left(a_{\pi} \hat{\pi}_{t}+a_{y} \hat{x}_{t}\right)+\zeta_{R, t},
$$

where $i_{t} \equiv-\log \left(Q_{t}\right)$, with $\hat{\imath}_{t}$ denoting the associated deviation from steady state, that is, $\hat{\imath}_{t} \equiv i_{t}-i$. Also, $\pi_{t} \equiv \log \Pi_{t}, \hat{\pi}_{t} \equiv \pi_{t}-\pi$ is the gap between inflation and its target, and $\hat{x}_{t} \equiv \log \left(Y_{t} / Y_{t}^{n}\right)$ where $Y_{t}^{n}$ is the efficient level of output, defined as the level of output that would prevail in an economy with flexible prices and wages and no cost-push shocks. Finally, $\zeta_{R, t}$ is a monetary policy shock.

Importantly, we interpret $\pi$ as the central bank target for change in the price index. An annual inflation target of 2 percent would thus imply $\pi=2 / 400=0.005$, as the model will be parameterized and estimated with quarterly data. Note that the inflation target thus defined may differ from average inflation.

Crucially for our purposes, the nominal interest rate $i_{t}$ is subject to a ZLB constraint:

$$
i_{t} \geq 0 \text {. }
$$

The steady-state level of the real interest rate is defined by $r^{*} \equiv i-\pi$. Given logarithmic utility, it is related to technology and preference parameters according to $r^{*}=\rho+\mu_{z}$. Combining these elements, it is convenient to write the ZLB constraint in terms of deviations from steady state

$$
\hat{\imath}_{t} \geq-\left(\mu_{z}+\rho+\pi\right) .
$$

The rule effectively implemented is given by:

$$
\hat{\imath}_{t}=\max \left\{\hat{\imath}_{t}^{n},-\left(\mu_{z}+\rho+\pi\right)\right\},
$$

where

$$
\hat{\imath}_{t}^{n}=\rho_{i} \hat{l}_{t-1}^{n}+\left(1-\rho_{i}\right)\left(a_{\pi} \hat{\pi}_{t}+a_{y} \hat{x}_{t}\right)+\zeta_{R, t},
$$

with $i_{t}^{n}$ denoting the shadow or notional rate, that is, the one that would be effective in the absence of the ZLB constraint. Thus the lagged rate that matters is the lagged notional interest rate, rather than the lagged actual rate. In making that assumption we follow Coibion, Gorodnichenko, and Wieland (2012) and a large share of the recent literature. 
Before proceeding, several remarks are in order. First, note that realized inflation might be on average below the target $\pi$ as a consequence of ZLB episodes, that is, $\mathbb{E}\left\{\pi_{t}\right\}<\pi$. In such instances of ZLB, monetary policy fails to deliver the appropriate degree of accommodation, resulting in a more severe recession and lower inflation than in an economy with no ZLB constraint. $^{8}$

Second, we assume the central bank policy is characterized by a simple interest rate rule rather than a Ramsey-like fully optimal policy of the type studied, for example, by Khan, King, and Wolman (2003) or SchmittGrohé and Uribe (2010). Such rules have been shown to be a good empirical characterization of the behavior of central banks in the last decades. ${ }^{9}$ Moreover, two features in our setup - the inertia in the monetary policy rule and the use of a lagged notional rate rather than a lagged actual raterender the policy more persistent and thus closer to a Ramsey-like fully optimal interest rate rule. In particular the dependence on the lagged notional rate $\hat{\imath}_{t}^{n}$ results in the nominal interest rate $\hat{\imath}_{t}$ being lower for longer in the aftermath of ZLB episodes (as $\hat{\imath}_{t}^{n}$ will stay negative for a protracted period). In section $\mathrm{V}$, we study how alternative strategies of lower for longer affect the $\left(r^{*}, \pi^{*}\right)$ relation.

As equation (3) makes clear, $\mu_{z}, \rho, \pi$ enter symmetrically in the ZLB constraint. Put another way, for given structural parameters and a given process for $\hat{l}_{t}$, the probability of hitting the ZLB would remain unchanged if productivity growth or the discount rate decline by 1 percent and the inflation target is increased by a commensurate amount at the same time. Based on these observations, one may be tempted to argue that in response to a permanent decline in $\mu_{z}$ or $\rho$, the optimal inflation target $\pi^{*}$ must necessarily change by the same amount (with a negative sign).

The previous conjecture is, however, incorrect. The reasons for this are twofold. First, any change in $\mu_{z}$ (or $\rho$ ) also translates into a change in the coefficients of the equilibrium dynamic system. It turns out that this effect is nonnegligible since, as our later results imply, after a 1 percentage point decline in $r^{*}$ the inflation target has to be raised by more than 1 percent in order to keep the probability of hitting the ZLB unchanged. Second, because there are welfare costs associated with increasing the inflation target, the policymaker would also have to balance the benefits of keeping the incidence of ZLB episodes constant with the additional costs in terms

8. For convenience, table A.1 in the online appendix summarizes the various notions of optimal inflation and long-run or target inflation considered in this paper.

9. See, for example, Clarida, Galí, and Gertler (1998). 
of extra price dispersion and inefficient resource allocation. These costs can be substantial and may more than offset the benefits of holding the probability of ZLB constant. Assessing these forces is precisely this paper's endeavor.

\section{Estimation and Simulations}

In the present section we discuss how the model is estimated and simulated, as well as how the welfare-based optimal inflation target is computed.

\section{II.A. Estimation without a Lower Bound on Nominal Interest Rates}

We estimate the model using data for a pre-crisis period over which the ZLB constraint is not binding. This enables us to use the linear version of the model. ${ }^{10}$

ESTIMATION PROCEDURE Because the model has a stochastic trend, we first induce stationarity by dividing trending variables by $Z_{t}$. The resulting system is then log-linearized in the neighborhood of its deterministic steady state. ${ }^{11}$ We append to the system a set of equations describing the dynamics of the structural shocks, namely,

$$
\zeta_{k, t}=\rho_{k} \zeta_{k, t-1}+\sigma_{k} \epsilon_{k, t}, \quad \epsilon_{k, t} \sim N(0,1)
$$

for $k \in\{R, g, u, q, z\}$.

Absent the ZLB constraint, the model can be solved and cast into the usual linear transition and observation equations:

$$
\begin{gathered}
s_{t}=\mathcal{T}(\theta) s_{t-1}+\mathcal{R}(\theta) \epsilon_{t}, \\
x_{t}=\mathcal{M}(\theta)+\mathcal{H}(\theta) s_{t},
\end{gathered}
$$

with $s_{t}$ a vector collecting the model's state variables, $x_{t}$ a vector of observable variables, and $\epsilon_{t}$ a vector of innovations to the shock processes $\epsilon_{t}=\left(\epsilon_{R, t}, \epsilon_{g, t}, \epsilon_{u, t}, \epsilon_{q, t}, \epsilon_{z, t}\right)^{\prime}$. The solution coefficients are regrouped in the conformable matrices $\mathcal{T}(\theta), \mathcal{R}(\theta), \mathcal{M}(\theta)$, and $\mathcal{H}(\theta)$ which depend on the vector of structural parameters $\theta$.

10. See Gust and others (2017) and Lindé, Maih, and Wouters (2017) for alternative methods that deal with the ZLB constraint at the estimation stage.

11. See the online appendix for further details. 
The sample of observable variables is $X_{T} \equiv\left\{x_{t}\right\}_{t=1}^{T}$ with

$$
x_{t}=\left[\begin{array}{c}
\Delta \log \left(\text { GDP }_{t}\right), \\
\Delta \log \left(\text { GDPDeflator }_{t}\right), \\
\Delta \log \left(\text { ( }_{\text {ages }}\right), \\
\text { ShortTerminterestRate }_{t}
\end{array}\right]^{\prime},
$$

where the short-term nominal interest rate is the effective federal funds rate. We use a sample of quarterly data covering the period 1985:Q2-2008:Q3. ${ }^{12}$ This choice is guided by two objectives. First, this sample strikes a balance between size and the concern of having a homogeneous monetary policy regime over the period considered. The sample covers the Volcker and post-Volcker period, arguably one of relative homogeneity of monetary policy. Second, we use a sample that coincides more or less with the so-called Great Moderation. Over the latter we expect smaller shocks to hit the economy. In principle, this will lead to a conservative assessment of the effects of the more stringent ZLB constraint due to lower real interest rates.

The parameters $\phi, \theta_{p}$, and $\theta_{w}$ are calibrated prior to estimation. The parameter $\theta_{p}$ is set to 6 , resulting in a steady-state price markup of 20 percent. Similarly, the parameter $\theta_{w}$ is set to 3 , resulting in a wage markup of 50 percent. These numbers fall into the arguably large ballpark of available values used in the literature. In a robustness section, we investigate the sensitivity of our results to these parameters. The parameter $\phi$ is set to $1 / 0.7$. Given the assumed subsidy correcting the steady-state price markup distortion, this results in a steady-state labor share of 70 percent.

We rely on a full-system Bayesian estimation approach to estimate the remaining model parameters. After having cast the dynamic system in the state-space representation for the set of observable variables, we use the Kalman filter to measure the likelihood of the observed variables. We then form the joint posterior distribution of the structural parameters by combining the likelihood function $p\left(X_{T} \mid \theta\right)$ with a joint density characterizing some prior beliefs $p(\theta)$. The joint posterior distribution thus obeys

$$
p\left(\theta \mid X_{T}\right) \propto p\left(X_{T} \mid \theta\right) p(\theta) .
$$

Given the specification of the model, the joint posterior distribution cannot be recovered analytically but may be computed numerically, using a

12. The data are obtained from the Federal Reserve Economic Data (FRED) database. GDP is expressed in per capita terms. 
Table 1. Estimation Results

\begin{tabular}{llcccccc}
\hline Parameter & Prior shape & $\begin{array}{c}\text { Prior } \\
\text { mean }\end{array}$ & $\begin{array}{c}\text { Prior } \\
\text { std. }\end{array}$ & $\begin{array}{c}\text { Posterior } \\
\text { mean }\end{array}$ & $\begin{array}{c}\text { Posterior } \\
\text { std. }\end{array}$ & Low & High \\
\hline$\rho$ & Normal & 0.20 & 0.05 & 0.19 & 0.05 & 0.11 & 0.27 \\
$\mu_{z}$ & Normal & 0.44 & 0.05 & 0.43 & 0.04 & 0.36 & 0.50 \\
$\pi^{*}$ & Normal & 0.61 & 0.05 & 0.62 & 0.05 & 0.54 & 0.69 \\
$\alpha_{p}$ & Beta & 0.66 & 0.05 & 0.67 & 0.03 & 0.61 & 0.73 \\
$\alpha_{w}$ & Beta & 0.66 & 0.05 & 0.50 & 0.05 & 0.43 & 0.58 \\
$\gamma_{p}$ & Beta & 0.50 & 0.15 & 0.20 & 0.07 & 0.08 & 0.32 \\
$\gamma_{w}$ & Beta & 0.50 & 0.15 & 0.44 & 0.16 & 0.21 & 0.68 \\
$\gamma_{z}$ & Beta & 0.50 & 0.15 & 0.50 & 0.18 & 0.26 & 0.75 \\
$\eta$ & Beta & 0.70 & 0.15 & 0.80 & 0.03 & 0.75 & 0.85 \\
$v$ & Gamma & 1.00 & 0.20 & 0.73 & 0.15 & 0.47 & 0.97 \\
$a_{p}$ & Gamma & 2.00 & 0.15 & 2.13 & 0.15 & 1.89 & 2.38 \\
$a_{y}$ & Gamma & 0.50 & 0.05 & 0.50 & 0.05 & 0.42 & 0.58 \\
$\rho_{T R}$ & Beta & 0.85 & 0.10 & 0.85 & 0.02 & 0.82 & 0.89 \\
$\sigma_{z}$ & Inverse Gamma & 0.25 & 1.00 & 1.06 & 0.22 & 0.74 & 1.38 \\
$\sigma_{R}$ & Inverse Gamma & 0.25 & 1.00 & 0.10 & 0.01 & 0.09 & 0.11 \\
$\sigma_{q}$ & Inverse Gamma & 0.25 & 1.00 & 0.39 & 0.11 & 0.16 & 0.61 \\
$\sigma_{g}$ & Inverse Gamma & 0.25 & 1.00 & 0.23 & 0.04 & 0.16 & 0.29 \\
$\sigma_{u}$ & Inverse Gamma & 0.25 & 1.00 & 0.24 & 0.05 & 0.06 & 0.46 \\
$\rho_{R}$ & Beta & 0.25 & 0.10 & 0.51 & 0.06 & 0.41 & 0.61 \\
$\rho_{z}$ & Beta & 0.25 & 0.10 & 0.27 & 0.13 & 0.09 & 0.45 \\
$\rho_{g}$ & Beta & 0.85 & 0.10 & 0.98 & 0.01 & 0.97 & 1.00 \\
$\rho_{q}$ & Beta & 0.85 & 0.10 & 0.88 & 0.04 & 0.80 & 0.95 \\
$\rho_{u}$ & Beta & 0.80 & 0.10 & 0.80 & 0.10 & 0.65 & 0.96 \\
\hline & & & & & & &
\end{tabular}

Source: Authors' calculations.

Note: "Low" and "High" denote the bounds of the 90 percent probability interval for the posterior distribution.

Markov chain Monte Carlo (MCMC) sampling approach. More specifically, we rely on the Metropolis-Hastings algorithm to obtain a random draw of size 1,000,000 from the joint posterior distribution of the parameters.

ESTIMATION RESULTS Table 1 reports the parameter's postulated priors (type of distribution, mean, and standard error) and estimation results, that is, the posterior mean and standard deviation, together with the bounds of the 90 percent probability interval for each parameter.

For the parameters $\pi, \mu_{z}$ and $\rho$, we impose Gaussian prior distributions. The parameters governing the latter are chosen so that the model steadystate values match the mean values of inflation, real per capita GDP growth, and the real interest rate in our U.S. sample. Our choice of priors for the other parameters are standard. In particular, we use beta distributions for parameters in $[0,1]$, gamma distributions for positive parameters, and inverse gamma distributions for the standard error of the structural shocks. 
Most of our estimated parameters are in line with the calibration adopted by Coibion, Gorodnichenko, and Wieland (2012), with important qualifications. First, we obtain a slightly higher degree of price rigidity than theirs (0.67 versus 0.55$)$. Second, our specification of monetary policy is different from theirs. In particular, they allow for two lags of the nominal interest rate in the monetary policy rule while we have only one lag. However, we can compare the overall degree of interest rate smoothing in the two setups. To this end, abstracting from the other elements of the rule, we simply focus on the sum of autoregressive coefficients. It amounts to 0.92 in their calibration while the degree of smoothing in our setup has a mean posterior value of 0.85 . While this might not seem to be a striking difference, it is useful to cast these figures in terms of half-life of convergence in the context of an autoregressive model of order 1 . Our value implies twice as small a halflife than theirs. Third, our monetary policy shock and our shocks to demand have approximately twice as small an unconditional standard deviation as theirs. Finally, we estimate the degree of indexation to past inflation rather than setting it to zero as in Coibion, Gorodnichenko, and Wieland (2012). We find small though nonzero degrees of indexation to past inflation. This will translate into a higher tolerance for inflation in our subsequent analysis of the optimal inflation target. This is because a higher indexation helps to mitigate the distortions induced by a higher inflation target. However, it turns out that, given these estimates, this effect is quantitatively small.

Properties of the estimated model, such as the response to a monetary policy shock, are standard (see online appendix, section B; online appendix, section $\mathrm{C}$, illustrates the lower for longer property embedded in the policy rule).

\section{II.B. Computing the Optimal Inflation Target}

Next we show how the optimal inflation target is computed.

SIMULATIONS WITH A ZLB CONSTRAINT The model becomes nonlinear when one allows the ZLB constraint to bind. The solution method we implement follows the approach developed by Bodenstein, Erceg, and Guerrieri (2009) and Guerrieri and Iacoviello (2015). The approach can be described as follows. There are two regimes: the no-ZLB regime $k=n$ and the ZLB regime $k=e$, and the canonical representation of the system in each regime is

$$
\mathbb{E}_{t}\left\{\mathcal{A}^{(k)} s_{t+1}+\mathscr{B}^{(k)} s_{t}+C^{(k)} s_{t-1}+\mathscr{D}^{(k)} \epsilon_{t}\right\}+f^{(k)}=0,
$$

where $s_{t}$ is a vector collecting all the model's variables, $\mathcal{A}^{(k)}, \mathscr{B}^{(k)}, C^{(k)}$, and $\mathcal{D}^{(k)}$ are conformable matrices, and $f^{(k)}$ is a vector of constants. In the 
no-ZLB regime, the vector $f^{(n)}$ is filled with zeros. In the ZLB regime, the row of $f^{(e)}$ associated with $i_{t}$ is equal to $\mu_{z}+\rho+\pi$. Similarly, the rows of the system matrices associated with $i_{t}$ in the no-ZLB regime correspond to the coefficients of the interest rate rule while in the ZLB regime, the coefficient associated with $i_{t}$ is equal to 1 and all the other coefficients are set to zero.

In each period $t$, given an initial state vector $s_{t-1}$ and vector stochastic innovations $\epsilon_{t}$, we simulate the model under perfect foresight (that is, assuming that no further shocks hit the economy) over the next $N$ periods, for $N$ sufficiently large. In case this particular draw is not conducive to a ZLB episode, we find $s_{t}$ using the linear solution stated above. In contrast, if this draw leads to a ZLB episode, we postulate integers $N_{e}<N$ and $N_{x}<N$ such that the ZLB is reached at time $t+N_{e}$ and left at time $t+N_{x}$. In this case, we solve the model by backward induction. We obtain the time varying solution

$$
s_{t+q}=d_{t+q}+\mathcal{T}_{t+q} s_{t+q-1}+R_{t+q} \epsilon_{t+q},
$$

with $\epsilon_{t+q}=0$ for $q>0$ and where, for $q \in\left\{N_{e}, \ldots, N_{x}-1\right\}$,

$$
\begin{gathered}
\mathcal{T}_{t+q}=-\left(\mathcal{A}^{(e)} \mathcal{T}_{t+q+1}+\mathcal{B}^{(e)}\right)^{-1} C^{(e)}, \\
\mathcal{R}_{t+q}=-\left(\mathcal{A}^{(e)} \mathcal{T}_{t+q+1}+\mathcal{B}^{(e)}\right)^{-1} \mathcal{D}^{(e)}, \\
d_{t+q}=-\left(\mathcal{A}^{(e)} \mathcal{T}_{t+q+1}+\mathcal{B}^{(e)}\right)^{-1}\left(\mathcal{A}^{(e)} d_{t+q+1}+f^{(e)}\right)
\end{gathered}
$$

and, for $q \in\left\{0, \ldots, N_{e}-1\right\}$,

$$
\begin{gathered}
\mathcal{T}_{t+q}=-\left(\mathcal{A}^{(n)} \mathcal{T}_{t+q+1}+B^{(n)}\right)^{-1} C^{(n)}, \\
\mathcal{R}_{t+q}=-\left(\mathcal{A}^{(n)} \mathcal{T}_{t+q+1}+\mathcal{B}^{(n)}\right)^{-1} \mathcal{D}^{(n)}, \\
d_{t+q}=-\left(\mathcal{A}^{(n)} \mathcal{T}_{t+q+1}+\mathcal{B}^{(n)}\right)^{-1}\left(\mathcal{A}^{(n)} d_{t+q+1}+f^{(n)}\right),
\end{gathered}
$$

using $\mathcal{T}_{t+N_{x}}=\mathcal{T}, \mathbb{R}_{t+N_{x}}=\mathbb{R}$ and $d_{t+N_{x}}$ set to a column filled with zeros as initial conditions of the backward recursion. 
We then check that given the obtained solution, the system hits the ZLB at $t+N_{e}$ and leaves the ZLB at $t+N_{x}$. Otherwise, we shift $N_{e}$ or $N_{x}$ forward or backward by one period and start all over again until convergence. Once convergence has been reached, we use the resulting matrices to compute $s_{t}$ and repeat the process for all the simulation periods.

Our approach is thus similar to the one used by Coibion, Gorodnichenko, and Wieland (2012) in their study of the optimal inflation target in a New Keynesian setup. ${ }^{13}$

A shortcoming of this approach is that the agents in the model are assumed to believe that the ZLB will not bind again in the future, once the current ZLB episode comes to an end. This may bias estimates, as explained by Gust and others (2017), even when, as in our case, estimation is performed on a pre-ZLB period. The scope of this concern is, however, dampened by the fact that in the pre-crisis environment there is evidence that even experts severely underestimated the probability of the ZLB occurring (Chung and others 2012). ${ }^{14}$

A WELFARE-BASED OPTIMAL INFLATION TARGET A second-order approximation of the household expected utility derived from the structural model is used to quantify welfare, in a similar manner as in Woodford (2003), assuming a small steady-state inflation rate. As detailed in the online appendix, this second-order approximation is given by:

$$
\begin{aligned}
U_{0}= & -\frac{1}{2} \frac{1-\beta \eta}{1-\eta} \mathbb{E}_{0} \sum_{t=0}^{\infty}\left\{\beta^{t} \lambda_{y}\left[\hat{x}_{t}-\delta \hat{x}_{t-1}+(1-\delta) \bar{x}\right]^{2}\right. \\
& +\lambda_{p}\left[\left(1-\gamma_{p}\right) \pi+\hat{\pi}_{t}-\gamma_{p} \hat{\pi}_{t-1}\right]^{2} \\
& \left.+\lambda_{w}\left[\left(1-\gamma_{z}\right) \mu_{z}+\left(1-\gamma_{w}\right) \pi+\hat{\pi}_{w, t}-\gamma_{w} \hat{\pi}_{t-1}\right]^{2}\right\} \\
& + \text { t.i. } p+O\left(\|\zeta, \pi\|^{3}\right),
\end{aligned}
$$

where t.i.p collects terms that are independent of monetary policy and $O\left(\|\zeta, \pi\|^{3}\right)$ denotes residual terms of order 3 , with $\|\zeta, \pi\|$ denoting a bound on

13. In practice we combine the implementation of the Bodenstein, Erceg, and Guerrieri (2009) algorithm developed by Coibion, Gorodnichenko, and Wieland (2012) with the solution algorithm and the parser from Dynare. Our implementation is in the spirit of Guerrieri and Iacoviello (2015), resulting in a less user-friendly yet faster suite of programs.

14. Global solution methods, such as advocated and implemented by Gust and others (2017), are in principle more accurate. However, given the size of our model and the large set of inflation targets and real interest rates that we need to consider (and given that these have to be considered for each and every parameter configuration in our simulations), a global solution would be computationally prohibitive. 
the amplitude of exogenous shocks and the inflation target. Parameters $\lambda_{y}$, $\lambda_{p}$, and $\lambda_{w}$ are effectively weights on an output gap term, a price inflation term, and a wage inflation term. Parameter $\delta$ fulfills $0 \leq \delta \leq 1$. The parameter $\bar{x}$ is the $\log$ ratio of steady-state output to efficient output; $\bar{x}$ is zero either when trend inflation and trend productivity growth are zero or when indexation is full, and negative otherwise (in which case, output is inefficiently low). Finally, $\lambda_{y}, \lambda_{p}, \lambda_{w}, \delta$, and $\bar{x}$ are functions of the structural parameters $\theta$.

We let $\mathcal{W}(\pi ; \theta)$ denote this welfare criterion to emphasize that welfare depends on the inflation target $\pi$ together with the rest of the structural parameters $\theta$. Two cases are considered concerning the latter. In the baseline case, the structural parameters $\theta$ are fixed at reference values and taken to be known with certainty by the policymaker. In an alternative exercise, the policymaker maximizes welfare while recognizing the uncertainty associated with the model's parameters.

The optimal inflation target associated with a given vector of parameters $\theta, \pi^{*}(\theta)$ is approximated via numerical simulations of the model allowing for an occasionally binding ZLB constraint, using the algorithm outlined above. ${ }^{15}$ The optimal inflation rate associated to a given vector of parameters $\theta$ is then obtained as the one maximizing the welfare function, that is:

$$
\pi *(\theta) \equiv \underset{\pi}{\arg \max } \mathcal{W}(\pi ; \theta)
$$

Given parameter estimates at the posterior mean, we can compute the weight on output and wage inflation relative to inflation, that is, $\lambda_{y} / \lambda_{p}$ and $\lambda_{w} / \lambda_{p}$. These relative weights are respectively equal to 0.22 and $0.10 .{ }^{16}$ Note these values are in the ballpark of values obtained in analyses of optimal inflation based on welfare criteria.

15. More precisely, a sample of size $T=100,000$ of innovations $\left\{\epsilon_{t}\right\}_{t=1}^{T}$ is drawn from a Gaussian distribution (we also allow for a burn in the sample of 200 points that we later discard). We use these shocks to simulate the model for given parameter vector $\theta$. The welfare function $\mathcal{W}(\pi ; \theta)$ is approximated by replacing expectations with sample averages. The procedure is repeated for each of $K=51$ inflation targets on the grid $\left\{\pi^{(k)}\right\}_{k=1}^{K}$ ranging from $\pi=\left(\frac{0.5}{4}\right)$ percent to $\pi=\left(\frac{5}{4}\right)$ percent (expressed in quarterly rates). Importantly, we use the exact same sequence of shocks $\left\{\boldsymbol{\epsilon}_{t}\right\}_{t=1}^{T}$ in each and every simulation over the inflation grid.

16. The absolute value of $\lambda_{p}$ is found to be 130.52. See the online appendix for equations stating the formulas for lambdap, lambdaw, and lambdax. 
Figure 1. Welfare and the Inflation Target

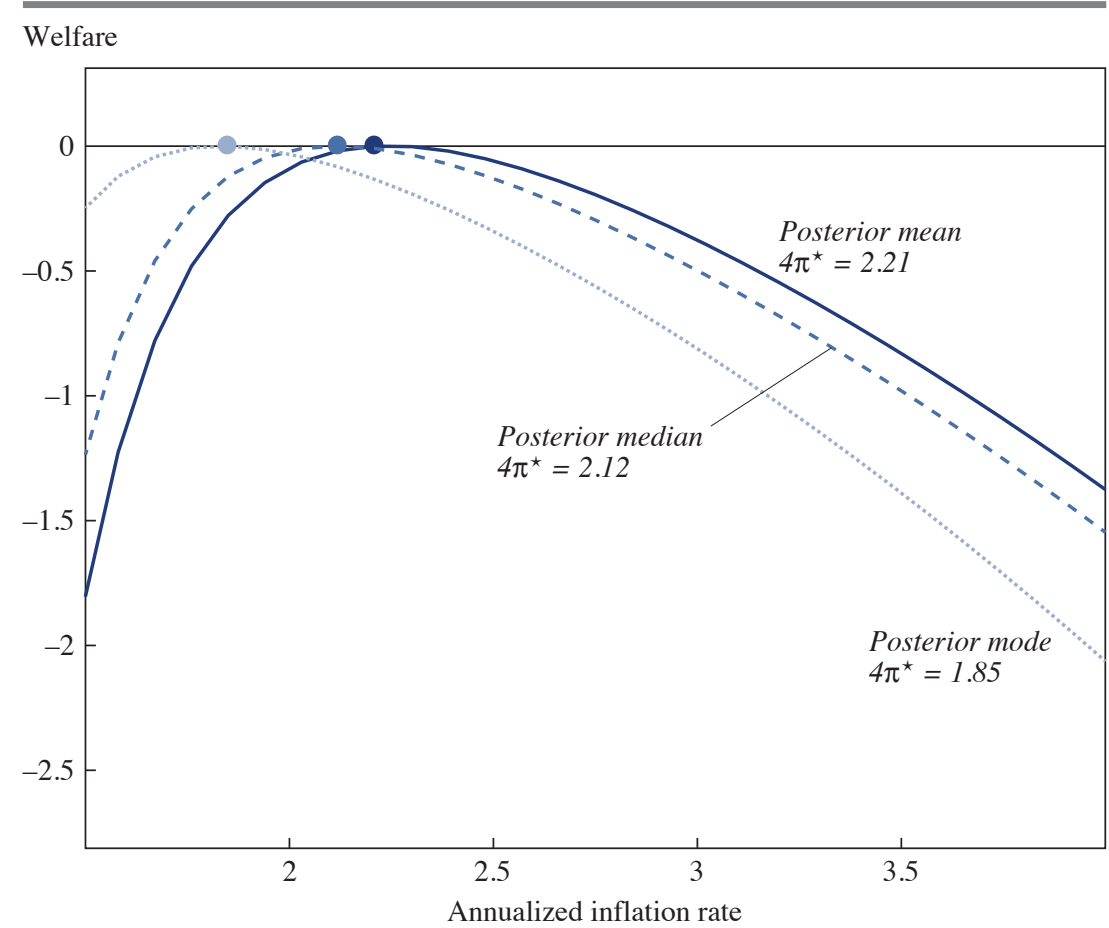

Source: Authors' calculations.

Note: Solid line indicates parameters set at the posterior mean; dashed line indicates parameters set at the posterior median; dotted line indicates parameters set at the posterior mode. The equation $\pi^{\star} \equiv \log \left(\Pi^{\star}\right)$ pertains. In all cases, the welfare functions are normalized so as to peak at zero.

\section{II.C. Some Properties of the Loss Function and the Optimal Inflation Target in the Estimated Model}

This section presents selected properties of the model related to the optimal inflation target. Figure 1 displays the welfare function-expressed as losses relative to the maximum social welfare-associated with three natural benchmarks for the parameter vector $\theta$ : the posterior mean (dark line), the median (medium line), and the mode (light line). For convenience, the peak of each welfare function is identified with a dot. Also, to facilitate interpretations, the inflation targets are expressed in annualized percentage rates.

As figure 1 illustrates, the U.S. optimal inflation target is close to 2 percent and varies between 1.85 percent and 2.21 percent depending on which indicator of central tendency (mean, mode, or median) is selected. This 
Figure 2. Probability of ZLB

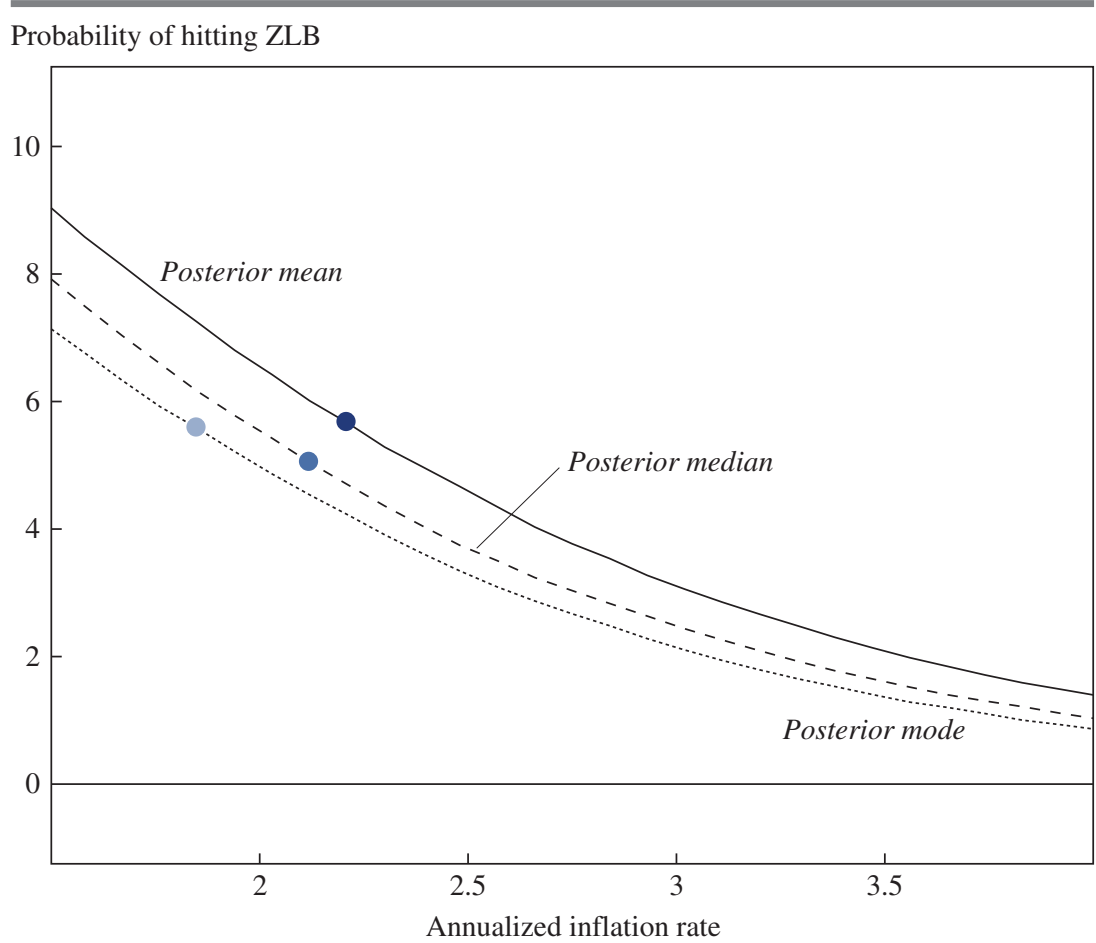

Source: Authors' calculations.

Note: Solid line indicates parameters set at the posterior mean; dashed line indicates parameters set at the posterior median; dotted line indicates parameters set at the posterior mode. The equation $\pi^{\star} \equiv \log \left(\Pi^{\star}\right)$ pertains.

range of values is consistent with those of Coibion, Gorodnichenko, and Wieland (2012) even though in the present paper it is derived from an estimated model over a much shorter sample. ${ }^{17}$ Importantly, while the larger shocks in Coibion, Gorodnichenko, and Wieland (2012) ceteris paribus induce larger inflation targets, the high degree of interest rate smoothing in their analysis works in the other direction (as documented in section $\mathrm{V}$ ).

To complement these illustrative results, figure 2 displays the probability of reaching the ZLB as a function of the annualized inflation target (again, with the parameter vector $\theta$ evaluated at the posterior mean, median,

17. Coibion, Gorodnichenko, and Wieland (2012) calibrate their model on a post-WWII, pre-Great Recession U.S. sample. By contrast, we use a Great Moderation sample. 
and mode). For convenience, the dot in each curve marks the corresponding optimal inflation target.

The probability of hitting the ZLB associated to these positive optimal inflation targets is relatively low, at about 6 percent. This result, as anticipated above, is the mere reflection of our choice of a Great Moderation sample. At the same time, our model is able to predict a fairly spread-out distribution of ZLB episode durations, with a significant fraction of ZLB episodes lasting more than, say, five years (see figure D.1 in the online appendix). Given the existence of a single ZLB episode in the recent history, we do not attempt here to take a stand on what is a relevant distribution of ZLB episodes. ${ }^{18}$

A property of our model, as noticed by Kiley (2019), is that ZLB episodes are rather costly, compared to other studies. This property reflects the absence in our model of ad hoc stabilizing devices sometimes present in other papers concerned with the ZLB, such as emergency fiscal packages or exogenous caps on the maximum duration of ZLB episodes, as in Kiley and Roberts (2017) and in Williams (2009). Allowing for such devices would mechanically reduce the severity of ZLB episodes in our framework, resulting in a lower optimal inflation target.

\section{The Optimal Inflation Target and the Steady-State Real Interest Rate}

The focus of this section is to investigate how the monetary authority should adjust its optimal inflation target $\pi^{*}$ in response to changes in the steady-state real interest rate, $r^{*} .{ }^{19}$ Intuitively, with a lower $r^{*}$ the ZLB is bound to bind more often, so one would expect a higher inflation target should be desirable in that case. But the answer to the practical question of how much should the target be increased is not obvious. Indeed, the benefit of providing a better hedge against hitting the ZLB, which is an infrequent event, comes at a cost of higher steady-state inflation which induces permanent costs, as argued by Bernanke (2016).

To start with, we compute the relation linking the optimal inflation target to the steady-state real interest rate, based on simulations of the estimated

18 See Dordal-i-Carreras and others (2016) for further analysis in that direction.

19. Note our exercise here is different from assessing what would be the optimal response to a time-varying steady state-a specification consistent with econometric work like that of Holston, Laubach, and Williams (2017). Our exercise is arguably consistent with secular stagnation-understood as a permanently lower real rate of interest-while doing without having to assume a unit root process in the real rate of interest. 
model and ignoring parameter uncertainty. We show that the link between $\pi^{*}$ and $r^{*}$ depends to some extent on the factor underlying a variation in $r^{*}$, that is, a change in the discount rate $\rho$ or a change in the growth rate of technology $\mu_{z}$. In our setup the first scenario roughly captures the "taste for safe asset" and "aging population" rationales for secular stagnation, while the second one captures the "decline in technological progress" rationale. Subsequently, we investigate how the relation between the optimal inflation target and the steady-state real interest rate depends on various features of the monetary policy framework, as well as on the size of shocks or on the steady-state price and wage markups.

\section{III.A. The Baseline $\left(r^{*}, \pi^{*}\right)$ Relation}

To characterize the link between $r^{*}$ and $\pi^{*}$, the following simulation exercise is conducted. The structural parameter vector $\theta$ is fixed at its posterior mean, $\bar{\theta}$, with the exception of $\mu_{z}$ and $\rho$. These two parameters are varied-each in turn, keeping the other parameter, $\mu_{z}$ or $\rho$, fixed at its baseline posterior mean value (namely, 1.72 percent and 0.76 percent, respectively, in annualized terms). For both $\mu_{z}$ and $\rho$, we consider values on a grid ranging from 0.4 percent to 10 percent in annualized percentage terms. The model is then simulated for each possible value of $\mu_{z}$ or $\rho$ and various values of inflation targets $\pi$ using the same procedure as before. ${ }^{20}$ The optimal value $\pi^{*}$ associated to each value of $r^{*}$ is obtained as the one maximizing the welfare criterion $\mathcal{W}(\pi ; \theta)$.

We finally obtain two curves. The first one links the optimal inflation target $\pi^{*}$ to the steady-state real interest rate $r^{*}$ for various growth rates of technology $\mu_{z}: \pi^{*}\left[r^{*}\left(\mu_{z}\right)\right]$, where the notation $r^{*}\left(\mu_{z}\right)$ highlights that the steady-state real interest rate varies as $\mu_{z}$ varies. The second one links the optimal inflation target $\pi^{*}$ to the steady-state real interest rate $r^{*}$ for various discount rates $\rho: \pi^{*}\left[r^{*}(\rho)\right]$. Here, the notation $r^{*}(\rho)$ highlights that the steady-state real interest rate varies as $\rho$ varies. ${ }^{21}$

Figure 3 depicts the $\left(r^{*}, \pi^{*}\right)$ relations thus obtained. The round dots correspond to the case when the steady-state real interest rate $r^{*}$ varies

20. In particular, we use the same sequence of shocks $\left\{\epsilon_{t}\right\}_{t=1}^{T}$ as used in the computation implemented in the baseline exercises of section II.B. Here again, we start from the same grid of inflation targets for all the possible values of $\mu_{z}$ or $\rho$. Then, for each value of $\mu_{z}$ or $\rho$, we refine the inflation grid over successive passes until the optimal inflation target associated with a particular value of $\mu_{z}$ or $\rho$ proves insensitive to the grid.

21. In the online appendix, figures G.1 and G.2 report similar results at the posterior mode and at the posterior median. Figure H.1 documents the relation in terms of the optimal nominal interest rate. 
Figure 3. Optimal Inflation Rate as a Function of the Steady-State Real Interest Rate (at the Posterior Mean)

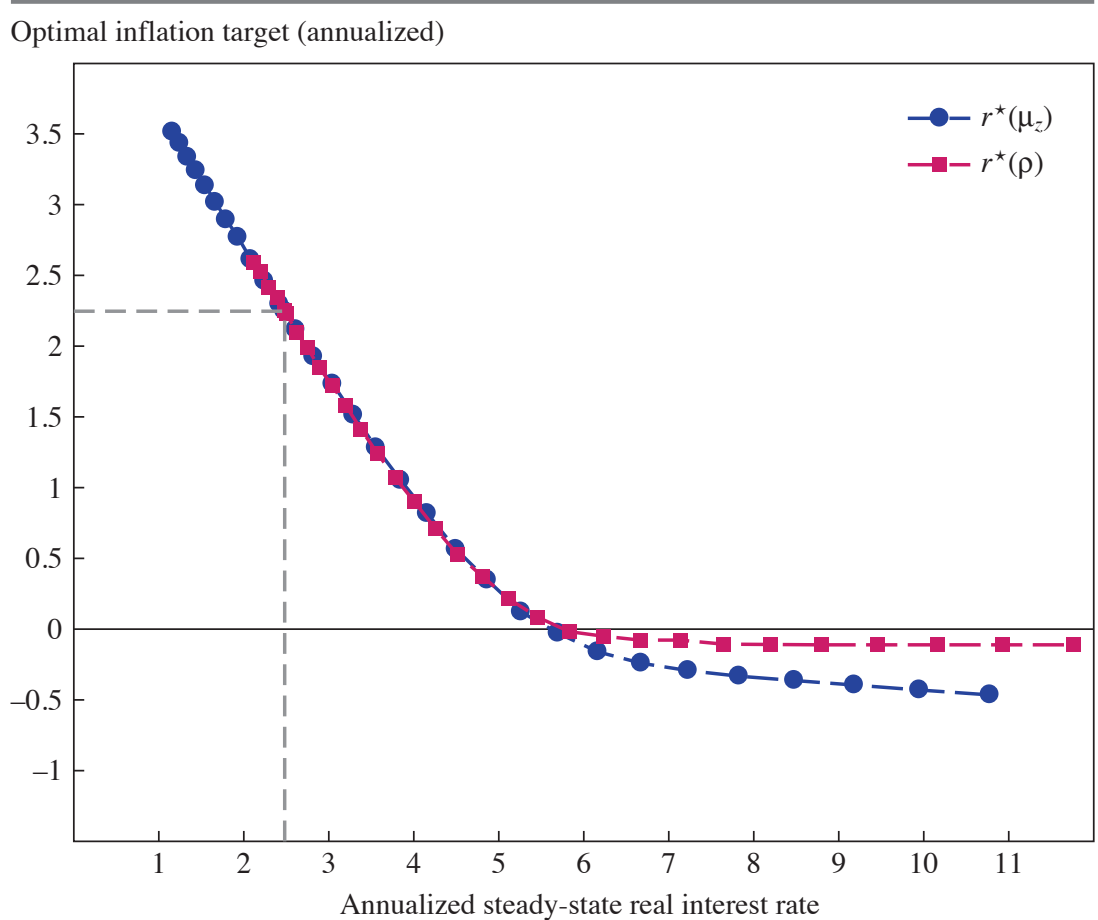

Source: Authors' calculations.

Note: The round dots correspond to the $\left(r^{\star}, \pi^{\star}\right)$ locus when $r^{\star}$ varies with $\mu_{z}$; the square dots correspond to the $\left(r^{\star}, \pi^{\star}\right)$ locus when $r^{\star}$ varies with $\rho$.

with $\mu_{z}$. The square dots correspond to the case when the steady-state real interest rate $r^{*}$ varies with $\rho$. For convenience, both the real interest rate and the associated optimal inflation target are expressed in annualized percentage rates. The dashed gray lines indicate the benchmark result corresponding to the optimal inflation target at the posterior mean of the structural parameter distribution.

These results are complemented with figure 4 which shows the relation between $r^{*}$ and the probability of hitting the ZLB, evaluated at the optimal inflation target. As with figure 3, round dots correspond to the case when $r^{*}$ varies with $\mu_{z}$, while square dots correspond to the case when it varies with $\rho .^{22}$

22. Figure E.1 in the online appendix shows the relation between $r^{*}$ and the nominal interest rate when the inflation target is set at its optimal value. 
Figure 4. Relation between Probability of ZLB at Optimal Inflation and $r^{*}$ (at the Posterior Mean)

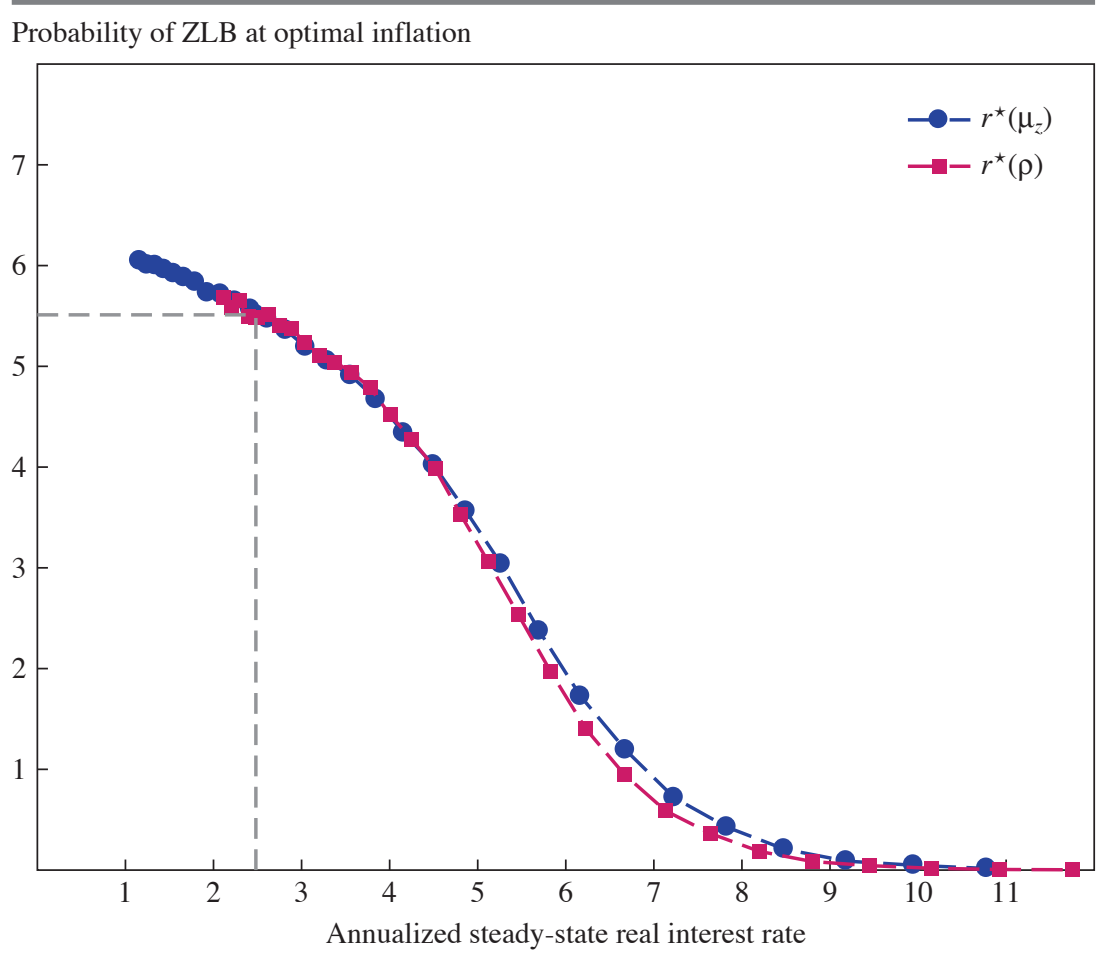

Source: Authors' calculations.

Note: The round dots correspond to the $\left(r^{\star}, \pi^{\star}\right)$ locus when $r^{\star}$ varies with $\mu_{z}$; the square dots correspond to the $\left(r^{\star}, \pi^{\star}\right)$ locus when $r^{\star}$ varies with $\rho$.

As expected, the relation in figure 3 is decreasing. However, the slope varies with the value of $r^{*}$. The slope is relatively large in absolute valuealthough smaller than 1 -for moderate values of $r^{*}$ (say, below 4 percent). The slope declines in absolute value as $r^{*}$ increases: lowering the inflation target to compensate for an increase in $r^{*}$ becomes less and less desirable. This reflects the fact that, as $r^{*}$ increases, the probability of hitting the ZLB becomes smaller and smaller. For very large $r^{*}$ values, the probability becomes almost zero, as figure 4 shows.

At some point, the optimal inflation target becomes insensitive to changes in $r^{*}$ when the latter originate from changes in the discount rate $\rho$. In this case, the inflation target stabilizes at a slightly negative value in order to lower the nominal wage inflation rate required to support positive productivity growth, given the imperfect indexation of nominal wages to 
productivity. At the steady state, the real wage must grow at a rate of $\mu_{z}$. It is optimal to obtain this steady-state growth as the result of a moderate nominal wage increase and a moderate price decrease, rather than as the result of a zero price inflation and a consequently larger nominal wage inflation. ${ }^{23}$

The previous tension is even more apparent when $r^{*}$ varies with $\mu_{z}$ since, in this case, the effects of imperfect indexation of wages to productivity are magnified given that a higher $\mu_{z}$ calls for a higher growth in the real wage, which is optimally attained through greater price deflation, as well as a higher wage inflation. Notice, however, that even in this case, the optimal inflation target becomes less sensitive to changes in $r^{*}$ for very large values of $r^{*}$, typically above 6 percent.

For low values of $r^{*}$, on the other hand, the slope of the curve is steeper. In particular, in the empirically relevant region, the relation is not far from one to one. More precisely, it shows that, starting from the posterior mean estimate of $\theta$, a 100 basis point decline in $r^{*}$ should lead to an over 99 basis point increase in $\pi^{*}$. Importantly, this increase in the optimal inflation target is virtually the same no matter the underlying factor causing the change in $r^{*}$ : a drop in potential growth, $\mu_{z}$, or a decrease in the discount factor, $\rho$. At the same time, the ZLB incidence evaluated at the optimal inflation rate also increases when the real rate decreases. At some point, the speed at which this probability increases slows down, reflecting that the social planner would choose to increase the inflation target as needed so as to avoid a higher ZLB incidence.

Figure 5 shows how the probability of ZLB changes as a function of $r^{*}$, holding the inflation target constant. We first set the inflation target at its optimal baseline value (that is, the value computed at the posterior mean, 2.21 percent). This is reported as the square dots. Similarly, we also compute an analog relation assuming, this time, that the inflation target is held constant at the optimal value consistent with a steady-state real interest rate 1 percentage point lower (thus, inflation is set to 3.20). Here again, the other parameters are set at their posterior mean. This corresponds to the

23. For very large $r^{*}$, as a rough approximation, we can ignore the effects of shocks and assume that the ZLB is a zero-mass event. Assuming also a negligible difference between steady-state and efficient outputs and letting $\lambda p$ and $\lambda_{w}$ denote the weights attached to price dispersion and wage dispersion, respectively, in the approximated welfare function, the optimal inflation obeys $\pi^{*} \approx-\lambda_{w}\left(1-\gamma_{z}\right)\left(1-\gamma_{w}\right) /\left[\lambda_{p}\left(1-\gamma_{p}\right)^{2}+\lambda_{w}\left(1-\gamma_{w}\right)^{2}\right] \mu_{z^{*}}$. Given the low values of $\lambda_{w}$ resulting from our estimation, it is not surprising that $\pi^{*}$ is negative but close to zero. See Amano and others (2009) for a similar point in the context of a model abstracting from ZLB issues. 
Figure 5. Relation between Probability of ZLB and $r^{*}$ (at the Posterior Mean)

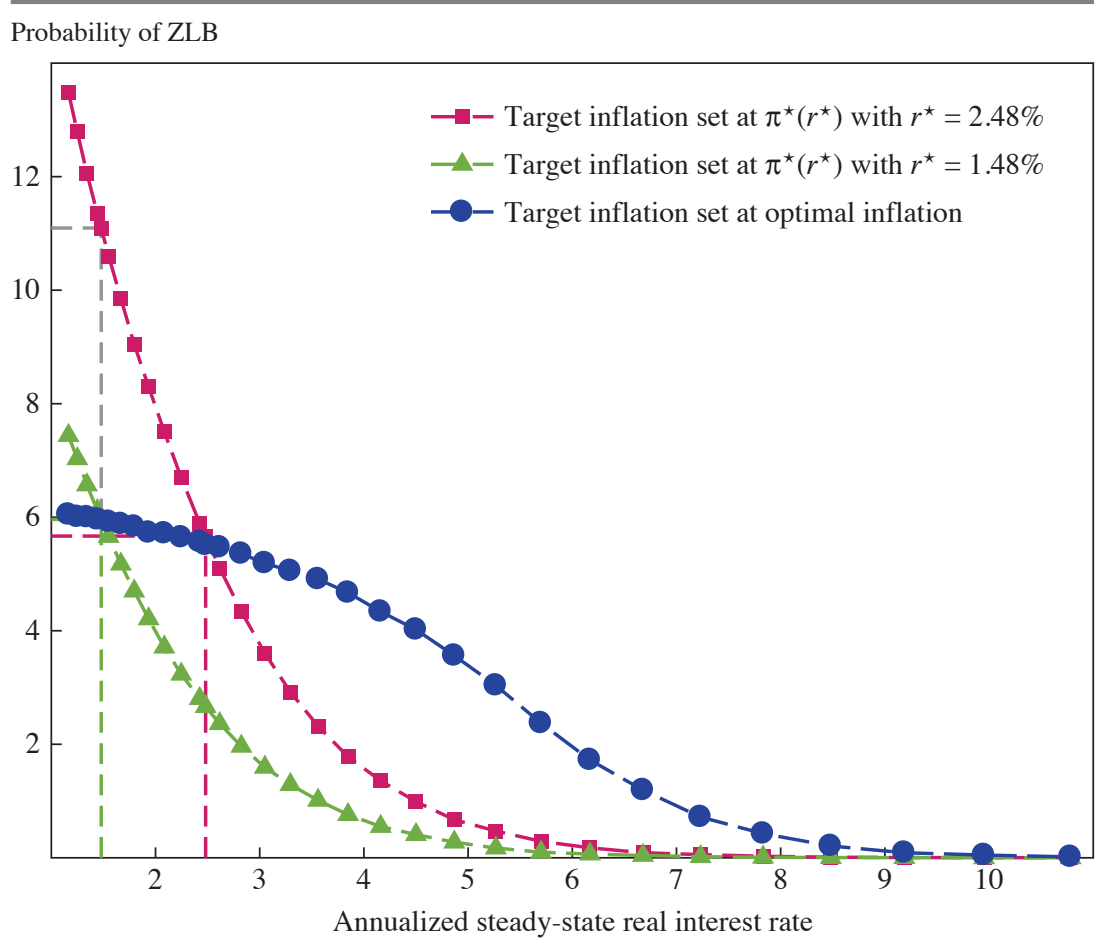

Source: Authors' calculations.

Note: The square dots correspond to the relation linking $r^{\star}$ and the probability of ZLB, holding the optimal inflation target $\pi^{\star}$ at the baseline value. The triangle dots correspond the same relation when the optimal inflation target $\pi^{\star}$ is set at the value consistent with a steady-state real interest rate one percentage point lower. The round dots correspond to the probability of ZLB obtained under the optimal inflation target $\pi^{\star}$ associated with a given value of $r^{\star}$.

triangle dots in the figure. For convenience, we also report the the probability of hitting the ZLB as a function of $r^{*}$ conditional on adjusting optimally the inflation target, as in figure 4. This corresponds to the round dots.

Consider first the square-dot curve. At the level of the real interest rate prevailing before the permanent decline, assuming that the central bank sets its target to the associated optimal level, the probability of reaching the ZLB would be slightly below 6 percent. Imagine now that the real interest rate experiences a decline of 100 basis points. Keeping the inflation target at the same level as prior to the shock, the probability of reaching the ZLB would now climb up to approximately 11 percent. However, the change in the optimal inflation target brings the probability of reaching the ZLB 
back to approximately 6 percent. Thus, the social planner would almost neutralize the effects of the natural rate decline on the probability of hitting the ZLB.

Finally we investigate whether the trade-off analyzed above translates into meaningful welfare costs, measured in terms of foregone per period consumption. Results are reported in the online appendix, section F. It turns out that, under sufficiently low $r^{*}$ values, agents faced with a 1 percentage point decline in the steady-state real interest rates would require up to a 1.5 percentage point increase in consumption to be as well off under the former optimal inflation target (that is, 2.21 percent) as under the optimal target associated with the lower real interest rate (3.20 percent in this case). In other words, the welfare costs of not adjusting the target in the face of a decline in $r^{*}$ are substantial.

\section{III.B. Robustness to Alternative Structural Assumptions}

In this section, we investigate the robustness of the $\left(r^{*}, \pi^{*}\right)$ relation to altering (or modifying) some structural features of the environment. We consider several relevant dimensions: the case of larger shocks, alternative calibrations for the steady-state price and wage markup, and changes in the degree of price and wage indexation. ${ }^{24}$

LARGER SHOCKS As argued before, the model is estimated using data from the Great Moderation period. One may legitimately argue that the decline in the real interest rate resulting from the secular stagnation has come hand in hand with larger shocks, as the Great Recession suggests. To address this concern, we simulate the model assuming that demand shocks have a standard deviation 30 percent larger than estimated.

We conduct this exercise assuming that changes in average productivity growth $\mu_{z}$ are the only driver of changes in the natural rate. Apart from $\sigma_{q}$ and $\sigma_{g}$, which are rescaled, all the other parameters are frozen at their posterior mean. Given this setup, the optimal inflation target is 3.7 percent as opposed to 2.21 percent conditional on the baseline value of $r^{*}$. Also, under the alternative shock configuration, the probability of hitting the ZLB is 5.3 percent, as opposed to 5.5 percent in the baseline. These probabilities may seem low, especially in the case of large shocks which we argue capture Great Recession-like shocks. However they are particularly low because the inflation target is chosen optimally in this setup. In particular, in the larger shocks case, the increase in the inflation target is large enough

24. Robustness to altering the monetary policy rule is assessed further in section V. 
to offset the impact of larger shocks in terms of ZLB incidence. When instead we keep the inflation target unchanged, the probability of hitting the ZLB rises to 18 percent in the face of a 1 percent decline in $r^{*} .^{25}$ In that case, these ZLB probabilities come close to the probabilities reported by Kiley and Roberts (2017) in the case of their DSGE model (albeit they find a higher probability of ZLB, of the order of 30 percent when using the FRB/US model), or by Chung and others (2019). ${ }^{26}$

Figure 6 reports the $\left(r^{*}, \pi^{*}\right)$ relation under larger demand shocks (square dots) and compares the outcome with the baseline relation (round dots). ${ }^{27}$ Interestingly, the $\left(r^{*}, \pi^{*}\right)$ locus has essentially the same slope in the low $r^{*}$ region. Here again, we find a slope close to -1 . However, the curve is somewhat steeper in the high $r^{*}$ region and shifted up, compared to the baseline scenario. This reflects that under larger demand shocks, even at very high levels of the natural rate, a drop in the latter is conducive to more frequent ZLB episodes. The social planner is then willing to increase the inflation target at a higher pace than in the baseline scenario and generically sets the inflation target at higher levels to hedge the economy against ZLB episodes.

ALTERNATIVE MARKUPS The optimal level of inflation in our setup depends on the elasticities of substitution among intermediate goods, $\theta_{p}$, and among labor types, $\theta_{w}$, since those parameters determine the extent to which the price and wage dispersion induced by inflation is translated into an inefficient allocation of resources. These parameters have been calibrated, as they cannot be identified from time-series data and a log-linearized version of the model.

In our calibration, the baseline value for the elasticity of substitution $\theta_{p}$ is 6 , leading to a steady-state price markup of 20 percent. While this value is in line with common textbook parameterizations (Galí 2015), and is close to the baseline value obtained in Hall (2018) and in Christiano, Eichenbaum, and Evans (2005), there is considerable uncertainty in the empirical literature about the level of markups. For example, some estimates in Basu and Fernald (1997) and Traina (2015) point to possibly much smaller values, while Autor and others (forthcoming), De Loecker

25. See the online appendix, section I, in which such counterfactual probabilities of ZLB are reported.

26. In addition to per period probability of ZLB, these authors also put forward and emphasize the probability that a ZLB event occurs in the next decade. By construction this number is a larger one, and the mapping between the two numbers is not fully straightforward.

27. We obtain this figure using the same procedure as outlined before. Here again, we run several passes with successively refined inflation grids. 
Figure 6. Optimal Inflation Rate as a Function of the Steady-State Real Interest Rate with Larger Demand Shocks

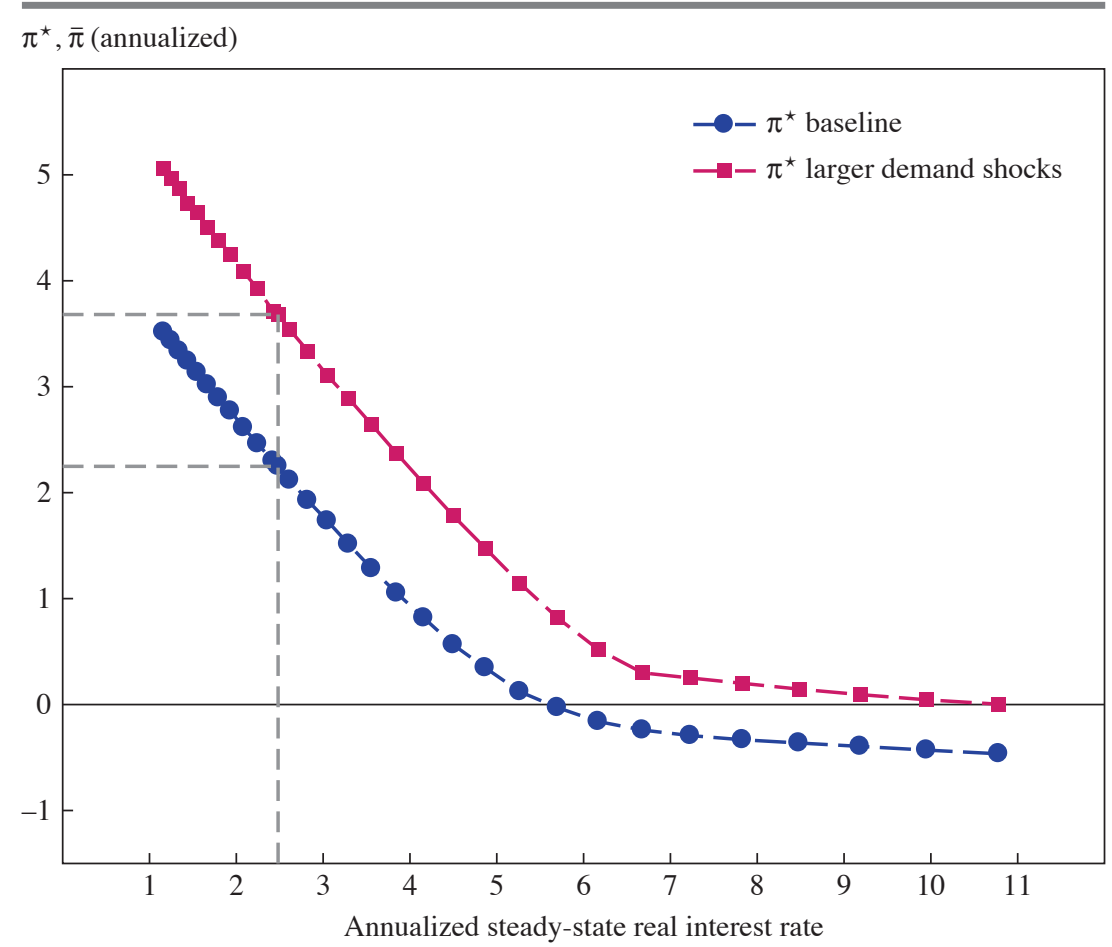

Source: Authors' calculations.

Note: The round dots correspond to the baseline scenario wherein all the structural parameters are set at their posterior mean $\bar{\theta}$. The square dots correspond to the counterfactual simulation with $\sigma_{q}$ and $\sigma_{g}$ set to twice their baseline value.

and Eeckhout (2017), and Farhi and Gourio (2018) suggest substantially larger figures. To investigate the robustness of our results, we redo our main simulation exercise, this time setting $\theta_{p}$ to a value as large as 10 or as low as 3 . These values largely encompass the range of available empirical estimates.

Similarly, for the wage markup, there is arguably even scarcer evidence, and in any case considerable uncertainty around our baseline parameterization, given by $\theta_{w}$ set to 3 . Here again, so as to cover a broad range of plausible estimates, we run alternatives exercises, setting in turn $\theta_{w}$ to 8 and $\theta_{w}$ to 1.5. Results are reported in figure 7 in the case of robustness with respect to the price markup and in figure 8 with respect to the wage markup.

The main takeaway from these figures is that our key result is by and large preserved. That is, in the empirically relevant region (for levels of 
Figure 7. Optimal Inflation Rate as a Function of the Steady-State Real Interest Rate with Alternative $\theta_{p}$

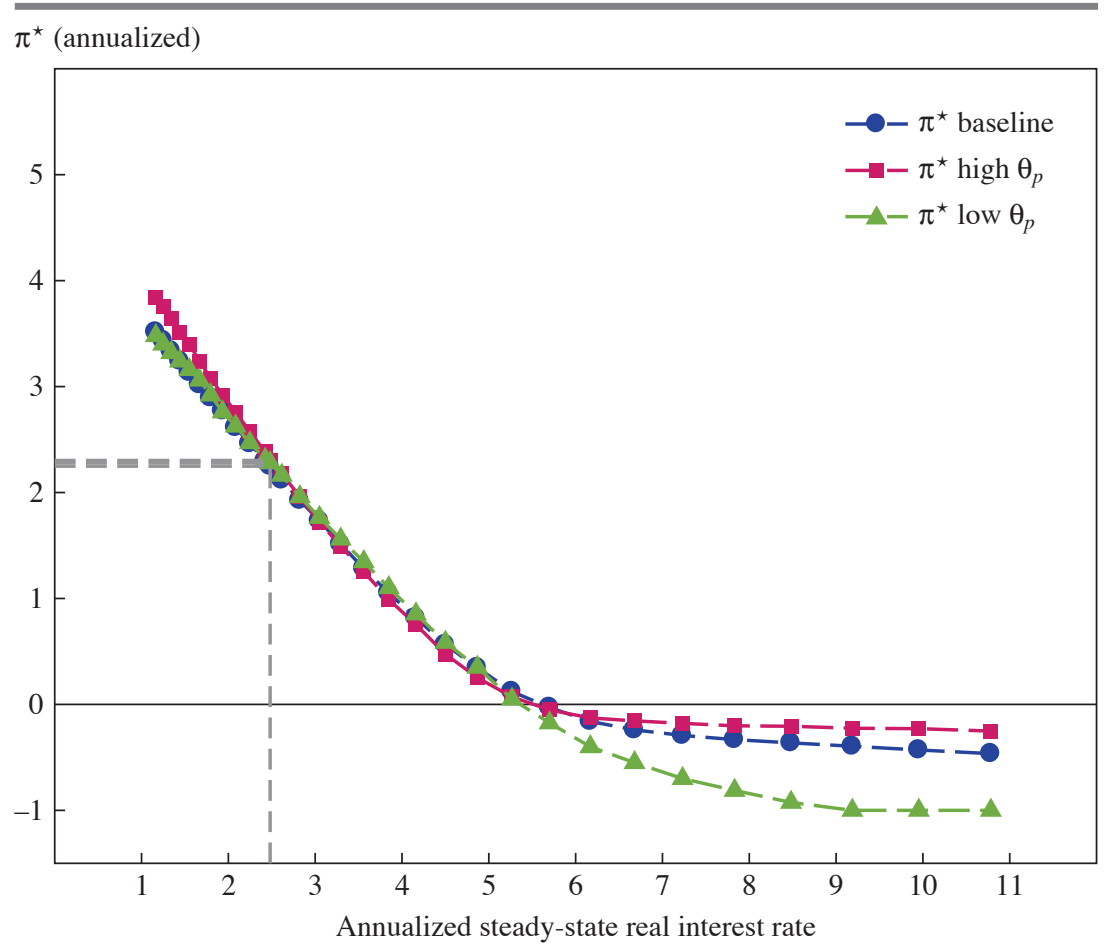

Source: Authors' calculations.

Note: The round dots correspond to the baseline scenario wherein all the structural parameters are set at their posterior mean $\bar{\theta}$. The square dots correspond to the counterfactual simulation with $\theta_{p}$ set to 10 . The triangle dots correspond to the counterfactual simulation with $\theta_{p}$ set to 3 .

$r^{*}$ lower than, say, 4 percent), the slope of the $\left(r^{*}, \pi^{*}\right)$ curve is only very mildly affected when changing the elasticity of substitution of goods or labor types.

Another noticeable result of this robustness exercise is that, by contrast, in the region with high steady-state real interest rates (say, $r^{*}$ larger than 5 percent) the value of the optimal inflation target and the slope of the curve of interest are more sensitive to the value of $\theta_{p}$ or $\theta_{w}$. To see why, first notice that, in this region, the ZLB is essentially irrelevant so the standard welfare cost of inflation setup applies. With less substitution across goods, a given level of price dispersion induced by inflation leads to smaller output dispersion (as is clear, for instance, in the polar case of complementary goods, which leads to no output dispersion across firms at all). The effect 
Figure 8. Optimal Inflation Rate as a Function of the Steady-State Real Interest Rate with Alternative $\theta_{w}$

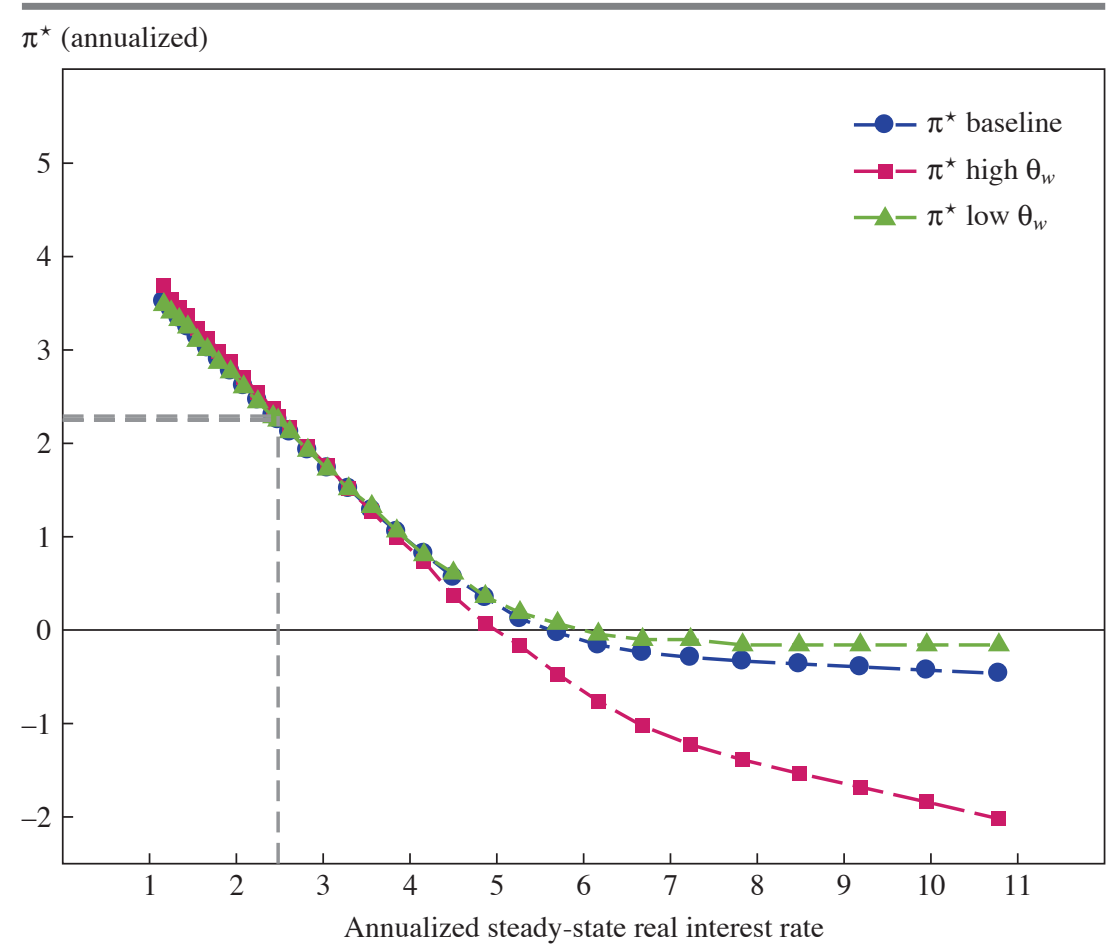

Source: Authors' calculations.

Note: The round dots correspond to the baseline scenario wherein all the structural parameters are set at their posterior mean $\bar{\theta}$. The square dots correspond to the counterfactual simulation with $\theta_{w}$ set to 8 . The triangle dots correspond to the counterfactual simulation with $\theta_{w}$ set to 1.5 .

of $\theta_{p}$ on output dispersion is apparent from the formulas in our online appendix or in textbook derivations of output dispersion, for example, chapter 3 in Galí (2015). Thus, with a low substitution (that is, a low $\theta_{p}$ ), the welfare loss due to inflation (or deflation) is smaller. Therefore a lower $\theta_{p}$ allows for an inflation target farther away from zero, insofar as there are motives for a nonzero steady-state inflation. Such a mechanism explains why, in figure 7, optimal inflation is more negative with lower substitution.

Interestingly, when we consider robustness with respect to parameter $\theta_{w}$, the ranking of the corresponding curves is reversed (see figure 8). That is, a larger $\theta_{w}$ induces a larger inflation target in absolute value. The reason is that, with a larger substitution across labor types, a given nominal wage 
growth generates dispersion of quantities across types of labor that turns out to be particularly costly. In that case, it is optimal that the burden of adjustment of real wages to growth is borne not by nominal wages but rather by nominal prices (thus leading to a more pronounced deflation). ${ }^{28}$

ALTERNATIVE DEGREES OF INDEXATION The degree of indexation of price and wage is an important determinant of the cost of inflation. In our empirical estimate the degrees of indexation are moderate: 0.22 for prices and 0.44 for wages at the posterior mean. It is worthwhile examining the sensitivity of our results to the degree of indexation. Indeed, some existing macro estimates find or impose a much larger degree of indexation (Christiano, Eichenbaum, and Evans 2005). By contrast, existing micro studies hardly find any evidence of indexation. In this robustness exercise, we consider in turn a zero indexation case, a high indexation case (setting $\gamma_{p}$ and $\gamma_{w}$ to 0.7), and a very high indexation case (setting $\gamma_{p}$ and $\gamma_{w}$ to 0.9 ). The last two configurations are arguably unrealistic. Results are presented in figure 9. In the absence of indexation, results are similar to those under our estimated indexation levels. For the high indexation case $\left(\gamma_{p}\right.$ and $\gamma_{w}$ equal to 0.7$)$, the results differ from the baseline only for relatively large values of the steady-state real interest rate.

In the very high indexation case, the position and shape of the curve are substantially affected: the curve is nearly a decreasing straight line. Indeed, for a very large indexation degree the welfare cost of inflation (or deflation) is substantially reduced. As a result, it is optimal to allow for a sizable trend deflation when the natural rate is large as a result of large productivity growth. However, we can note that in the empirically relevant region, that is, for $r^{*}$ below 2 percent, the local slope of the curve is similar whatever the degree of indexation.

\section{The Effect of Parameter Uncertainty}

In this section we investigate the impact of parameter uncertainty on the relation between the optimal inflation target and the steady-state real interest rate. Specifically, we analyze how a Bayesian-theoretic optimal inflation target reacts to a downward shift in the distribution of the steady-state real interest rate.

28. This can be illustrated again in the approximated welfare function, ignoring the effects of shocks. Then the optimal inflation obeys $\pi^{*} \approx-\left(\lambda_{w}\left(1-\gamma_{z}\right)\left(1-\gamma_{w}\right) /\left[\lambda p\left(1-\gamma_{p}\right)^{2}+\right.\right.$ $\left.\left.\lambda_{w}\left(1-\gamma_{w}\right)^{2}\right]\right) \mu_{z}$. The inflation target is a decreasing function of $\lambda_{w}$, thus of $\theta_{w}$. 
Figure 9. Optimal Inflation Rate as a Function of the Steady-State Real Interest Rate with Alternative Indexation Degrees

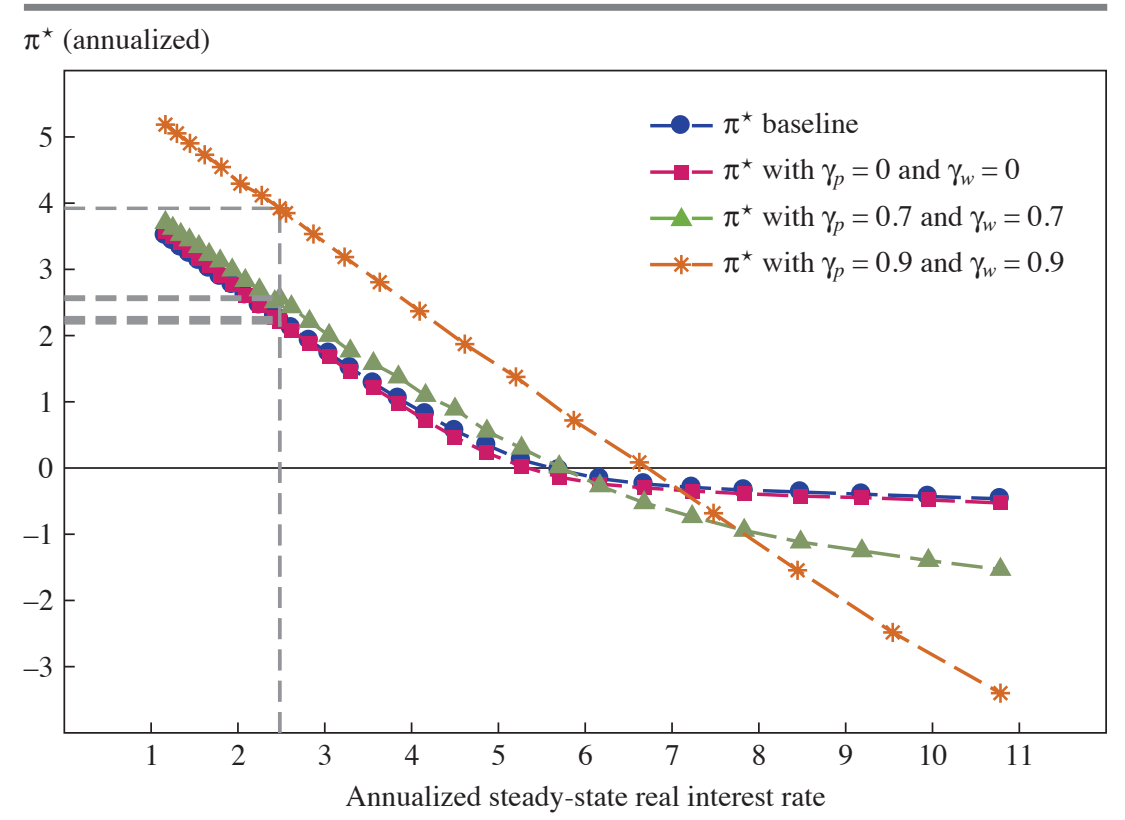

Source: Authors' calculations.

Note: The round dots correspond to the baseline scenario wherein all the structural parameters are set at their posterior mean $\bar{\theta}$. The square dots correspond to the counterfactual simulation with $\gamma_{p}=\gamma_{w}=0$. The triangle dots correspond to the counterfactual simulation with $\gamma_{p}=\gamma_{w}=0.7$. The star dots correspond to the counterfactual simulation with $\gamma_{p}=\gamma_{w}=0.9$.

\section{IV.A. A Bayesian-Theoretic Optimal Inflation Target}

The location of the loss function $\mathcal{W}(\pi ; \theta)$ evidently depends on the vector of parameters $\theta$ describing the economy. As a result of estimation uncertainty around $\theta$, the optimal inflation rate $\pi^{*}(\theta)$ will be subject to uncertainty. Further, a policymaker may wish to take into account the uncertainty surrounding $\theta$ when determining the optimal inflation target. A relevant feature of the welfare functions in our setup is that, in general, and as shown above, they are markedly asymmetric: adopting an inflation target 1 percentage point below the optimal value generates welfare losses larger than setting it 1 percentage point above. As a result, the certainty equivalence does not hold. A policymaker maximizing expected welfare while recognizing the uncertainty will choose an inflation target differing from that corresponding to the case where $\theta$ is set to its expected value and taken to be known with certainty, as in our baseline analysis. 
Formally, the estimated posterior distribution of parameters $p\left(\theta \mid X_{T}\right)$ can be exploited to quantify the impact of parameter uncertainty on the optimal inflation target and to compute a Bayesian-theoretic optimal inflation target. We define the latter as the inflation target $\pi^{* *}$ which maximizes the expected welfare not only over the realizations of shocks but also over the realizations of parameters: ${ }^{29}$

$$
\pi^{* *} \equiv \underset{\pi}{\arg \max } \int_{\theta} \mathcal{W}(\pi ; \theta) p\left(\theta \mid X_{T}\right) \mathrm{d} \theta .
$$

We interpret the spread between the optimal Bayesian inflation target and the certainty-equivalent optimal inflation target at the posterior mean $\bar{\theta}$ as a measure of how uncertainty about the parameter values affects optimal inflation. Given the nature of the asymmetry in the welfare function, the spread will turn out to be positive: a Bayesian policymaker will tend to choose a higher inflation target than a policymaker taking $\theta$ to be known and equal to the mean of its distribution. A higher inflation target indeed acts as a buffer to hedge against particularly detrimental parameter values (either because they lead to more frequent ZLB episodes or because they lead to particularly acute inflation distortions). We define

$$
\operatorname{Spr}(\theta) \equiv \pi^{* *}-\pi^{*}(\theta)
$$

and assess below $\operatorname{Spr}(\bar{\theta})$.

\section{IV.B. Results}

According to the simulation exercise, $\pi^{* *}=2.40$ percent. This robust optimal inflation target is higher than the value obtained with $\theta$ set at its

29. This Bayesian inflation target is recovered from simulating the model under a ZLB constraint using the exact same sequence of shocks $\left\{\epsilon_{t}\right\}_{t=1}^{T}$ with $T=100,000$ as in the previous subsection (together with the same burn-in sample) and combining it with $N$ draws of parameters $\left\{\theta_{j}\right\}_{j=1}^{N}$ from the estimated posterior distribution $p\left(\theta \mid X_{T}\right)$, with $N=500$. As in the previous section, the social welfare function $\mathcal{W}(\pi ; \theta)$ is evaluated for each draw of $\theta$ over a grid of inflation targets $\left\{\pi^{(k)}\right\}_{k=1}^{K}$. The Bayesian welfare criterion is then computed as the average welfare across parameter draws. Here, we start with the same inflation grid as before and then run several passes. In the first pass, we identify the inflation target maximizing the Bayesian welfare criterion. We then set a finer grid of $K=51$ inflation targets around this value. We repeat this process several times with successively finer grids of inflation targets until the identified optimal inflation target proves insensitive to the grid. In this particular exercise, some parameter draws for $\theta$ lead to convergence failure in the algorithm implementing the ZLB. These draws are discarded. 
central tendency. As expected, a Bayesian policymaker chooses a higher inflation target to hedge against particularly harmful states of the world (that is, parameter draws) where the frequency of hitting the ZLB is high.

Assessing how a change in $r^{*}$ affects $\pi^{* *}$ for every value of $r^{*}$ is not possible, due to the computational cost involved. Such a reaction is thus investigated for a particular scenario: it is assumed that the economy starts from the posterior distribution of parameters $p\left(\theta \mid X_{T}\right)$ and that, everything else being constant, the mean of $r^{*}$ decreases by 100 basis points. Such a 1 percentage point decline is chosen mainly for illustrative purposes. Yet, it is of a comparable order of magnitude, although somewhat smaller in absolute value, than recent estimates of the drop of the natural rate after the crisis, such as Laubach and Williams (2016) and Holston, Laubach, and Williams (2017). The counterfactual exercise considered can therefore be seen as a relatively conservative characterization of the shift in the steadystate real interest rate. Figure 10 depicts the counterfactual shift in the distribution of $r^{*}$ that is considered.

The Bayesian-theoretic optimal inflation target corresponding to the counterfactual lower distribution of $r^{*}$ is obtained from a simulation exercise that relies on the same procedure as before. ${ }^{30}$ Given a draw in the posterior of parameter vector $\theta$, the value of the steady-state real interest rate is computed using the expression implied by the postulated structural model $r^{*}(\theta)=\rho(\theta)+\mu_{z}(\theta)$. From this particular draw, a counterfactual lower steady-state real interest rate, $r^{*}\left(\theta_{\Delta}\right)$, is obtained by shifting the long-run growth component of the model $\mu_{z}$ downward by 1 percentage point (in annualized terms). The welfare function $\mathcal{W}\left(\pi ; \theta_{\Delta}\right)$ is then evaluated. Since there are no other changes than this shift in the mean value of $\mu_{z}$ in the distribution of the structural parameters, we can characterize the counterfactual distribution $p\left(\theta_{\Delta} \mid X_{T}\right)$ as a simple transformation of the estimated posterior $p\left(\theta \mid X_{T}\right)$. The counterfactual Bayesian-theoretic optimal inflation target is then obtained as

$$
\pi_{\Delta}^{* *} \equiv \underset{\pi}{\arg \max } \int_{\theta_{\Delta}} \mathcal{W}\left(\pi ; \theta_{\Delta}\right) p\left(\theta_{\Delta} \mid X_{T}\right) \mathrm{d} \theta_{\Delta}
$$

Figure 11 illustrates the counterfactual change in optimal inflation target obtained when the mean of the distibution of the steady-state real interest rate declines by 100 basis points. The simulation exercise returns a value

30. Again, we use the same sequence of shocks and the same parameter draws as in section II.B. 
Figure 10. Posterior Distributions of $r^{*}$ and Counterfactual $r^{*}$

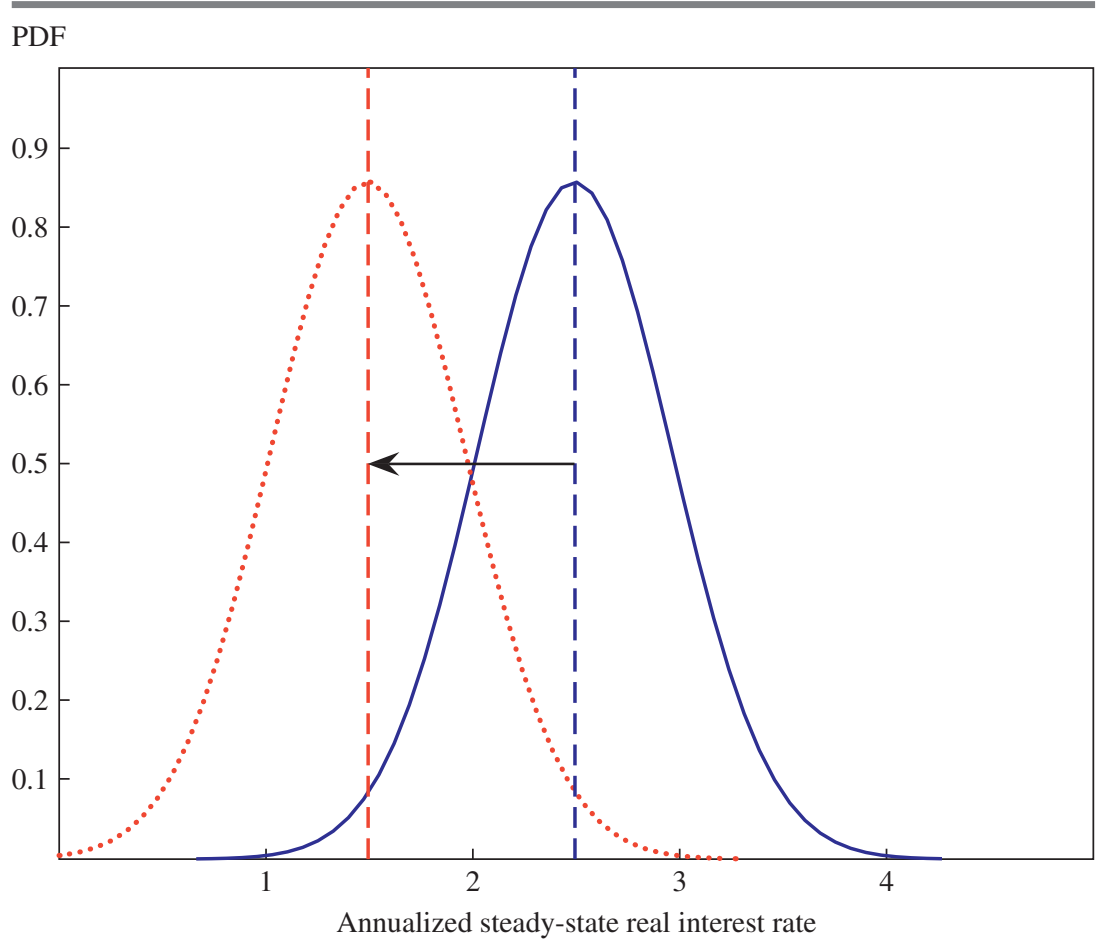

Source: Authors' calculations.

Note: The curves indicate PDFs of $r^{\star}$ (baseline solid and counterfactual dotted); the dashed vertical lines indicate mean value of $r^{\star}$.

of $\pi_{\Delta}^{* *}=3.30$ percent, that is, 90 basis points higher than the optimal value under uncertainty obtained with the posterior distribution of parameters in the pre-crisis sample $\pi_{\Delta}^{* *}=2.40$ percent. ${ }^{31}$

Thus, in our setup, a monetary authority that is concerned about the uncertainty surrounding the parameters driving the costs and benefits of the inflation chooses a higher optimal inflation target. However, the reaction of this optimal inflation target following a drop in the mean $r^{*}$ is hardly altered: a 100 basis point decrease in the steady-state real interest rate calls for a roughly 90 basis point increase in the optimal inflation target, in the vicinity of pre-crisis parameter estimates.

31. Figure J.1 in the online appendix shows how the posterior distribution of $\pi *$ is shifted after the permanent decline in the mean of $r^{*}$. 
Figure 11. Expected Bayesian Welfare in Baseline and Counterfactual

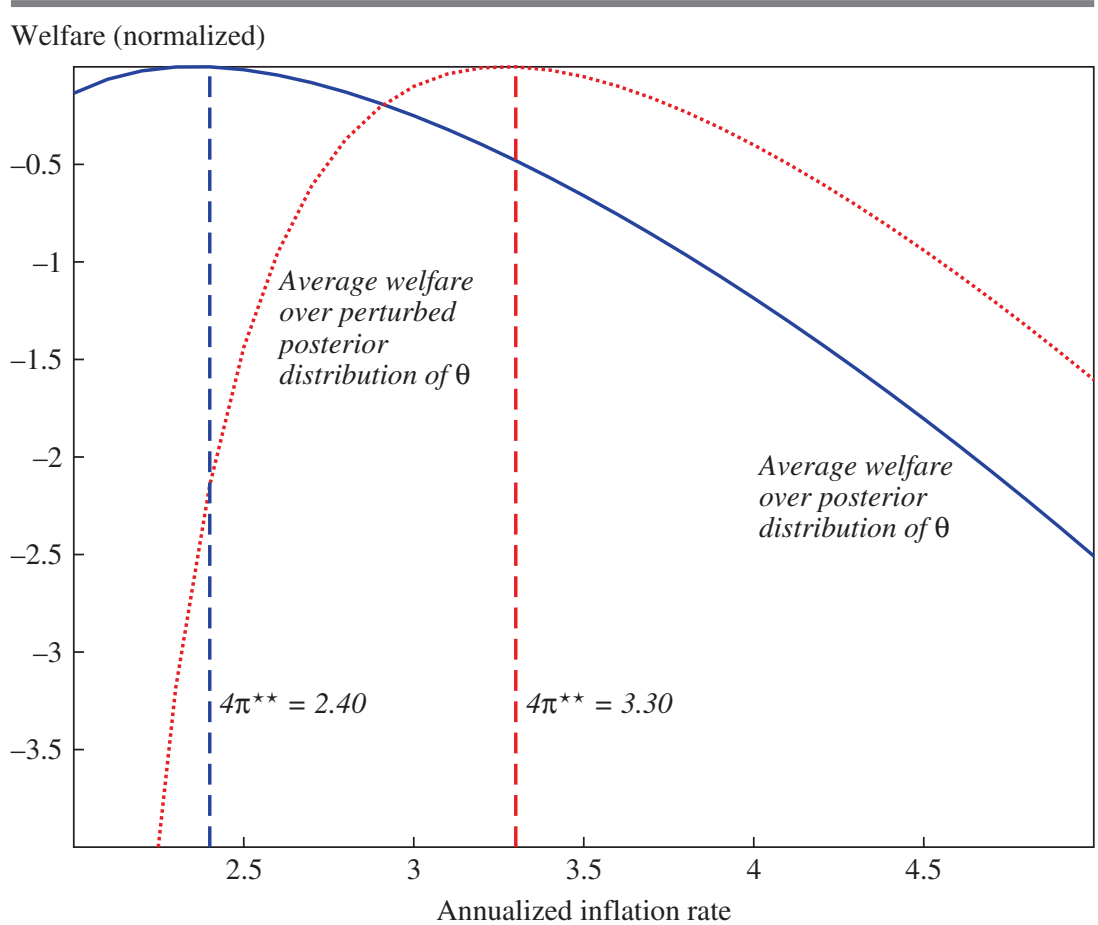

Source: Authors' calculations.

Note: Solid line is the curve $\mathbb{E}_{\theta}(\mathcal{W}(\pi, \theta))$; dotted line is the curve $\mathbb{E}_{\theta}(\mathcal{W}(\pi, \theta))$ with lower $r^{\star}$.

\section{IV.C. A Known Reaction Function}

Here we study the consequences of the (plausible) assumption that the central bank actually knows the coefficients of its interest rate rule with certainty. More specifically we repeat the same simulation exercise as in the previous subsection but with parameters $a_{\pi}, a_{y}$, and $\rho_{i}$ in the reaction function (equation 2) taken to be known with certainty. In practice we fix these three parameters at their posterior mean instead of sampling them from their posterior distribution. This is arguably the relevant approach from the point of view of the policymaker. ${ }^{32}$ Note, however, that all the other parameters are subject to uncertainty from the standpoint of the central bank.

32. In practice, long-run inflation targets are seldom reconsidered while the rotation in monetary policy committees happens at a higher frequency. From this viewpoint, our baseline assumption of uncertainty on all the monetary policy rule parameters is not necessarily unwarranted. 
Figure 12. Expected Bayesian Welfare

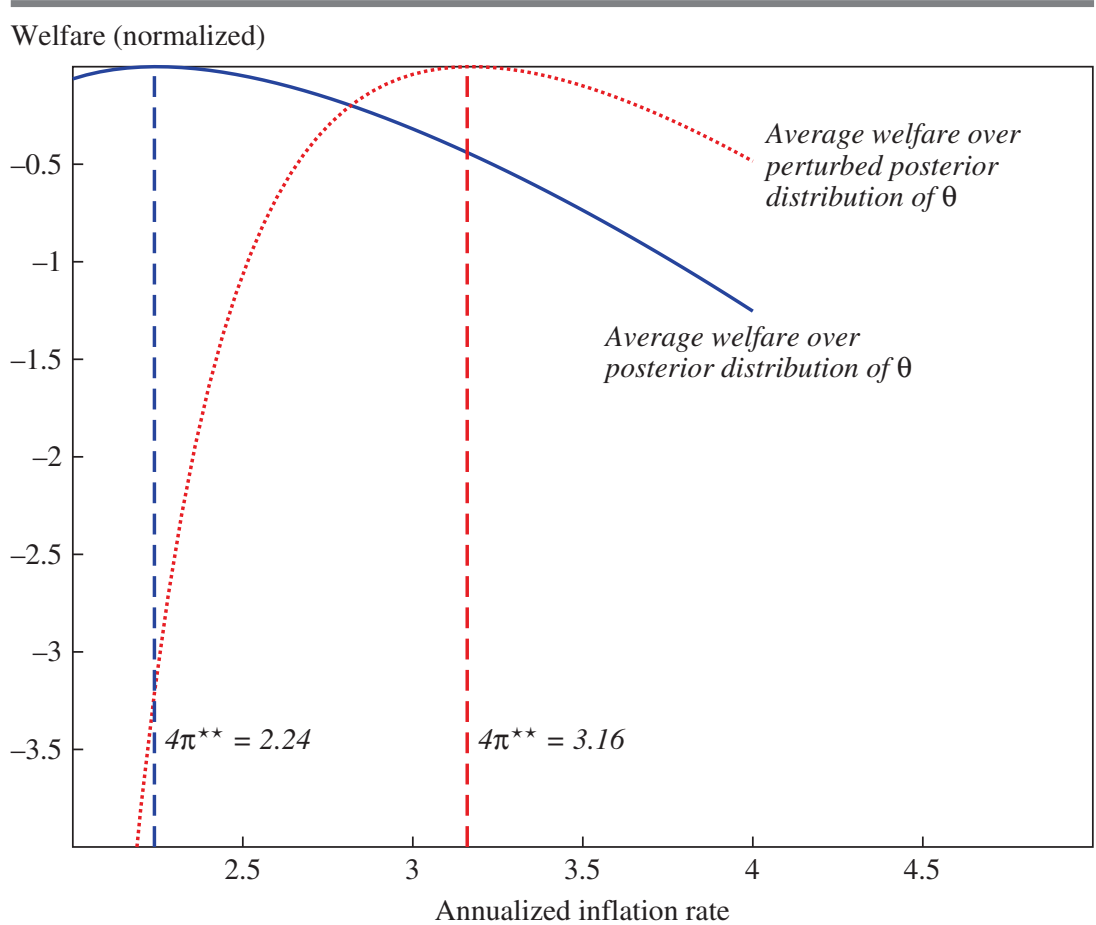

Source: Authors' calculations.

Note: The solid line indicates curve $\mathbb{E}_{\theta}(\mathcal{W}(\pi, \theta))$; the dotted line indicates curve $\mathbb{E}_{\theta}(\mathcal{W}(\pi, \theta))$ with lower $r^{\star}$. In each case, $\rho_{i}, a_{\pi}$, and $a_{y}$ are frozen at their posterior mean values.

Figure 12 presents the Bayesian-theoretic optimal inflation targets obtained when simulating the model at the initial posteriors and after a -100 basis point level shift in the posterior distribution of the long-run growth rate $\mu_{z}$ and, hence, the steady-state real interest rate $r^{*}$. According to these simulations, the inflation target should initially be $\pi^{* *}=2.24$ percent. After the counterfactual change in the distribution of $r^{*}$ considered, $\pi^{* *}$ should be increased to 3.16 percent, again in the ballpark of a 90 basis point increase in $\pi^{*}$ in response to a 100 basis point downward shift in the distribution of $r^{*}$.

\section{Alternative Monetary Policy Rules and Environments}

In the present section we study the optimal adjustment of the inflation target in response to a change in the steady-state real interest rate under five alternative assumptions regarding monetary policy: setting the inflation 
target in terms of average realized inflation; an effective lower bound on the policy rate that can be below zero; alternative degrees of smoothing in the policy rule; a central bank with no lower for longer strategy; and a price level targeting rule. For simplicity, throughout this section we ignore the role of uncertainty and treat the model parameters as known.

\section{V.A. Average vs. Target Inflation}

As emphasized in recent works (Hills, Nakata, and Schmidt 2016; Kiley and Roberts 2017), when the probability of hitting the ZLB is nonnegligible, realized inflation is on average significantly lower than the inflation rate that the central bank targets in the interest rate rule (and which would correspond to steady-state inflation in the absence of shocks or in a linear model). This results from the fact that anytime the ZLB is binding (a recurrent event), the central bank effectively loses its ability to stabilize inflation around the target. Knowing this, it may be relevant to assess the central bank's outcomes and set the corresponding target in terms of the effective average realized inflation. In this section, we investigate whether measuring the inflation target in this alternative way matters.

To this end, the analysis of the $\left(r^{*}, \pi^{*}\right)$ relation in section II.B is complemented here with the analysis of the relation between $r^{*}$ and the average realized inflation rate $\mathbb{E}\left\{\pi_{t}\right\}$ obtained when simulating the model for various values of $r^{*}$ and the associated optimal inflation target $\pi *$. In the interest of brevity, the calculations are presented only in the case when the source of variation in the natural interest rate is the change in average productivity growth $\mu_{z}$.

Figure 13 illustrates the difference between the $\left(r^{*}, \pi *\right)$ curve (round dots) and the $\left(r^{*}, \mathbb{E}\left\{\pi_{t}\right\}\right)$ curve (square dots). The overall shape of the curve is unchanged. Unsurprisingly, both curves are identical when $r^{*}$ is high enough. In this case, the ZLB is (almost) not binding and average realized inflation does not differ much from $\pi^{*}$. A spread between the two emerges for very low values of $r^{*}$. There, for low values of the natural rate, the ZLB incidence is higher and, as a result, average realized inflation becomes indeed lower than the optimal inflation target. However, that spread remains limited, less than 10 basis points. The reason is that the implied optimal inflation target is sufficiently high to prevent the ZLB from binding too frequently, thus limiting the extent to which average realized inflation and $\pi^{*}$ can differ.

Unreported simulation results show that the gap between $\pi^{*}$ and average realized inflation becomes more substantial when the inflation target is below its optimal value. For instance, mean inflation is roughly zero when 
Figure 13. Average Realized Inflation and Optimal Inflation

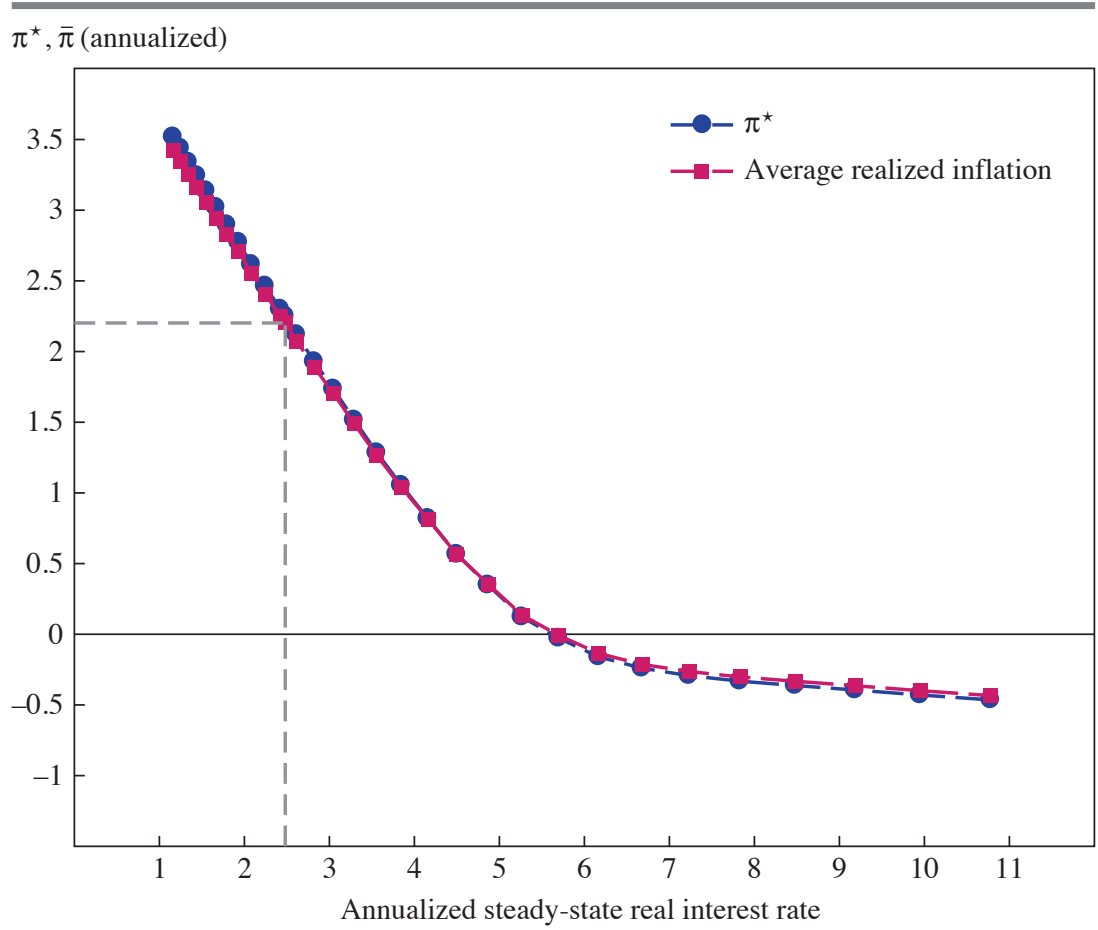

Source: Authors' calculations.

Note: The round dots correspond to the optimal inflation target $\pi^{\star}$ associated to a given value of $r^{\star}$. The square dots correspond to the average realized inflation associated to a given value of $r^{\star}$.

the central bank adopts a 1 percent inflation target in an economy where the optimal inflation target is $\pi^{*}=2$ percent.

\section{V.B. A Negative Effective Lower Bound}

The recent experience of many advanced economies (including the euro area) points to an effective lower bound (ELB) for the nominal interest rate below zero. For instance, the ECB's deposit facility rate, which gears the overnight money market rate because of excess liquidity, was set at a negative value of -10 basis points in June 2014 and has been further lowered down to -40 basis points in March $2016 .{ }^{33}$

33. In September 2019, the rate on the deposit facility was lowered to -0.5 percent. 
Figure 14. Optimal Inflation Rate as a Function of the Steady-State Real Interest Rate with a Negative ELB

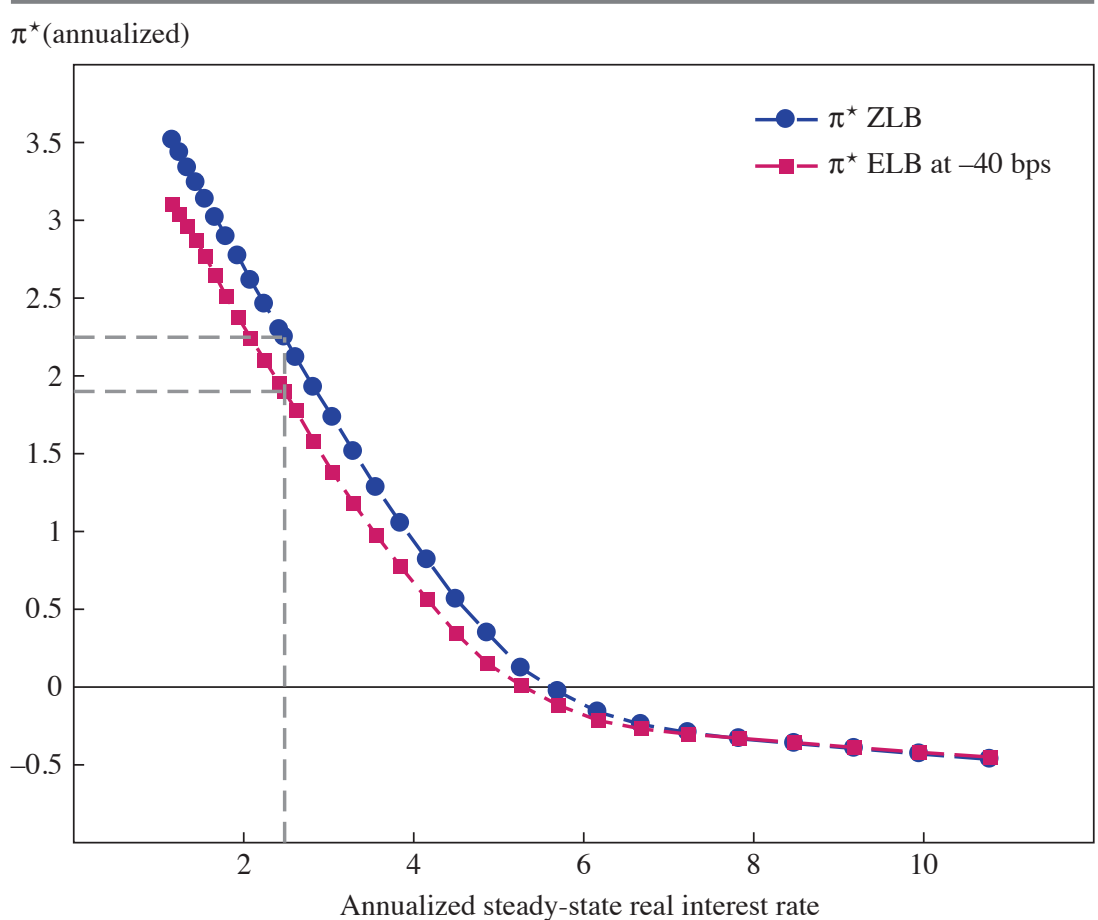

Source: Authors' calculations.

Note: The round dots correspond to the optimal inflation target $\pi^{\star}$ associated with a given value of $r^{\star}$ in the baseline scenario. The square dots correspond to the average realized inflation associated with a given value of $r^{\star}$ under an ELB set at minus 50 basis points.

We use the estimated model to evaluate the implications of a negative ELB in the United States. More precisely, we set the lower bound on the nominal rate $i_{t}$ so that

$$
i_{t} \geq e,
$$

and we set $e$ to -40 basis points (in annual terms) instead of zero. Results are presented in figure 14. As expected, the $\left(r^{*}, \pi^{*}\right)$ locus is shifted downward, though by somewhat less than 40 basis points. Importantly, its slope remains identical to the baseline case: around the baseline value 
for the real interest rate, a 100 basis point downward shift in the distribution of $r^{*}$ calls for around a 90 basis point increase in $\pi^{*}$.

\section{V.C. Alternative Degrees of Interest Rate Smoothing}

Our analysis is conditional on a specific reaction function of the central bank, described in our setup by the set of parameters $a_{\pi}, a_{y}$, and $\rho_{i}$. Among these parameters, the smoothing parameter, $\rho_{i}$, has a key influence on the probability of being in a ZLB regime. A higher smoothing has two effects in our model. The first effect-through standard monetary policy rule inertia - is to reduce the speed at which interest rates are raised when the economy exits the lower bound regime since the current rate inherits the past values of the effective nominal rate. The second effect comes from the fact that the smoothing applies to the notional rate $i_{t}^{n}$ that would prevail absent the lower bound constraint (see equation 5) while the effective nominal interest rate is the maximum of zero and the notional rate (see equation 4). Thus the interest rate inherits the past negative values of the notional nominal rate. So, a higher smoothing results in maintaining the effective interest rate at zero for an extended period of time beyond that implied by the macroeconomic shocks that initially brought the economy to the zero lower bound constraint. Such a monetary policy strategy introduces history dependence whereby, in the instance of a ZLB episode, the central bank is committed to keep rates lower for longer. As this reaction function is known to the agents in the model, this commitment to future accommodation, through generating higher expected inflation and output, helps with exiting the trap (or even avoiding entering it).

Through both effects, a higher degree of smoothing thus reinforces the history dependence of monetary policy and tends to shorten the length of ZLB episodes and the probability of hitting the ZLB constraint. Everything else equal, one should therefore expect a lower optimal inflation rate for higher values of the smoothing parameters. This property of the model is illustrated in figure 15 which depicts the $\left(r^{*}, \pi^{*}\right)$ relation under three possible values of the smoothing parameter $\rho_{i}$. The value used under our baseline scenario, that is, posterior mean estimates, is 0.85 . We also consider two alternative settings: a higher value of $\rho_{i}=0.95$, which is close to the inertia of the central bank reaction function in Coibion, Gorodnichenko, and Wieland (2012), and a lower value of $\rho_{i}=0.8$. These two values arguably encompass the existing empirical uncertainty on the degree of smoothing, as they stand outside the 90 percent probability interval of our posterior parameter estimates. 
Figure 15. Optimal Inflation Rate as a Function of the Steady-State Real Interest Rate with Alternative $\rho_{i}$

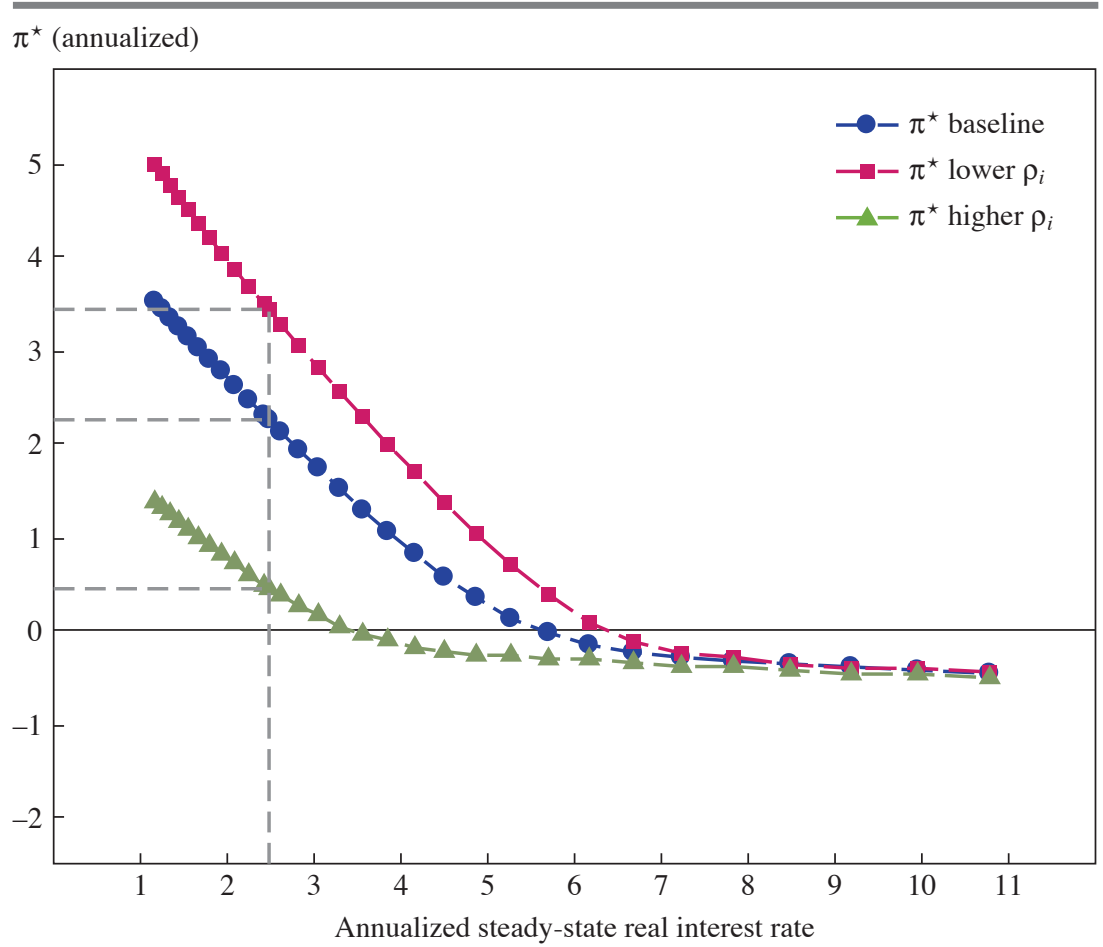

Source: Authors' calculations.

Note: The round dots correspond to the baseline scenario wherein all the structural parameters are set at their posterior mean $\bar{\theta}$. The square dots correspond to the counterfactual simulation with $\rho_{i}$ set to 0.8 . The triangle dots correspond to the counterfactual simulation with $\rho_{i}$ set to 0.95 .

The effect of a higher interest rate smoothing is to shift the $\left(r^{*}, \pi^{*}\right)$ curve downward except for high values of $r^{*}$ for which the probability of hitting the ZLB is close to zero and the optimal inflation target is slightly negative. Under this strategy, the pre-crisis optimal inflation rate would be close to 0.5 percent in the United States. ${ }^{34}$ Conversely, a lower interest rate

34. This is not inconsistent with the result in Coibion, Gorodnichenko, and Wieland (2012), who report an optimal inflation target of 1.5 percent under their baseline calibration on U.S. post-WWII data. Indeed, the variance of their underlying shocks is higher than in our baseline, which is based on Great Moderation estimates. As discussed above, a higher variance of shocks induces more frequent ZLB episodes; hence, it calls for a higher optimal inflation target. 
smoothing shifts the $\left(r^{*}, \pi^{*}\right)$ curve upward, even for relatively high values of $r^{*}$, because the probability of being in a ZLB regime increases under this strategy. With a lower $\rho_{i}$, the pre-crisis optimal inflation rate would be close to 3.5 percent.

As for the slope of the $\left(r^{*}, \pi^{*}\right)$ curve, in the empirically relevant region (that is, for values close to the baseline estimates), it is much less affected than the level of this locus. It is, however, more affected in this exercise than in other robustness experiments considered above. A very large smoothing parameter, due to its effect outlined above on the probability of ZLB, somewhat alleviates the extent to which an increase in the inflation target is needed. The slope is indeed close to -0.7 in that case. For a strategy associated with a low smoothing parameter, the slope is close to -1 , so closer to the benchmark case. For large values of $r^{*}$, the degree of smoothing is irrelevant.

\section{V.D. More Traditional Specifications of the Policy Rule}

We also considered the case of a monetary policy rule featuring no shadow rate (that is, no lower for longer feature), as well as of a simple nonintertial Taylor rule. Results are reported in figures 16 and 17. In the first case, the lagged interest rate is the lagged actual rate. As soon as the liftoff occurs after a ZLB episode, the interest rate follows a standard path, so monetary policy does not retain the memory of having been constrained for some periods by the ZLB (unlike under our baseline specification). In the second case, there is no inertia at all, but we use a four-quarter inflation rate as in the standard Taylor (1993) rule and its implementation in Kiley and Roberts (2017). In both cases, the overall degree of monetary policy inertia decreases, and so the stabilization property of the policy rule is weaker in our forward-looking model, materializing in more frequent ZLB episodes. As a result, the optimal inflation rate is in both cases larger than in the baseline for realistic values of the real interest rate. Also the optimal inflation rate is positive for a wider range of values of $r^{*}$. However, in both variants the slope of the $\left(r^{*}, \pi^{*}\right)$ is similar to that of our baseline curve around the sample value of $r^{*}$.

\section{V.E. A Price Level Targeting Rule}

We finally consider that the rule effectively implemented by the central bank reacts to deviations of the $(\log )$ price level $\hat{p}_{t}=\hat{p}_{t-1}+\hat{\pi}_{t}$ to a targeted path, instead of the gap $\hat{\pi}_{t}$ between the inflation rate and its 
Figure 16. Optimal Inflation Rate as a Function of the Steady-State Real Interest Rate with Simple Standard Taylor Rule

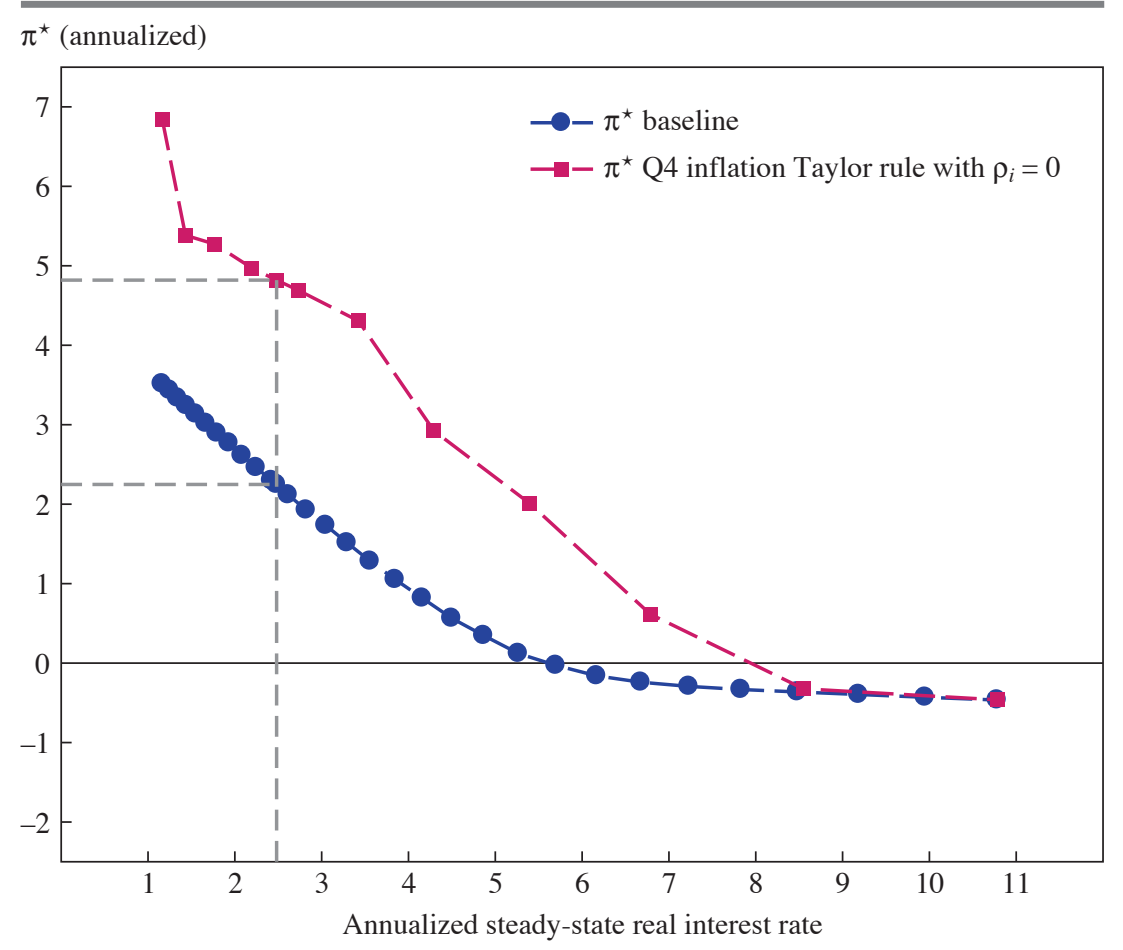

Source: Authors' calculations.

Note: The round dots correspond to the baseline scenario. The square dots correspond to the counterfactual simulation with simple standard Taylor rule used. Parameters of the rules on inflation and output gap are the same as in the baseline, but there is no inertia and year-on-year inflation is used.

target. Formally, we assume that the central bank sets the policy rate according to the following rule:

$$
\hat{\imath}_{t}^{p l t}=\rho_{i} \hat{i}_{t-1}^{p l t}+\left(1-\rho_{i}\right)\left(a_{p} \hat{p}_{t}+a_{y} \hat{x}_{t}\right)+\zeta_{R, t}
$$

with $\hat{\imath}_{t}=\max \left\{\hat{\imath}_{t}^{\text {plt }},-\left(\mu_{z}+\rho+\pi\right)\right\}$.

We perform the same exercises as before, focusing on the case in which average productivity growth $\mu_{z}$ is the driver of changes in the natural rate. We consider two values for $a_{p}: .1$ and .5. All the other parameters of the model are set to their posterior mean.

Figure 18 reports the $\left(r^{*}, \pi^{*}\right)$ relation obtained under these two alternative scenarios. A striking feature of that new curve is that the optimal 
Figure 17. Optimal Inflation Rate as a Function of the Steady-State Real Interest Rate with "No Shadow Rate" Rule

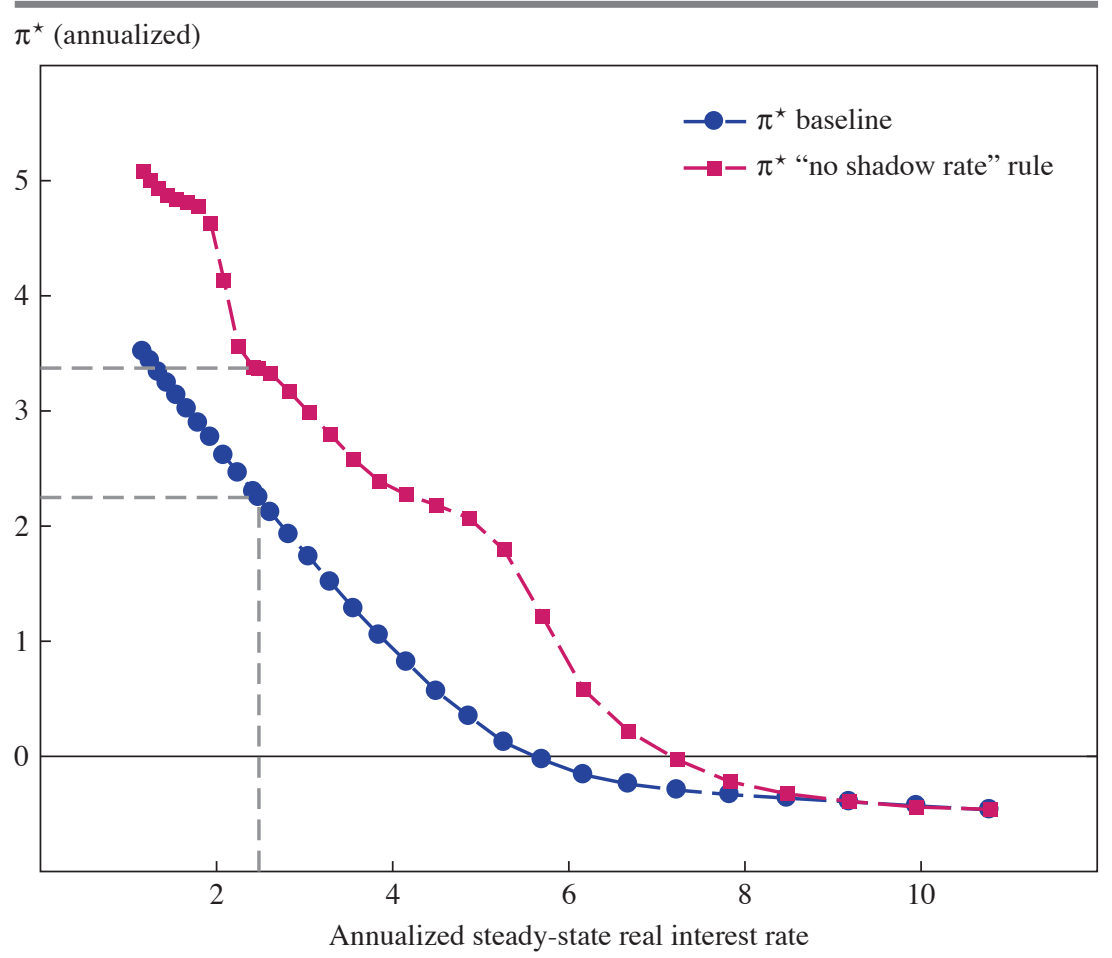

Source: Authors' calculations.

Note: The round dots correspond to the baseline scenario. The square dots correspond to the counterfactual noninertial policy rule used.

inflation target lies then between 0 percent and 1 percent as opposed to 2.21 percent in the baseline. Price level targeting makes the commitment to make up for past inflation undershooting (or overshooting) even stronger than what can be obtained when increasing the smoothing parameters in a rule which targets inflation instead. This commitment stabilizes inflation expectations so that both the probability of hitting the zero lower bound and the average length of such episodes are reduced. As a consequence, there is no incentive to bear the costs of a positive steady-state inflation and the optimal inflation target is close to zero. This holds whether the central bank reacts aggressively or not to the price level deviating from its targeted path.

Another striking result is that the $\left(r^{*}, \pi^{*}\right)$ relation is much flatter in the vicinity of the pre-crisis level for $r^{*}$ than under alternative inflation 
Figure 18. Optimal Inflation Rate as a Function of the Steady-State Real Interest Rate with Price Level Targeting Strategy

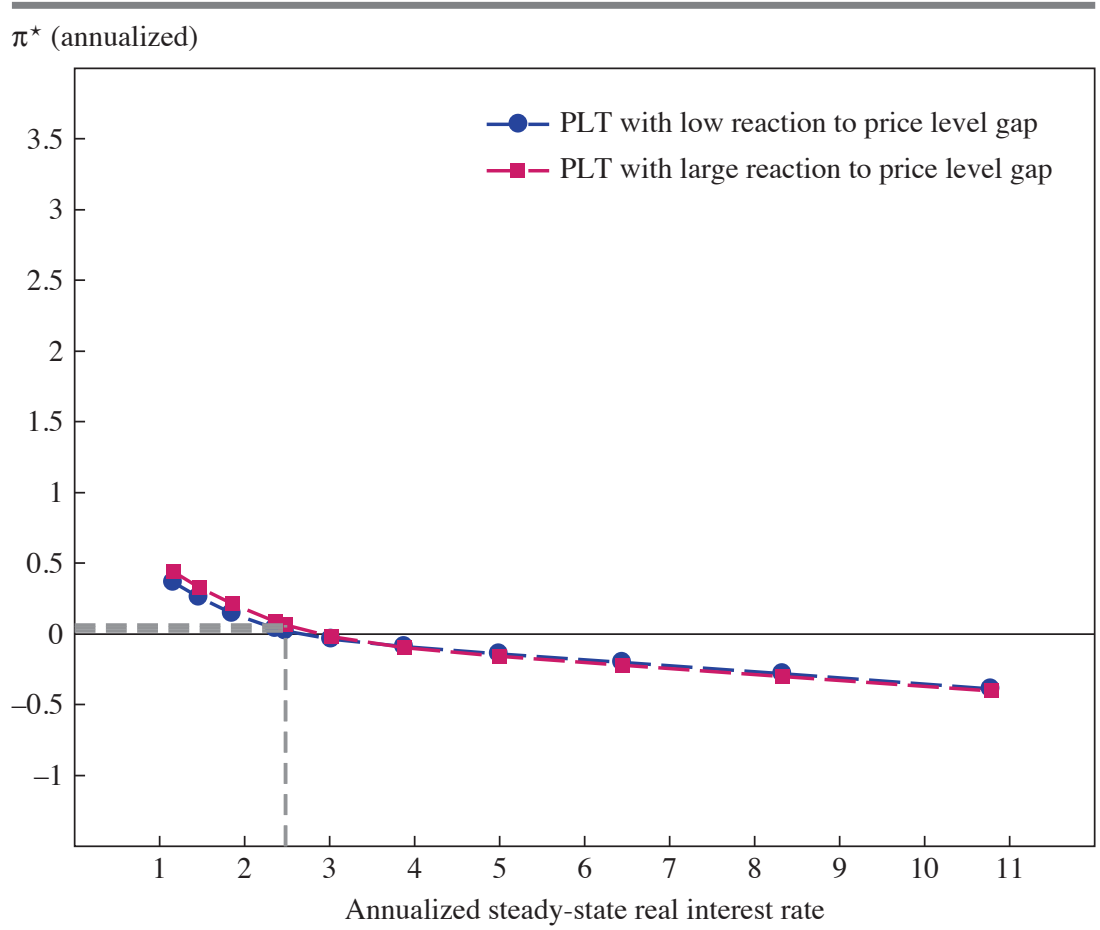

Source: Authors' calculations.

Note: Simulations obtained under the price level targeting policy rule given in equation 7 . The round (square) dots correspond to the scenario wherein $\alpha_{p}=.1$ (.5). All the other structural parameters are set at their posterior mean $\bar{\theta}$.

targeting monetary policy strategies. The slope is close to -0.3 instead of the $[-1,-0.7]$ range obtained previously. A price level targeting strategy thus allows the costs of the ZLB to be kept small even if the natural rate of interest dropped by, say, 1 percent compared to the pre-crisis regime.

\section{Summary and Conclusions}

In this paper, we have assessed how changes in the steady-state natural interest rate $\left(r^{*}\right)$ translate into changes in the optimal inflation target in a model subject to the ZLB. Our main finding is that, starting from pre-crisis values, a 1 percentage point decline in $r^{*}$ should be accommodated by an increase in the optimal inflation target between 0.9 and 1 percentage point. 
Table 2. Effect of a Decline in $r^{*}$ under Alternative Notions of Optimal Inflation

\begin{tabular}{lccr} 
& Baseline & Lower $\mathrm{r}^{*}$ & \multicolumn{1}{c}{$\Delta$} \\
\hline Mean of $\pi^{*}$ & 2.00 & 3.00 & 1.00 \\
Median of $\pi^{*}$ & 1.96 & 2.90 & .94 \\
$\pi^{*}$ at posterior mean & 2.21 & 3.20 & .99 \\
$\pi^{*}$ at posterior median & 2.12 & 3.11 & .99 \\
$\pi^{* *}$ & 2.40 & 3.30 & .90 \\
$\pi^{* *}$, frozen MP & 2.24 & 3.16 & .92 \\
Average realized inflation at posterior mean & 2.20 & 3.19 & .99 \\
$\pi^{*}$ at posterior mean, ELB 40 bp & 1.90 & 2.83 & .93 \\
Average realized inflation at posterior mean, & 1.86 & 2.77 & .91 \\
$\quad$ ELB -40 bp & & & \\
$\pi^{*}$ at posterior mean, higher $\rho_{i}$ & 0.44 & 1.13 & .69 \\
$\pi^{*}$ at posterior mean, price level targeting & 0.06 & 0.32 & .26 \\
\hline
\end{tabular}

Source: Authors' calculations.

Note: All figures are in annualized percentage rate.

For convenience, table 2 recapitulates our results. Overall, across the different concepts of optimal inflation considered in this paper, the level of optimal inflation does vary. However, it is a very robust finding that the slope of the $\left(r^{*}, \pi^{*}\right)$ relation is close to -1 in the vicinity of the pre-crisis value of steady-state real interest rates.

In our analysis, we have considered adjusting the inflation target as the only option at the policymaker's disposal, while preserving all other elements of the monetary policy strategy. In reality policymakers have a larger set of options. As a matter of fact, recent discussions revolving around monetary policy in the new normal have suggested that the various nonconventional measures - forward guidance on interest rates and largescale asset purchases - used in the aftermath of the Great Recession could feature permanently in the policy toolbox. In particular, unconventional monetary policies could represent useful second-best instruments when the ZLB is reached, as advocated by Reifschneider (2016), Swanson (2018), and Sims and Wu (2019). ${ }^{35}$ By implying a low for long interest rate at the end of a liquidity trap, the monetary policy rule that we consider in our exercise accounts, at least partially, for the effect of nonconventional policies that were implemented at the ZLB. But more aggressive nonconventional packages could be considered as alternative strategies. Beyond these monetary policy measures, fiscal policies could also play a significant

35. See also Eberly, Stock, and Wright (2019) and Chung and others (2019) for recent work documenting the effectiveness of such instruments. 
role, as emphasized by Correia and others (2013). As a result, the ZLB might be less stringent a constraint in a practical policy context than in our analysis, as argued in Debortoli, Galí, and Gambetti (forthcoming). However, the efficacy and the costs of these policies should also be part of the analysis. The complete comparison of these policy trade-offs goes beyond the scope of the present paper.

An alternative would consist of a change of the monetary policy strategy, for example, adopting variants of the price level targeting strategy, as recently advocated by Williams (2016) and Bernanke, Kiley, and Roberts (2019). Our exercise emphasizes that, when the central bank follows a strategy of making up for past inflation deviations from target, the case for increasing the inflation target is much reduced. Nevertheless, these results are obtained under the assumption that private agents believe and understand the commitment of the central bank to deviate from its inflation target in order to compensate for previous deviations. This is a debatable assumption. Andrade and others (2019) show that the lower for longer guidance on future interest rates that the Federal Open Market Committee gave during the recent ZLB episode was interpreted differently by private agents, including professional forecasters: some viewed it as good news of a commitment to future accommodation, and some viewed it as bad news that the lowflation will last longer. As they emphasize, lower for longer policies are much less effective in practice than implied by theoretical models with perfect credibility, full information, and rational expectations. They can even be detrimental if the bad signals prevail.

We have discussed the potential desirability of a higher inflation target, abstracting from the challenges of implementing an eventual transition to the new objective. In the current lowflation environment, increasing the inflation target in reaction to a drop in the steady-state value of the real interest rate might raise some credibility issues. However, a move toward makeup strategies would as well raise substantial credibility issues, as these imply an arguably time-inconsistent commitment to deviate from the inflation target once it has been reached.

Finally, our analysis has also abstracted from forces identified in the literature as warranting a small, positive inflation target, irrespective of ZLB issues, as emphasized in, for example, Bernanke and others (1999) and Kiley, Mauskopf, and Wilcox (2007). The first argument is grounded on measurement issues, following the finding from the 1996 Boskin report that the consumer price index did probably overestimate inflation in the United States by more than 1 percentage point in the early 1990s. The second argument is rooted in downward nominal rigidities. In an economy 
where there are such downward rigidities (for example, in nominal wages) a positive inflation rate can help "grease the wheel" of the labor market by facilitating relative price adjustments. Symmetrically, we also abstracted from forces calling for lower inflation targets. The most obvious is the so-called Friedman (1969) rule, according to which average inflation should be equal to minus the steady-state real interest rate, hence be negative, in order to minimize loss of resources or utility and the distortionary wedge between cash and credit goods (for example, consumption and leisure) induced by a nonzero nominal interest rate. Presumably, these and several other factors were taken into account when an inflation target of 2 percent was chosen. But an estimate of $r^{*}$ was, undoubtedly, one of the key factors in that choice. Accordingly, the current reassessment of $r^{*}$ by the Federal Reserve and other central banks would seem to call for a simultaneous reassessment of the optimal inflation target.

ACKNOWLEDGMENTS Andrade: philippe.andrade@bos.frb.org. Galí: jgali@crei.cat. Le Bihan: herve.lebihan@banque-france.fr. Matheron: julien. matheron@banque-france.fr. We thank Janice Eberly, James Stock and our discussants, Mike Kiley and Luminita Stevens, for their comments and suggestions. We also thank Olivier Blanchard, Olivier Coibion, Isabel Correia, Kevin Lansing, Kemal Ozhan, Argia Sbordone, Raf Wouters, and Johannes Wieland, as well as participants at several conferences and seminars, for comments and discussions on an earlier draft. The views expressed herein are those of the authors and do not necessarily reflect those of the Banque de France, the Eurosystem, the Federal Reserve Bank of Boston, or the Federal Reserve System. 


\section{References}

Adam, Klaus, and Henning Weber. 2019. "Optimal Trend Inflation.” American Economic Review 109, no. 2: 702-37.

Alvarez, Fernando, Hervé Le Bihan, and Francesco Lippi. 2016. "The Real Effects of Monetary Shocks in Sticky Price Models: A Sufficient Statistic Approach." American Economic Review 106, no. 10: 2817-51.

Amano, Robert, Kevin Moran, Stephen Murchison, and Andrew Rennison. 2009. "Trend Inflation, Wage and Price Rigidities, and Productivity Growth." Journal of Monetary Economics 56, no. 3: 353-64.

Andrade, Philippe, Gaetano Gaballo, Eric Mengus, and Benoît Mojon. 2019. "Forward Guidance and Heterogeneous Beliefs." American Economic Journal: Macroeconomics 11, no. 3: 1-29.

Andrade, Philippe, Hervé Le Bihan, Jordi Galí, and Julien Matheron. 2020. "Should the ECB Adjust Its Strategy in the Face of a Lower Natural Interest Rate?" Mimeo, Banque de France.

Ascari, Guido, Louis Phaneuf, and Eric R. Sims. 2018. "On the Welfare and Cyclical Implications of Moderate Trend Inflation." Journal of Monetary Economics 99:56-71.

Ascari, Guido, and Argia M. Sbordone. 2014. "The Macroeconomics of Trend Inflation." Journal of Economic Literature 52, no. 3: 679-739.

Autor, David, David Dorn, Lawrence F. Katz, Christina Patterson, and John Van Reenen. Forthcoming. "The Fall of the Labor Share and the Rise of Superstar Firms." Quarterly Journal of Economics.

Ball, Laurence M. 2014. "The Case for a Long-Run Inflation Target of Four Percent." Working Paper 14/92. Washington, D.C.: International Monetary Fund. https:// www.imf.org/en/Publications/WP/Issues/2016/12/31/The-Case-for-a-Long-RunInflation-Target-of-Four-Percent-41625.

Basu, Susanto, and John G. Fernald. 1997. "Returns to Scale in U.S. Production: Estimates and Implications." Journal of Political Economy 105, no. 2: 249-83.

Bernanke, Ben S. 2016. "Modifying the Fed's Policy Framework: Does a Higher Inflation Target Beat Negative Interest Rates?” Blog post, September 13, Brookings Institution. https://www.brookings.edu/blog/ben-bernanke/2016/ 09/13/modifying-the-feds-policy-framework-does-a-higher-inflation-target-beatnegative-interest-rates/.

Bernanke, Ben S., Michael T. Kiley, and John M. Roberts. 2019. "Monetary Policy Strategies for a Low-Rate Environment." AEA Papers and Proceedings 109:421-26.

Bernanke, Ben S., Thomas Laubach, Frederic Mishkin, and Adam S. Posen. 1999. Inflation Targeting: Lessons from the International Experience. Princeton, N.J.: Princeton University Press.

Bilbiie, Florin O., Ippei Fujiwara, and Fabio Ghironi. 2014. "Optimal Monetary Policy with Endogenous Entry and Product Variety." Journal of Monetary Economics 64:1-20. 
Blanchard, Olivier, Giovanni Dell'Ariccia, and Paolo Mauro. 2010. "Rethinking Macroeconomic Policy." Journal of Money, Credit and Banking 42, no. S1: 199-215.

Blanco, Julio A. Forthcoming. "Optimal Inflation Target in an Economy with Menu Costs and Zero Lower Bound." American Economic Journal: Macroeconomics.

Bodenstein, Martin, Christopher J. Erceg, and Luca Guerrieri. 2009. "The Effects of Foreign Shocks when Interest Rates Are at Zero." Canadian Journal of Economics 50, no. 3: 660-84.

Boskin, Michael, Ellen Dulberger, Robert J. Gordon, Zvi Griliches, and Dale Jorgenson. 1996. "Toward a More Accurate Measure of the Cost of Living." Final Report to the Senate Finance Committee.

Brand, Claus, Marcin Bielecki, and Adrian Penalver. 2019. "The Natural Rate of Interest: Estimates, Drivers, and Challenges to Monetary Policy." Occasional Paper 217. Frankfurt: European Central Bank. https://www.ecb.europa.eu/pub/ pdf/scpops/ecb.op217.en.pdf.

Burstein, Ariel, and Christian Hellwig. 2008. "Welfare Costs of Inflation in a Menu Cost Model." American Economic Review 98, no. 2: 438-43.

Caballero, Ricardo J., and Emmanuel Farhi. 2018. "The Safety Trap.” Review of Economic Studies 85, no. 1: 223-74.

Carlsson, Mikael, and Andreas Westermark. 2016. "Labor Market Frictions and Optimal Steady-State Inflation.” Journal of Monetary Economics 78:67-79.

Christiano, Lawrence J., Martin Eichenbaum, and Charles L. Evans. 2005. "Nominal Rigidities and the Dynamic Effects of a Shock to Monetary Policy." Journal of Political Economy 113, no. 1: 1-45.

Chung, Hess, Etienne Gagnon, Taisuke Nakata, Matthias Paustian, Bernd Schlusche, James Trevino, Diego Vilán, and Wei Zheng. 2019. "Monetary Policy Options at the Effective Lower Bound: Assessing the Federal Reserve's Current Policy Toolkit." Finance and Economics Discussion Series 2019-003. Washington, D.C.: Board of Governors of the Federal Reserve System. https://www.federalreserve. gov/econres/feds/files/2019003pap.pdf.

Chung, Hess, Jean-Philippe Laforte, David Reifschneider, and John C. Williams. 2012. "Have We Underestimated the Likelihood and Severity of Zero Lower Bound Events?" Journal of Money, Credit and Banking 44, no. S1: 47-82.

Clarida, Richard H. 2019. “The Federal Reserve's Review of Its Monetary Policy Strategy, Tools, and Communication Practices." Speech given at the 2019 U.S. Monetary Policy Forum, Initiative on Global Markets, University of Chicago Booth School of Business, New York, February 22.

Clarida, Richard H., Jordi Galí, and Mark Gertler. 1998. "Monetary Policy Rules in Practice: Some International Evidence." European Economic Review 42: 1033-67.

Coibion, Olivier, Yuriy Gorodnichenko, and Johannes Wieland. 2012. "The Optimal Inflation Rate in New Keynesian Models: Should Central Banks Raise Their Inflation Targets in Light of the Zero Lower Bound?" Review of Economic Studies 79, no. 4: 1371-1406. 
Correia, Isabel, Emmanuel Farhi, Juan Pablo Nicolini, and Pedro Teles. 2013. "Unconventional Fiscal Policy at the Zero Bound." American Economic Review 103, no. 4: 1172-1211.

Debortoli, Davide, Jordi Galí, and Luca Gambetti. Forthcoming. "On the Empirical (Ir)Relevance of the Zero Lower Bound Constraint." NBER Macroeconomics Annual 34.

Del Negro, Marco D., Domenico Giannone, Marc P. Giannoni, and Andrea Tambalotti. 2017. "Safety, Liquidity, and the Natural Rate of Interest." Brookings Papers on Economic Activity, Spring, 235-316.

Del Negro, Marco D., Domenico Giannone, Marc P. Giannoni, and Andrea Tambalotti. 2019. "Global Trends in Interest Rates." Journal of International Economics 118:248-62.

De Loecker, Jan, and Jan Eeckhout. 2017. "The Rise of Market Power and the Macroeconomic Implications.” Working Paper 23687. Cambridge, Mass.: National Bureau of Economic Research. https:/www.nber.org/papers/w23687.

Dordal-i-Carreras, Marc, Olivier Coibion, Yuriy Gorodnichenko, and Johannes Wieland. 2016. "Infrequent but Long-Lived Zero-Bound Episodes and the Optimal Rate of Inflation." Annual Review of Economics 8:497-520.

Eberly, Janice C., James H. Stock, and Jonathan H. Wright. 2019. "The Federal Reserve's Current Framework for Monetary Policy: A Review and Assessment." Working Paper 26002. Cambridge, Mass.: National Bureau of Economic Research. https://www.nber.org/papers/w26002.

Eggertsson, Gauti B., Neil R. Mehrotra, and Jacob A. Robbins. 2019. "A Model of Secular Stagnation: Theory and Quantitative Evaluation.” American Economic Journal: Macroeconomics 11, no. 1: 1-48.

Erceg, Christopher J., Dale W. Henderson, and Andrew T. Levin. 2000. "Optimal Monetary Policy with Staggered Wage and Price Contracts." Journal of Monetary Economics 46, no. 2: 281-313.

Farhi, Emmanuel, and François Gourio. 2018. "Accounting for Macro-Finance Trends: Market Power, Intangibles, and Risk Premia.” Brookings Papers on Economic Activity, Fall, 147-250.

Friedman, Milton. 1969. The Optimum Quantity of Money and Other Essays. Chicago: Aldine Press.

Fuhrer, Jeff, Giovanni P. Olivei, Eric S. Rosengren, and Geoffrey M. B. Tootell. 2018. "Should the Federal Reserve Regularly Evaluate Its Monetary Policy Framework?" Brookings Papers on Economic Activity, Fall, 443-517.

Galí, Jordi. 2015. Monetary Policy, Inflation, and the Business Cycle: An Introduction to the New Keynesian Framework. Princeton, N.J.: Princeton University Press.

Golosov, Mikhail, and Robert E. Lucas Jr. 2007. "Menu Costs and Phillips Curves." Journal of Political Economy 115, no. 2: 171-99.

Gordon, Robert J. 2015. "Secular Stagnation: A Supply-Side View." American Economic Review 105, no. 5: 54-59. 
Guerrieri, Luca, and Matteo Iacoviello. 2015. "OccBin: A Toolkit for Solving Dynamic Models with Occasionally Binding Constraints Easily." Journal of Monetary Economics 70:22-38.

Gust, Christopher, Edward Herbst, David López-Salido, and Matthew E. Smith. 2017. "The Empirical Implications of the Interest-Rate Lower Bound." American Economic Review 107, no. 7: 1971-2006.

Hall, Robert E. 2018. "New Evidence on the Markup of Prices over Marginal Costs and the Role of Mega-Firms in the US Economy." Working Paper 24574. Cambridge, Mass.: National Bureau of Economic Research. https://www.nber. org/papers/w24574.

Hills, Timothy S., Taisuke Nakata, and Sebastian Schmidt. 2016. "The Risky Steady State and the Interest Rate Lower Bound." Finance and Economics Discussion Series 2016-009. Washington, D.C.: Board of Governors of the Federal Reserve System. https://www.federalreserve.gov/econresdata/feds/2016/ files/2016009pap.pdf.

Holston, Kathryn, Thomas Laubach, and John C. Williams. 2017. "Measuring the Natural Rate of Interest: International Trends and Determinants." Journal of International Economics 108, no. S1: 59-75.

Khan, Aubhik, Robert G. King, and Alexander L. Wolman. 2003. "Optimal Monetary Policy." Review of Economic Studies 70, no. 4: 825-60.

Kiley, Michael. 2019. Comment on "The Optimal Inflation Target and the Natural Rate of Interest," by Philippe Andrade, Jordi Galí, Hervé Le Bihan, and Julien Matheron. In the present volume of Brookings Papers on Economic Activity.

Kiley, Michael, Eileen Mauskopf, and David Wilcox. 2007. "Issues Pertaining to the Specification of a Numerical Price-Related Objective for Monetary Policy." FOMC memo. Washington, D.C.: Board of Governors of the Federal Reserve System. https://www.federalreserve.gov/monetarypolicy/files/FOMC20070312 memo01.pdf.

Kiley, Michael T., and John M. Roberts. 2017. "Monetary Policy in a Low Interest Rate World." Brookings Papers on Economic Activity, Spring, 317-96.

Laubach, Thomas, and John C. Williams. 2016. "Measuring the Natural Rate of Interest Redux." Working Paper 2016-11. Washington, D.C.: Board of Governors of the Federal Reserve System. https://www.frbsf.org/economic-research/ files/wp2015-16.pdf.

Lepetit, Antoine. 2018. "The Optimal Inflation Rate with Discount Factor Heterogeneity." Finance and Economics Discussion Series 2018-086. Washington, D.C.: Board of Governors of the Federal Reserve System. https://www.federalreserve. gov/econres/feds/files/2018086pap.pdf.

Levin, Andrew T., Alexei Onatski, John Williams, and Noah M. Williams. 2006. "Monetary Policy under Uncertainty in Micro-Founded Macroeconometric Models." In NBER Macroeconomics Annual 20:229-312.

Lindé, Jesper, Junior Maih, and Rafael Wouters. 2017. "Estimation of Operational Macromodels at the Zero Lower Bound." Working paper. 
Nakamura, Emi, Jón Steinsson, Patrick Sun, and Daniel Villar. 2018. "The Elusive Costs of Inflation: Price Dispersion during the U.S. Great Inflation." Quarterly Journal of Economics 133, no. 4: 1933-80.

Rachel, Łukasz, and Lawrence H. Summers. 2019. "On Falling Neutral Real Rates, Fiscal Policy, and the Risk of Secular Stagnation.” Brookings Papers on Economic Activity, Spring, 1-76.

Reifschneider, David. 2016. "Gauging the Ability of the FOMC to Respond to Future Recessions." Finance and Economics Discussion Series 2016-068. Washington, D.C.: Board of Governors of the Federal Reserve System. https:// www.federalreserve.gov/econresdata/feds/2016/files/2016068pap.pdf.

Schmitt-Grohé, Stephanie, and Martín Uribe. 2010. "The Optimal Rate of Inflation.” In Handbook of Monetary Economics, vol. 3, edited by Benjamin M. Friedman and Michael Woodford. Amsterdam: North Holland.

Sims, Eric R., and Jing Cynthia Wu. 2019. 'Evaluating Central Banks' Tool Kit: Past, Present, and Future." Working Paper 26040. Cambridge, Mass.: National Bureau of Economic Research. https://www.nber.org/papers/w26040.

Summers, Lawrence H. 2014. "U.S. Economic Prospects: Secular Stagnation, Hysteresis, and the Zero Lower Bound." Business Economics 49, no. 2: 65-73.

Swanson, Eric T. 2018. "The Federal Reserve Is Not Very Constrained by the Lower Bound on Nominal Interest Rates." Brookings Papers on Economic Activity, Fall, 555-72.

Taylor, John B. 1993. "Discretion versus Policy Rules in Practice." CarnegieRochester Conference Series on Public Policy 39: 195-214.

Traina, James. 2015. "Is Aggregate Market Power Increasing? Production Trends Using Financial Statements." Working Paper 17. Chicago: Chicago Booth, Stigler Center for the Study of the Economy and the State. https://research. chicagobooth.edu/-/media/research/stigler/pdfs/workingpapers/17isaggregate marketpowerincreasing.pdf.

Williams, John C. 2009. "Heeding Daedalus: Optimal Inflation and the Zero Lower Bound." Brookings Papers on Economic Activity, Fall, 1-49.

Williams, John C. 2013. "A Defense of Moderation in Monetary Policy.” Journal of Macroeconomics 38, no. B: 137-50.

Williams, John C. 2016. "Monetary Policy in a Low R-Star World." Economic Letter 2016-23. Federal Reserve Bank of San Francisco. https://www.frbsf.org/ economic-research/publications/economic-letter/2016/august/monetary-policyand-low-r-star-natural-rate-of-interest/.

Woodford, Michael. 2003. Interest and Prices. Princeton, N.J.: Princeton University Press. 


\section{Comments and Discussion}

\section{COMMENT BY}

MICHAEL T. KILEY ${ }^{1}$ How should central banks adjust their approach to economic stabilization in light of the low level of nominal interest rates among advanced economies? This question is one of the most central facing monetary policymakers, as short-term policy interest rates have been at or below zero for most of the period since 2008 in the United States, the Euro area, and Japan. The challenges associated with the low interest rate environment are one of the considerations motivating the review by the Federal Reserve of its monetary policy framework in $2019 .{ }^{2}$

The paper by Philippe Andrade, Jordi Galí, Hervé Le Bihan, and Julien Matheron confronts this issue head-on through an assessment of the degree to which a decline in the equilibrium real interest rate $\left(r^{*}\right)$ calls for an increase in the inflation target in a New Keynesian dynamic stochastic general equilibrium (DSGE) model. In their analysis, the inflation target affects economic efficiency and activity through two primary channels: the dispersion inflation induces in the distribution of nominal prices and wages and the effect of the level of the inflation target on the likelihood that monetary policy is constrained by its effective lower bound (ELB) and the consequent deterioration in economic stability. Using the welfare function of the representative household as the policymaker's objective function, the model implies that declines in the equilibrium real interest rate, within the 1-3 percent range the authors emphasize, should be accompanied by a nearly equal increase in the inflation target. As a result, they find that a shift in $r^{*}$ from around 2 percent to 1 percent would increase the optimal

1. The analysis and conclusions set forth are those of the presenter and do not indicate concurrence by the Federal Reserve Board or other members of its staff.

2. For a discussion of the Federal Reserve's review, see Clarida (2019). 
Figure 1. Outcomes under a Fixed 2 Percent Inflation Target

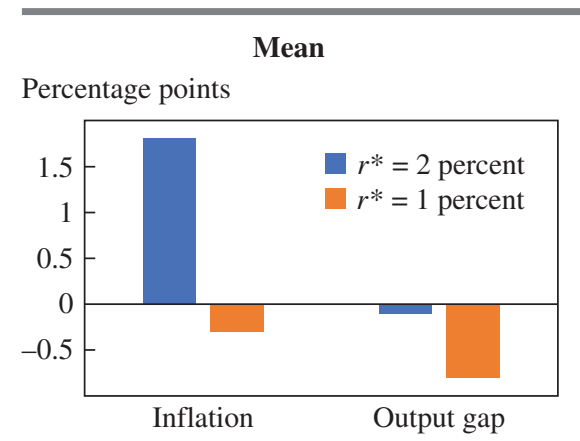

Root-mean squared deviation

Percentage points

Source: Author's calculations.

inflation target from $2+$ percent to $3+$ percent. Although the authors do not emphasize the implications for their model of a failure to raise the inflation target when $r^{*}$ declines, their framework adds to the findings in Kiley and Roberts (2017) that suggest that the effects of the ELB on economic performance absent adjustments in policy strategy are large. To see this, figure 1 presents the mean and root-mean-squared deviation of inflation and the output gap implied by their model assuming an inflation target of 2 percent and $r^{*}$ equal to either 1 or 2 percent. When $r^{*}$ is 2 percent, inflation is near the 2 percent target and output is near potential, on average, while economic volatility is low (with root-mean squared deviations from target of about 1 percentage point). If $r^{*}$ is 1 percent, inflation averages below 0 percent, the output gap averages about -.75 percent, and economic volatility is very high. Indeed, these effects are larger than in Kiley and Roberts (2017), and my remarks will return to the quantitative properties of their model below.

Overall, the analysis is an important extension of earlier work on the optimal inflation target within the New Keynesian framework, including joint consideration of stickiness in nominal prices and wages, estimation of the model to match U.S. macroeconomic dynamics over the period from 1985 to 2008, and consideration of the effects of a low level of $r *{ }^{*}$ However, a number of important considerations affect interpretation of their results. First, the analysis ignores a range of costs and benefits of inflation

3. Earlier similar analyses include Schmitt-Grohé and Uribe (2010) and, most directly, Coibion, Gorodnichenko, and Wieland (2012). 
that may be important determinants of the optimal inflation rate. Second, the close link between the New Keynesian microeconomic foundations of the model and the notions of economic welfare underlying the analysis, combined with the assumption that the steady state is efficient, may understate the welfare costs of economic fluctuations. Third, some empirical properties of the model are questionable, including a large role for efficient fluctuations in output and labor input over the business cycle, a steep Phillips curve, and powerful effects of monetary policy forward guidance under their baseline monetary policy rule. Fourth, the analysis appears implicitly optimistic about the level of $r^{*}$ over the medium term. And fifth, the analysis briefly mentions, but does not emphasize, changes in policy strategy to address ELB risks, such as temporary price level targets or quantitative easing as part of policymakers' systematic reaction function.

THE COSTS AND BENEFITS OF INFLATION In the authors' analysis, the cost/ benefit trade-off associated with the choice of inflation target is relatively simple. A higher inflation target lowers costs to economic stability associated with the ELB, as higher nominal interest rates (in the steady state) imply more scope to reduce interest rates during periods of weak economic activity or low inflation. At the same time, a higher inflation target raises costs associated with the inefficient distribution of prices and wages arising from nominal rigidities, which lead to an inefficient distribution of output and labor input and hence lower economic activity and welfare. These mechanisms are quite standard but represent a narrow set of the costs and benefits of inflation that have been discussed in economic research. For example, Kiley, Mauskopf, and Wilcox (2007) review the literature on the costs and benefits of inflation. The costs of positive inflation, beyond those associated with price dispersion, include nominal illusion (the failure of households and firms to understand inflation and make appropriate economic decisions), non-indexation of the tax code and the resulting distortions to investment, redistribution of wealth between borrowers and lenders, and the inflation tax on money balances. The costs of too-low inflation, beyond those associated with ELB risk, include the costs of downward nominal wage rigidity, debt deflation costs, and the loss in government revenue associated with the inflation tax.

In light of these additional costs and benefits of inflation, the New Keynesian tradition's emphasis on costs associated with wage and price dispersion may be overly narrow, and consideration of a broader set of costs and benefits may be desirable. Moreover, Nakamura and others (2018) find limited support for the link between the level of inflation and price dispersion emphasized in the authors' DSGE model. 
THE ROLE OF NOMINAL RIGIDITIES IN NOTIONS OF WELFARE The centrality of nominal rigidities in the model's characterization of welfare and economic fluctuations may affect the results, and almost certainly their translation to policy discussions, in other significant ways. It is well known that the New Keynesian welfare function places a large weight on inflation stability relative to stability in economic activity (Coibion, Gorodnichenko, and Wieland 2012). In contrast, policymakers appear to place a large weight on stability of economic activity - as highlighted, for example, by the discussion of optimal policy using a welfare function with equal weights on inflation and unemployment gaps in Yellen (2012). This disconnect may suggest that important considerations are missing from the model.

In addition, the model's steady state is assumed to involve an efficient level of resource utilization through a set of subsidies that undo the inefficiencies associated with monopolistic competition. But the level of resource utilization in the economy is likely not efficient: the effects of monopoly power in product and labor markets are not unwound through subsidies, and distortionary taxation to finance government activities implies that resource utilization falls short of "first-best" levels, to name just two distortions. These real-world complications have important implications. The fact that the typical level of resource utilization is likely lower than the efficient level implies that there are first-order welfare losses associated with the level of economic activity (Benigno and Woodford 2005; Galí, Gertler, and López-Salido 2007). As a result, the asymmetric effects of the ELB, in which severe recessions are deeper than economic expansions and hence the average level of resource utilization is depressed by ELB risk, lead to first-order welfare losses. These effects are ignored by the authors but may well be sizable and thereby have important effects on the optimal level of inflation. For example, figure 1 and Kiley and Roberts (2017) estimate sizable downside skewness in the distribution of economic activity associated with the ELB.

QUANTITATIVE PROPERTIES OF THE MODEL AND THE POWER OF FORWARD GUIDANCE The highly restrictive microfoundations of the model may also contribute to a number of quantitative properties of the model that are questionable, especially among the central banking community. For example, a focus on welfare analysis and the monetary policy rule in the model is a measure of resource utilization based on the deviation of activity from flexible price levels. And the model includes a large role for efficient, flexible price movements in output and labor hours, reflecting the fact that the most important source of fluctuations in output and labor input is a shock to household preferences (which implies that flexible price output and labor 
input are quite volatile). In contrast, there is a limited role for inefficient sources of fluctuations under flexible prices; for example, the model does not include shocks to financial frictions as a source of economic volatility. These properties may differ from those underlying (some) policy analysis, as policymaker actions appear to point to concern over fluctuations in labor input more generally, perhaps reflecting skepticism regarding the importance of efficient sources of fluctuations in unemployment associated with changes in household preferences. ${ }^{4}$

The large role of efficient shifts in household preferences as a source of economic fluctuations is not the only concern with the quantitative properties of the authors' model. While the authors estimate their model using data from 1985 to 2008 on output, price and wage inflation, and the nominal federal funds rate, estimation does not guarantee a good fit to a broad range of macroeconomic facts, and the model has some properties that call into question the quantitative results. Two noteworthy quantitative properties are the sensitivity of inflation to shifts in monetary policy and the effects of monetary policy forward guidance.

Monetary policy appears to have an outsized effect on inflation in the model. Figure 2 presents the impulse responses of the federal funds rate, inflation (at an annual rate), and output to a (contemporaneous) 100 basis point (annual rate) reduction in the federal funds rate in the dotted lines. Inflation and output respond quickly. More importantly, inflation responds sizably, and by more than output. This response appears inconsistent with research suggesting that the Phillips curve has become quite flat (Kiley 2015; Blanchard 2016) and that this development has important implications for monetary policy (Yellen 2017).

Forward guidance also appears to be very powerful in the authors' model. The solid lines in figure 2 present impulse responses to a 100 basis point reduction in the federal funds rate four quarters into the future, with a commitment to hold the funds rate unchanged prior to the fourth quarter. The effects of forward guidance on output and inflation are several times larger than contemporaneous monetary policy-the model has a forward guidance puzzle. ${ }^{5}$ This significantly affects the authors' findings on

4. Kiley (2013) discusses alternative notions of resource utilization within DSGE models.

5. A large body of literature discusses the forward guidance puzzle. Kiley (2016) and McKay, Nakamura, and Steinsson (2016) discuss how the Phillips curve and IS curve affect the forward guidance puzzle. Chung, Herbst, and Kiley (2015) and Bernanke, Kiley, and Roberts (2019) discuss how the power of expectations management affects the efficacy of alternative monetary policy strategies. 
Figure 2. Impulse Responses Following Monetary Policy Shocks
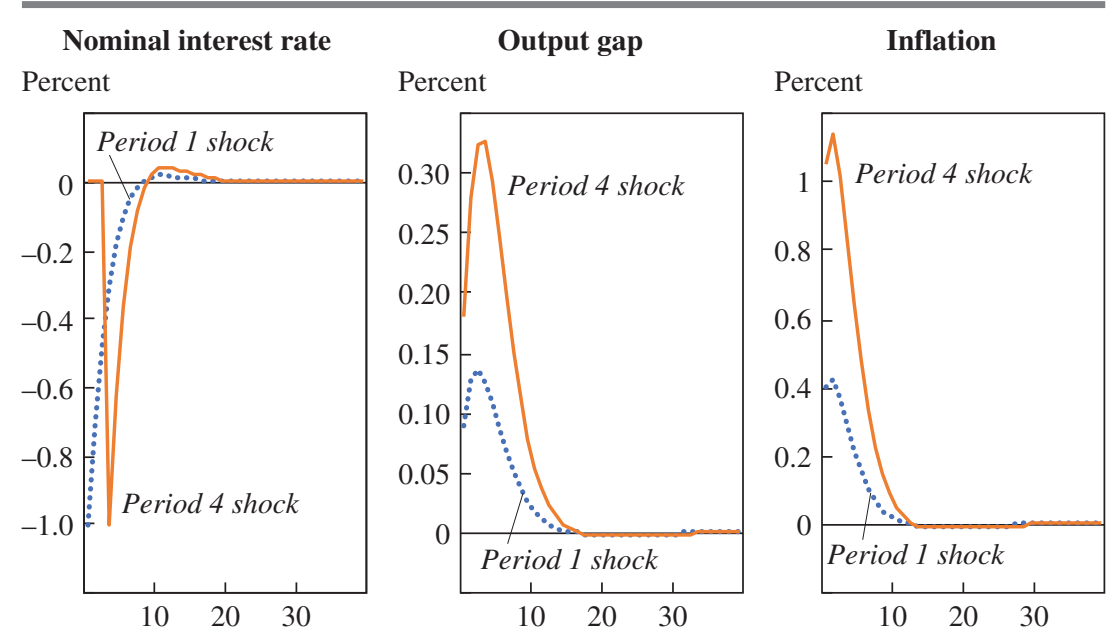

Source: Author's calculations.

the risks associated with the ELB. Specifically (and as the authors discuss clearly), their policy rule embeds a significant amount of inertia/history dependence in monetary policy. Moreover, they emphasize the case in which policymakers keep track of the value of the policy interest rate that would prevail absent the ELB and use this value as the lagged value of the policy rate in the policy rule when determining exit from the ELB. The joint effect of these assumptions is that a sizable degree of forward guidance is provided under their baseline rule, and this sizable amount of forward guidance limits the degree of ELB risk and the size of the optimal inflation rate. While the authors' econometric exercise strongly suggests that inertia is high, the types of policy rules that have been discussed in the Federal Reserve Board's Monetary Policy Report include many without such inertia, it is not clear policymakers have embraced the degree of Odyssean forward guidance associated with shadow rates (Campbell and others 2012), and some work questions the importance of inertia (Rudebusch 2002).

Quantitatively, these issues are very important. For example, if policy inertia equals 0.8 , rather than the authors' baseline 0.85 , the optimal rate of inflation when $r^{*}$ equals 1 percent is about 5 percent, far above the $3+$ percent obtained under their baseline degree of inertia (authors' figure 15); if a standard Taylor rule, without inertia, is used, the optimal inflation rate for 
$r^{*}$ equal to 1 percent is much higher (authors' figure 16). This is because ELB risk is much larger when the policy rule is not as efficient as in the authors' baseline case.

THE LEVEL OF $r^{*}$ The authors focus on values for the steady-state real interest rate ranging from 1 percent to 3 percent or higher. The lower end of this range is linked, in part, to the structural characteristics of their model, as they constrain themselves to consider values of $r *$ linked to the representative household's discount rate or to the trend growth rate of the economy and hence do not consider very low (or negative) values for $r^{*}$. However, the range considered by the authors is arguably too high. For example, the Summary of Economic Projections produced by the Federal Open Market Committee (FOMC) four times a year suggests that FOMC participants generally expect the real federal funds rate over the longer term to lie below 1 percent. This is consistent with model-based estimates of $r^{*}$ for the United States and Euro area; for example, the model by Holston, Laubach, and Williams (2017) suggests $r^{*}$ equals about .5 percent in the United States and lies below zero in the Euro area (figure 3, top panel). Finally, financial instruments suggest such views are widely shared: a simple estimate of the real five-year, five-year forward rate (that is, the real rate for years 5-10 implied by five-year and ten-year inflation-protected securities) has recently been near zero in the United States (TIPS) and has been deeply negative in Germany (iBunds) in recent years (figure 3, bottom panel). While model-based estimates of $r^{*}$ rely on assumptions and real forward rates from inflation-protected securities reflect a range of determinants, these values raise the possibility that $r^{*}$ is below 1 percent. ${ }^{6}$ Extrapolation of the relationship the authors find between $r^{*}$ and the optimal inflation rate suggests an optimal inflation target near or above 4 percent for values of $r^{*}$ in the range estimated by policymakers, statistical models, and financial market prices.

SUMMARY ASSESSMENT So what are the key points I glean from the authors' analysis? First, future work may wish to consider a richer set of possible costs and benefits of inflation, as the emphasis on price dispersion in the New Keynesian model may be overdone. At the same time, these additional considerations are likely to affect the optimal inflation target in positive and negative directions. As a result, the authors' conclusion that a decline in $r^{*}$ calls for a nearly equal-sized increase in the optimal inflation target is a reasonable rule of thumb for future work to debate.

6. For a discussion of challenges faced in model-based estimates of $r^{*}$, see Kiley (2019, forthcoming). 
Figure 3. Estimates of Interest Rates over the Intermediate Term

Estimates of equilibrium real interest rate $r^{*}$

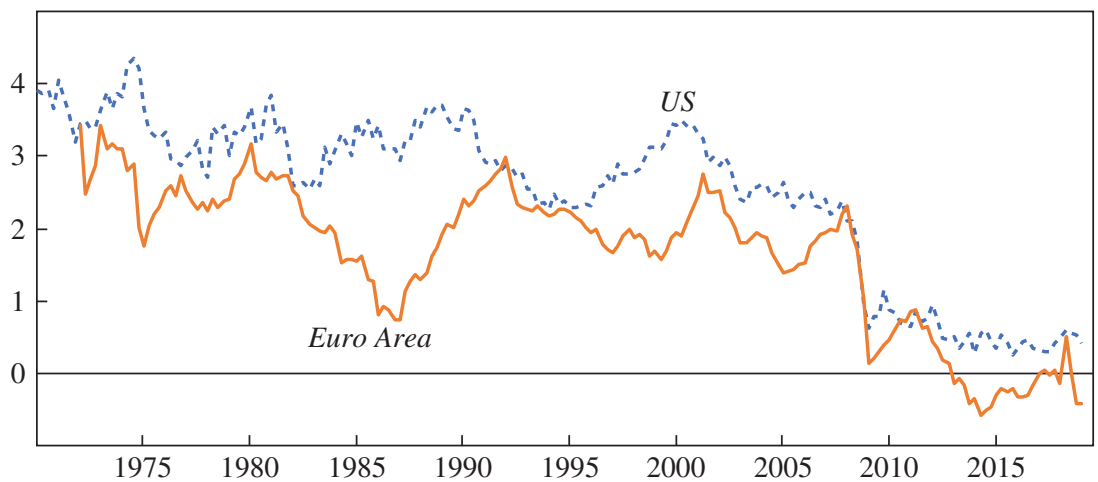

Comparison of inflation-protected securities in the United States and Germany

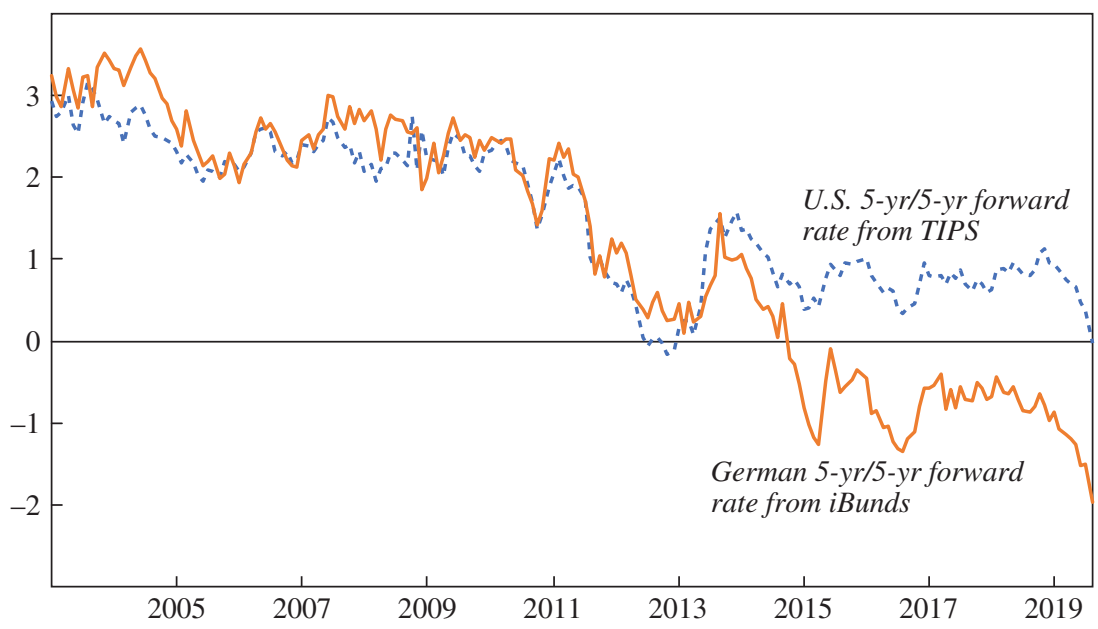

Sources: Federal Reserve Bank of New York, https://www.newyorkfed.org/research/policy/rstar/overview (top panel); author's calculations, U.S. Treasury, and Deutsche Bundesbank (bottom panel).

Moreover, I have discussed a number of quantitative properties of the model that are questionable, including the power of forward guidance. A less-powerful degree of forward guidance, as illustrated in the authors' simulations with less monetary policy inertia, is likely to raise ELB risks and the optimal inflation target. Indeed, the authors' example with less forward guidance suggests optimal inflation near 5 percent, a value that makes 
the suggestion of a 4 percent inflation target in Blanchard, Dell'ariccia, and Mauro (2010) and Ball (2014) appear timid. As a result, the authors' paper should be seen as a spur to further analysis of the optimal level of inflation.

At the same time, a crucial issue-and one largely set aside by the authors-is how changes in monetary policy strategy may lower ELB risk and allow a low optimal inflation rate. Within the DSGE model in the paper, price level targeting is preferable to a higher inflation target, and a credible price level targeting regime implies optimal inflation well below 1 percent. While the extreme power of price level targeting may be overstated owing to the concerns over the power of forward guidance raised above, Bernanke, Kiley, and Roberts (2019) suggest that more limited adjustments, such as simple threshold strategies linked to attainment of the inflation objective, may lower ELB risks even in models with a less powerful role for expectations management.

\section{REFERENCES FOR THE KILEY COMMENT}

Ball, Laurence M. 2014. "The Case for a Long-Run Inflation Target of Four Percent." Working Paper 14/92. Washington: International Monetary Fund. https://www.imf.org/en/Publications/WP/Issues/2016/12/31/The-Case-for-aLong-Run-Inflation-Target-of-Four-Percent-41625.

Benigno, Pierpaolo, and Michael Woodford. 2005. "Inflation Stabilization and Welfare: The Case of a Distorted Steady State." Journal of the European Economic Association 3, no. 6: 1185-1236.

Bernanke, Ben S., Michael T. Kiley, and John M. Roberts. 2019. "Monetary Policy Strategies for a Low-Rate Environment." AEA Papers and Proceedings 109: 421-26.

Blanchard, Olivier. 2016. "The Phillips Curve: Back to the "60s?" American Economic Review 106, no. 5: 31-34.

Blanchard, Olivier, Giovanni Dell'ariccia, and Paolo Mauro. 2010. "Rethinking Macroeconomic Policy." Journal of Money, Credit and Banking 42, no. S1: 199-215.

Campbell, Jeffrey R., Charles L. Evans, Jonas D. M. Fisher, and Alejandro Justiniano. 2012. "Macroeconomic Effects of Federal Reserve Forward Guidance." Brookings Papers on Economic Activity, Spring, 1-80.

Chung, Hess, Edward Herbst, and Michael T. Kiley. 2015. "Effective Monetary Policy Strategies in New Keynesian Models: A Reexamination." NBER Macroeconomics Annual 29: 289-344.

Clarida, Richard H. 2019. "The Federal Reserve's Review of Its Monetary Policy Strategy, Tools, and Communication Practices." Speech given at the Bank of Finland Conference on Monetary Policy and Future of EMU [Economic and Monetary Union], Helsinki, July 1. 
Coibion, Olivier, Yuriy Gorodnichenko, and Johannes Wieland. 2012. "The Optimal Inflation Rate in New Keynesian Models: Should Central Banks Raise Their Inflation Targets in Light of the Zero Lower Bound?" Review of Economic Studies 79, no. 4: 1371-1406.

Galí, Jordi, Mark Gertler, and J. David López-Salido. 2007. "Markups, Gaps, and the Welfare Costs of Business Fluctuations." Review of Economics and Statistics 89, no. 1: 44-59.

Holston, Kathryn, Thomas Laubach, and John C. Williams. 2017. "Measuring the Natural Rate of Interest: International Trends and Determinants." Journal of International Economics 108, no. S1: 59-75.

Kiley, Michael T. 2013. "Output Gaps.” Journal of Macroeconomics 37, no. C: $1-18$.

Kiley, Michael T. 2015. "Low Inflation in the United States: A Summary of Recent Research." FEDS Notes 2015-11-23. Washington: Board of Governors of the Federal Reserve System. https:/www.federalreserve.gov/econresdata/notes/ feds-notes/2015/low-inflation-in-the-united-states-a-summary-of-recent-research20151123.html.

Kiley, Michael T. 2016. "Policy Paradoxes in the New Keynesian Model." Review of Economic Dynamics 21: 1-15.

Kiley, Michael T. 2019. "The Global Equilibrium Real Interest Rate: Concepts, Estimates, and Challenges." Working Paper 2019-076. Washington: Board of Governors of the Federal Reserve System. https://www.federalreserve.gov/ econres/feds/the-global-equilibrium-real-interest-rate-concepts-estimates-andchallenges.htm.

Kiley, Michael T. Forthcoming. "What Can the Data Tell Us about the Equilibrium Real Interest Rate?" International Journal of Central Banking.

Kiley, Michael T., Eileen Mauskopf, and David Wilcox. 2007. "Issues Pertaining to the Specification of a Numerical Price-Related Objective for Monetary Policy." FOMC memo. Washington: Board of Governors of the Federal Reserve System. https://fraser.stlouisfed.org/title/677/item/23295/content/pdf/ fomc20070312memo01/toc/517269.

Kiley, Michael T. , and John M. Roberts. 2017. "Monetary Policy in a Low Interest Rate World." Brookings Papers on Economic Activity, Spring, 317-96.

McKay, Alisdair, Emi Nakamura, and Jón Steinsson. 2016. "The Power of Forward Guidance Revisited.” American Economic Review 106, no. 10: 3133-58.

Nakamura, Emi, Jón Steinsson, Patrick Sun, and Daniel Villar. 2018. "The Elusive Costs of Inflation: Price Dispersion during the U.S. Great Inflation." Quarterly Journal of Economics 133, no. 4: 1933-80.

Rudebusch, Glenn. 2002. "Term Structure Evidence on Interest Rate Smoothing and Monetary Policy Inertia." Journal of Monetary Economics 49, no. 6: 1161-87.

Schmitt-Grohé, Stephanie, and Martín Uribe. 2010. “The Optimal Rate of Inflation." In Handbook of Monetary Economics, vol. 3, edited by Benjamin M. Friedman and Michael Woodford. Amsterdam: North Holland. 
Yellen, Janet. 2012. "Perspectives on Monetary Policy." Speech given at the Boston Economic Club Dinner, Boston, June 6. https://www.federalreserve. gov/newsevents/speech/yellen20120606a.htm.

Yellen, Janet. 2017. "Inflation, Uncertainty, and Monetary Policy.” Speech given at Prospects for Growth: Reassessing the Fundamentals, 59th Annual Meeting of the National Association for Business Economics, Cleveland, September 26.

\section{COMMENT BY}

LUMINITA STEVENS In this paper, Philippe Andrade, Jordi Galí, Hervé Le Bihan, and Julien Matheron study how the inflation rate targeted by the monetary authority should vary with changes in the natural rate of interest. The authors characterize the $\left(r^{*}, \pi^{*}\right)$ relationship in the textbook mediumscale New Keynesian model, augmented with a zero (or effective) lower bound on nominal interest rates. They quantify the following trade-off: a higher inflation target reduces the costs associated with the zero lower bound (ZLB) constraint, but it also entails larger welfare losses from allowing higher permanent inflation. When disciplined by the properties of the modern U.S. economy, the model generates a "hockey stick" relationship between the inflation target and the natural rate, with the slope near -1 for $r^{*}$ less than 5 percent, when ZLB concerns dominate the welfare analysis, and near zero for $r^{*}$ larger than 6 percent (roughly), when the probability of hitting the ZLB is effectively zero. In terms of levels, when the natural rate falls below 1 percent, the optimal inflation target exceeds 3.5 percent. The authors conclude by calling for a reassessment of the Federal Reserve's inflation target in light of the recent decline of the real rate. ${ }^{1}$

There is little to quibble with inside the framework set up by the authors: the paper offers an incredibly transparent and comprehensive analysis, with extensive robustness checks. It provides a wide range of valuable results that all future work will be benchmarked against. My discussion approaches the paper's results from the practical question of what the Federal Reserve should do with respect to its inflation target in the current environment. I will push outside the authors' framework to highlight the large uncertainties regarding some key components of the net welfare gains that the model associates with a higher inflation target. In turn, these uncertainties imply a large degree of uncertainty regarding the model's policy prescription.

1. For example, in their model of the U.S. economy, Christiano, Eichenbaum, and Evans (2005) target a steady-state real rate of 3 percent, whereas in its 2017 projections, the Federal Reserve's estimate was 1 percent. See Holston, Laubach, and Williams (2017) for a detailed analysis of the recent decline in real rates. 
While future research may reduce some of these uncertainties, it may be more prudent for now to embrace strategies that are specific to ZLB episodes, such as makeup policies in the aftermath of ZLB realizations (Yellen 2016; Bernanke 2017). This is especially the case since many of the uncertainties and credibility concerns that critics raise for these alternative policies likely apply to the same extent—if not even more - to the transition to a higher inflation target.

THE SEVERITY OF ZLB EPISODES: THEORY AND PRACTICE The welfare gains of a higher inflation target depend critically on the average severity of ZLB episodes. Given the scarcity of historical ZLB episodes, estimates of the associated output loss are entirely model-based. The standard New Keynesian model generates very strong incentives to avoid the ZLB because of large output losses and the risk of deflationary spirals, as the economy's selfcorrecting mechanism breaks down: when nominal rates reach zero, if prices continue to fall, real rates rise, demand contracts, prices fall more, and so on.

Key to the severity of ZLB episodes is the formation of expectations by private agents. But what is the empirical evidence of large ZLB contractions? And what are the mechanisms that trigger or dampen any associated deflationary spirals? $?^{2}$ In practice, large ZLB contractions have not been observed since the Great Depression and did not occur even during the Great Recession. The severity of the Great Recession had more to do with the nature and size of the shocks that hit the economy than with reaching the ZLB per se. By the time the ZLB was reached in December 2008, 70 percent of the output decline and half of the unemployment increase had already occurred. ${ }^{3}$ Sustained deflation was avoided despite the large drop in output and the liquidity trap.

A number of explanations have been proposed for the relative stability of inflation during the Great Recession, bearing mixed news for inflation dynamics in future ZLB episodes. Coibion and Gorodnichenko (2015) argue that inflation was stable because the increase in oil prices between 2009 and 2011 kept consumer inflation expectations high. This does not bode well for the future: if expectations respond to oil price changes, then they are not well anchored and hence may spiral next time if an inflationary shock

2. Of note, once the ZLB has been reached, the likelihood of converging to the deflationary equilibrium is independent of the inflation target prior to the downturn (Aruoba and Schorfheide 2015).

3. These calculations are peak-to-trough numbers using data from FRED for the monthly seasonally adjusted unemployment rate and quarterly seasonally adjusted real GDP per capita. 
does not happen to coincide with the ZLB entry. Countering this concern at least somewhat, Baqaee (forthcoming) documents that household inflation expectations are in fact rigid downward, and he rationalizes this asymmetry with a model of household ambiguity aversion. Wiederholt (2015) points to survey evidence of dispersed and sluggish household inflation expectations and shows that deflationary spirals become less severe in a New Keynesian model with imperfect, dispersed information among consumers. Moreover, the high uncertainty that characterized the Great Recession gave information-constrained firms the incentive to keep prices relatively high, to protect themselves against losses in a volatile environment (Stevens 2019). These mechanisms all work to limit deflationary spirals when decisionmakers are very uncertain about the future. Lastly, controlled laboratory experiments also provide some potentially relevant news: asset market experiments reliably produce overvaluation relative to the rational expectations response in markets with decreasing fundamental values (Smith, Suchanek, and Williams 1988; Stöckl, Huber, and Kirchler 2015).

These theoretical, survey-based, and experimental findings suggest that deviations from the benchmark model-particularly in terms of how expectations are formed and updated-need to be studied much more closely in the context of liquidity traps. For now, it is not clear that we can draw strong conclusions about the costs we are willing to bear to avoid such episodes, if we are not sure how and under what conditions they give rise to large deflation-fueled contractions.

THE PROBABILITY OF ZLB EPISODES VERSUS THAT OF INFLATIONARY PRESSURES The model estimates a probability of at least 10 percent of reaching the ZLB going forward, if the inflation target is kept around 2 percent. One distinguishing feature of the results is that they are based on a model that is estimated on pre-Great Recession data. ${ }^{4}$ Such an approach is useful yet subject to the same challenges faced by any attempt to estimate rare events using limited time series, and it comes with large error bands. Another key feature of the model is that it does not incorporate capital, inventories, or housing, all of which significantly affect the likelihood of reaching the lower bound, thus adding to the uncertainty surrounding these estimates.

Whatever its value, the probability of reaching the ZLB should be weighed against the probability of inflationary shocks we face today. The paper presents the trade-offs of higher inflation given historical shocks. However, not just the size of shocks (which the authors experiment with) but also the nature of the shocks may change in the future. First, relative to

4. In contrast, Coibion, Gorodnichenko, and Wieland (2012) calibrate their ZLB model. 
the Great Moderation period, increased policy uncertainty regarding fiscal, trade, and monetary policies may be inflationary. There is precedent for such policy uncertainty to raise long-run inflation expectations. Second, more risk taking in a low interest rate environment may increase the likelihood and magnitude of financial shocks in the future. In a controlled lab experiment, Lian, Ma, and Wang $(2018,2108)$ find that "individuals demonstrate a stronger preference for risky assets when the risk-free rate is low." In turn, more risk taking may fuel more financial cycles and inflation variability. Depending on the mechanism that is active, financial shocks may either raise or lower inflation. But on net, Abbate, Eickmeier, and Prieto (2016) find that in the modern U.S. economy, financial shocks have moved output and inflation in opposite directions.

Inflationary shocks may make it more challenging for the Federal Reserve to control inflation, especially since these challenges rise convexly as inflation rises above 5 percent or so. At the same time, they may limit deflationary spirals that make ZLB episodes so costly, tipping the scales toward a lower inflation target. Overall, an analysis of the desirability of changing the monetary policy regime and increasing inflation expectations should take into account the possibility of such risks going forward.

THE NATURE AND SEVERITY OF PRICING FRICTIONS The cost of having a higher inflation target depends on the severity of inefficient nominal price dispersion and its sensitivity to inflation. The model considered by Andrade and his colleagues generates price dispersion by incorporating nominal price and wage rigidities a la Calvo (1983), augmented with exogenous indexation. The authors estimate the parameters of price and wage rigidities to match time series data on inflation, GDP, wages, and real rates. The estimated values imply low price rigidity. This makes having higher inflation not so costly in normal times, and it also makes deflation more severe in ZLB times. Both of these effects favor higher inflation targets for a given real rate. An alternative would be to estimate the severity of pricing frictions so as to match the degree of monetary nonneutrality implied by the U.S. economy in normal times (Christiano, Eichenbaum, and Evans 2005).

Moreover, the results may be sensitive to the nature of pricing frictions. Calvo frictions do not generate a good approximation of the welfare costs of nominal price rigidities (Sheremirov forthcoming). They underestimate the level of inefficient price dispersion versus the data, and they also generate a sensitivity of inefficient price dispersion to inflation that is at odds with the data. Conversely, a model of information-constrained pricing yields higher price rigidity for a given degree of price dispersion and larger inefficient price dispersion for a given level of inflation (Morales-Jimenez 
and Stevens 2019). Both of these forces would push toward a lower inflation target.

A VOLATILE AND UNCERTAIN POLICY? The results imply considerable variation in the optimal inflation target. Optimality would require increasingly frequent increases in the inflation target in the United States: 1.2 percent circa 1990, 2.2 percent circa 2005, 3.5 percent circa 2015, and 4.2 percent circa $2020 .{ }^{5}$ Another challenge, as illustrated by much of the literature trying to estimate $r^{*}$, is that these estimates are very imprecise, dependent on the estimation method, and subject to considerable revisions as we accumulate more data (Del Negro and others 2019). This means that not only is there a risk that what is perceived as a permanent decline in $r^{*}$ turns out to be transitory, but there is also the practical difficulty of knowing what the rate currently is so as to know what the current inflation target should be. Since the model predicts that the inflation target is very sensitive to changes in the real rate for rates below 5 percent, it seems it would be a unstable inflation target. We may prefer instead to solve for a robust policy in the face of natural rate uncertainty (Orphanides and Williams 2002).

INTERPRETATION, CREDIBILITY, AND EXPECTATIONS How should we expect private agents to interpret and respond to such a path of the inflation target? First, private agents could differ in how they update their beliefsfor example, immediately or in a gradual, adaptive way, resulting in very different welfare implications. Experiments on the formation of expectations find significant support for gradual adjustment rather than sharp updating in response to regime changes (Khaw, Stevens, and Woodford 2019). Second, private agents could have one or more interpretations of a given policy action: they may correctly understand and respond to the change (either on impact or gradually), they may think that the inflation target has been abandoned, or, conversely, they may not believe the commitment to a higher target long term at all. In any case, it is quite likely that any announcement of a potential change in policy regime would result in increased dispersion in expectations and would increase the probability of unanchoring long-term expectations. Falck, Hoffmann, and Hürtgen (forthcoming) show that disagreement about inflation expectations can result in contractionary monetary policy being inflationary, as agents update beliefs about the state of the economy. In a similar vein, Andrade and others (2019) show a decrease in the effectiveness of forward guidance when private agents have heterogeneous beliefs. More pointedly, Branch

5. I use the figures for the real rate implied by the Laubach and Williams (2003) model for historical estimates and simple extrapolations for 2020 . 
and Evans (2017) show how increasing the inflation target can lead to overshooting and instability in the inflation rate when agents have adaptive expectations. In light of this work, the present analysis of the net benefits of a higher inflation target should be extended in the future to include deviations from fully informed rational private agents, allowing for dispersed and sluggish updating of beliefs regarding the state of the economy and the policy regime expected to prevail.

CONCLUSION This paper by Andrade and his colleagues presents a strong conclusion. It pushes us further from Friedman's (1969) optimal disinflation rule, from the complete price stability prescribed by the textbook New Keynesian model (Woodford 2003), and from the 2 percent level that is the current inflation target of the Federal Reserve and the standard among inflation targeting economies. It does so in the context of a well understood and widely used model of the aggregate economy, and hence it serves as both benchmark and launching pad for future work.

More generally, the analysis also makes the point that the target of an inflation-targeting monetary authority is not an invariant constant; rather, it can vary with the economic environment and perhaps other policies. This raises the question of how other structural changes in the economy may affect the optimality of different monetary policy regimes.

In practice, there remain big uncertainties surrounding how deflationary spirals arise, persist, and end. We furthermore face great uncertainties regarding inflationary pressures going forward, the prevailing rate of natural interest and its stability, and the costs in such an environment of targeting higher average inflation. Last but not least, the literature offers virtually no encouraging guidance in terms of how agents' expectations would respond to such a policy change. Along all of these dimensions, departures from the benchmark of fully informed, rational agents consistently push against the results based on full information. To what degree remains an open question, but it seems urgent to incorporate such departures more consistently in basic analyses of monetary policy.

In the meantime, for the purposes of practical policy recommendations, it may be more prudent to focus on ZLB-specific policies such as pursuing a lower for longer policy for the nominal rate upon exiting the ZLB, rather than attempting to implement a higher inflation target uniformly, thus increasing distortions all the time to help deal with infrequent episodes of unknown frequency and severity. ${ }^{6}$ While such ZLB-specific policies 
may have credibility issues of their own, they at least do not come with the added cost of additional distortions outside the ZLB. The paper is encouraging on this front. One meaningful deviation to the baseline results is that smaller changes in the inflation target are optimal when the monetary authority implements policies that have this flavor, since these alternatives substantially reduce the costs of the ZLB constraint. I found this deviation encouraging and worthy of future exploration.

\section{REFERENCES FOR THE STEVENS COMMENT}

Abbate, Angela, Sandra Eickmeier, and Esteban Prieto. 2016. "Financial Shocks and Inflation Dynamics." Discussion Paper 41/2016. Frankfurt: Deutsche Bundesbank. https://papers.ssrn.com/sol3/papers.cfm?abstract_id=2857845.

Andrade, Philippe, Gaetano Gaballo, Eric Mengus, and Benoît Mojon. 2019. "Forward Guidance and Heterogeneous Beliefs." American Economic Journal: Macroeconomics 11, no. 3: 1-29.

Aruoba, S. Borağan, and Frank Schorfheide. 2015. "Inflation during and after the Effective Lower Bound." In Economic Policy Symposium Proceedings: Inflation Dynamics and Monetary Policy. Jackson Hole, Wyo.: Federal Reserve Bank of Kansas City.

Baqaee, David Rezza. Forthcoming. "Asymmetric Inflation Expectations, Downward Rigidity of Wages, and Asymmetric Business Cycles." Journal of Monetary Economics.

Bernanke, Ben S. 2017. "Monetary Policy in a New Era." In Proceedings of Rethinking Macroeconomic Policy. Washington: Petersen Institute for International Economics. https://www.brookings.edu/research/monetary-policy-ina-new-era/.

Branch, William A., and George W. Evans. 2017. "Unstable Inflation Targets." Journal of Money, Credit and Banking 49, no. 4: 767-806.

Calvo, Guillermo. 1983. "Staggered Prices in a Utility-Maximizing Framework." Journal of Monetary Economics 12, no. 3: 383-98.

Christiano, Lawrence J., Martin Eichenbaum, and Charles L. Evans. 2005. "Nominal Rigidities and the Dynamic Effects of a Shock to Monetary Policy." Journal of Political Economy 113, no. 1: 1-45.

Coibion, Olivier, and Yuriy Gorodnichenko. 2015. "Is the Phillips Curve Alive and Well after All? Inflation Expectations and the Missing Disinflation." American Economic Journal: Macroeconomics 7, no. 1: 197-232.

Coibion, Olivier, Yuriy Gorodnichenko, and Johannes Wieland. 2012. "The Optimal Inflation Rate in New Keynesian Models: Should Central Banks Raise Their Inflation Targets in Light of the Zero Lower Bound?" Review of Economic Studies 79, no. 4: 1371-1406.

Del Negro, Marco, Domenico Giannone, Marc P. Giannoni, and Andrea Tambalotti. 2019. "Global Trends in Interest Rates." Journal of International Economics 118:248-62. 
Falck, E., M. Hoffmann, and P. Hürtgen. Forthcoming. "Disagreement about Inflation Expectations and Monetary Policy Transmission." Journal of Monetary Economics.

Friedman, Milton. 1969. The Optimum Quantity of Money and Other Essays. Chicago: Aldine.

Holston, Kathryn, Thomas Laubach, and John C. Williams. 2017. "Measuring the Natural Rate of Interest: International Trends and Determinants." Journal of International Economics 108, no. S1: 59-75.

Khaw, Mel Win, Luminita Stevens, and Michael Woodford. 2019. “Adjustment Dynamics during a Strategic Estimation Task.” Working Paper. https://ideas. repec.org/p/red/sed018/1315.html.

Laubach, Thomas, and John C. Williams. 2003. "Measuring the Natural Rate of Interest," Review of Economics and Statistics 85, no. 4: 1063-70.

Lian, Chen, Yueran Ma, and Carmen Wang. 2018. "Low Interest Rates and RiskTaking: Evidence from Individual Investment Decisions." Review of Financial Studies 32, no. 6: 2107-48.

Morales-Jimenez, Camilo, and Luminita Stevens. 2019. "Price Rigidity during the Great Recession." Working Paper. http://econweb.umd.edu/ stevens/MJS_ Rigidity.

Orphanides, Athanasios, and John C. Williams. 2002. "Robust Monetary Policy Rules with Unknown Natural Rates." Brookings Papers on Economic Activity, no. 2: 63-145.

Reifschneider, David, and John C. Williams. 2000. "Three Lessons for Monetary Policy in a Low-Inflation Era.” Journal of Money, Credit and Banking 32, no. 4: 936-66.

Sheremirov, Viacheslav. Forthcoming. "Price Dispersion and Inflation: New Facts and Theoretical Implications." Journal of Monetary Economics.

Smith, Vernon L., Gerry L. Suchanek, and Arlington W. Williams. 1988. "Bubbles, Crashes, and Endogenous Expectations in Experimental Spot Asset Markets." Econometrica 56, no. 5: 1119-51.

Stevens, Luminita. 2019. "Coarse Pricing Policies." Review of Economic Studies 87, no. 1: 420-53.

Stöckl, Thomas, Jürgen Huber, and Michael Kirchler. 2015. "Multi-Period Experimental Asset Markets with Distinct Fundamental Value Regimes." Experimental Economics 18, no. 2: 314-34.

Wiederholt, Mirko. 2015. "Empirical Properties of Inflation Expectations and the Zero Lower Bound." Working Paper. https://sites.google.com/site/ wiederholtmirko/.

Woodford, Michael. 2003. Interest and Prices: Foundations of a Theory of Monetary Policy. Princeton, N.J.: Princeton University Press.

Woodford, Michael. 2012. "Methods of Monetary Policy Accommodation at the Interest-Rate Lower Bound." In Economic Policy Symposium Proceedings: The Changing Policy Landscape. Jackson Hole, Wyo.: Federal Reserve Bank of Kansas City. 
Yellen, Janet. 2016. Opening Remarks for "The Federal Reserve Monetary Policy Toolkit: Past, Present and Future." In Economic Policy Symposium Proceedings: Designing Resilient Monetary Policy Frameworks for the Future. Jackson Hole, Wyo.: Federal Reserve Bank of Kansas City.

GENERAL DISCUSSION Narayana Kocherlakota found the paper and discussions very helpful. He said that terms like the effective lower bound and zero lower bound are technical and it is important to remember what they represent. They represent a limit on how far a central bank's policy rate can fall given that banks and households have the option of holding cash, which has a zero return. Therefore, it is important to discuss how valuable cash is to people when thinking about where the zero lower bound is and the costs that the zero lower bound imposes. Kocherlakota also wondered how general the authors' finding of a one-to-one response of the optimal inflation target to changes in $r^{*}$ is and what aspects of the model are driving this result.

Frederic Mishkin said that the slope of the Phillips curve is a very important issue, and one on which he disagrees with Michael Kiley. While there is a view, supported by regression analysis, that the Phillips curve has become very flat, Mishkin argued that the observed flatness is an artifact of good monetary policy. A central bank that is focused on controlling inflation will respond to positive inflation shocks by tightening monetary policy that would raise the unemployment rate. This endogenous monetary policy induces a positive correlation between the unemployment rate and inflation that masks the underlying negative Phillips curve relationship between the unemployment rate and inflation. Mishkin's interpretation is supported by his own research for the US Monetary Policy Forum and research by McLeay and Tenreyro, he said. ${ }^{1}$ Mishkin is therefore less concerned than Kiley that the authors' model features a steep Phillips curve.

Furthermore, Mishkin pointed out that an important implication of the paper, emphasized by Luminita Stevens, is for economists to examine policies that lessen the consequences of the zero lower bound, for instance, policies that no longer let bygones be bygones when it comes to past inflation and policies that make monetary policy more effective at the zero

1. Peter Hooper, Frederic S. Mishkin, and Amir Sufi, "Prospects for Inflation in a High Pressure Economy: Is the Phillips Curve Dead or Is It Just Hibernating?" US Monetary Policy Forum, February 2019, https://research.chicagobooth.edu/igm/usmpf/usmpf-paper (forthcoming in Research in Economics); Michael McLeay and Silvana Tenreyro,"Optimal Inflation and the Identification of the Phillips Curve," NBER Macroeconomics Annual 34. 
lower bound. Mishkin also highlighted that central banks are currently struggling to raise inflation. Economists may need to start thinking outside of the box to solve this issue and may have to think about linking monetary and fiscal policies, he concluded.

Ben Bernanke noted that a key result from the paper is that a Taylor rule performs very poorly in a world where the zero lower bound on interest rates binds frequently. Thus, he remarked, the authors' findings imply that the inflation target should be raised in order to reduce the likelihood of hitting the zero lower bound. Bernanke expressed two concerns about this implication.

First, the paper's one-for-one relationship between $r^{*}$ and the optimal inflation target indicates that there is no trade-off between policy space and higher inflation, which implies that the marginal cost of inflation in the authors' model must be very low. Bernanke wondered about the realism of this assumption. Second, he noted, it is difficult to change the inflation target in practice as it requires people to change and re-anchor their inflation expectations, which can take years. The Bank of Japan, for instance, has been making announcements about its 2 percent inflation target-first implemented in 2013-for years with little effect. Furthermore, he commented, the authors treat the inflation target like a policy variable that could change again in the future, which would make it even more difficult to re-anchor expectations in practice.

Bernanke pointed out that moving away from a Taylor rule-toward lower for longer, forward guidance, and quantitative easing policiesis an alternative to raising the inflation target. For example, in a recent paper with Kiley and Roberts using the Federal Reserve's model of the US economy-FRB/US - he finds that inflation threshold forward guidance policies and temporary price level targeting can fully compensate for the zero lower bound when real $r^{*}$ is 1 percent and nominal $r^{*}$ is 3 percent. ${ }^{2}$ Another Kiley paper shows that quantitative easing can offset the zero lower bound as well. ${ }^{3}$ Bernanke concluded that changing the way we conduct monetary policy is preferable to raising the inflation target.

John Haltiwanger highlighted a recent paper by Redding and Weinstein that uses item level transaction data to show that conventional price indices

2. Ben S. Bernanke, Michael T. Kiley, and John M. Roberts, "Monetary Policy Strategies for a Low-Rate Environment," AEA Papers and Proceedings 109 (2019): 421-26.

3. Michael T. Kiley, "Quantitative Easing and the "New Normal' in Monetary Policy," Working Paper no. 2018-004 (Washington, DC: Board of Governors of the Federal Reserve System, 2018), https://www.federalreserve.gov/econres/feds/files/2018004pap.pdf. 
substantially overstate inflation because they fail to account for rapid product turnover and quality improvements. ${ }^{4}$ Haltiwanger pointed out that if inflation is mismeasured, then productivity and output estimates will be wrong as well. He wondered how sensitive the inferences from the paper and the general discussion are to economic mismeasurement, and the mismeasurement of inflation in particular.

William Brainard noted that in the authors' model the costs of inflation reflected the inefficient production of intermediate products because of the price distortions caused by Calvo pricing. Firms face a constant probability of not being able to re-optimize prices. With Calvo pricing the resulting allocation inefficiencies are dominated by the large distortions caused by the prices of firms who have had bad luck, not having had a chance to adjust their price even though there is a great difference between it and its profit-maximizing value. As Robert Lucas has observed, this is implausible and implies that estimates of the welfare cost of price distortions estimated with Calvo prices are a poor measure of their actual cost. They are not well suited to determine the balance between the allocational costs of inflation with the risks of hitting the lower bound.

While Brainard believed that high rates of inflation would be costly, he noted Akerlof, Dickens, and Perry finding that low, but positive, levels of inflation actually improve welfare relative to zero inflation by raising employment rates. ${ }^{5}$ Their findings suggest that moving from a 2 percent inflation target to a 3 or 4 percent target might not entail any significant allocation costs. Brainard thought that while 2 percent inflation is low enough that it doesn't factor into most individuals' and firms' behavior, at a much higher rate it would, and high target rates run a risk of triggering an inflationary spiral.

Channeling James Tobin, Benjamin Friedman argued that there are many worse things than 3 percent inflation, yet despite changed economic conditions - specifically, as this paper points out, a lower equilibrium real interest rate - central bankers are becoming increasingly desperate in their attachment to the 2 percent target. He regrets that despite what we have

4. Stephen J. Redding and David E. Weinstein, "Measuring Aggregate Price Indexes with Taste Shocks: Theory and Evidence for CES Preferences," Working Paper no. 22479 (Cambridge, Mass.: National Bureau of Economic Research, 2016), https://www.nber.org/ papers/w22479.

5. George A. Akerlof, William T. Dickens, and George L. Perry, "The Macroeconomics of Low Inflation," Brookings Papers on Economic Activity, no. 1 (1996), https:// www.brookings.edu/bpea-articles/the-macroeconomics-of-low-inflation/. 
learned about the importance of avoiding getting stuck at the zero lower bound, the Federal Reserve has ruled out raising its inflation target as part of its ongoing framework review. Their argument is that because they said in the past that the target was 2 percent, it must always remain there. Friedman asked whether when we get to 2016, Federal Reserve policymakers will still say that the target must be 2 percent because that's what they announced in 2012.

Robert Hall pointed out that while this paper focuses on the effect of $r^{*}$ on the optimal inflation target, it also has implications for the effect of $r^{*}$ on $r$-the central bank's policy rate. In a standard Taylor rule, when $r^{*}$ falls by 1 percentage point $r$ declines by the same amount. If the central bank were to also raise the inflation target by 1 percentage point- the authors' prescribed response - then $r$ would need to fall by more. This is because the inflation target would increase immediately when $r^{*}$ declines, while actual inflation responds gradually. This slow response creates a gap between actual inflation and the target. Therefore, the authors imply that central banks should respond more aggressively to changes in $r^{*}$ than under a standard Taylor rule.

In response to Bernanke's point that changing the inflation target is difficult in practice, Jay Shambaugh wondered whether we should also consider fiscal policy as an alternative way of getting away from the zero lower bound rather than focusing on more complicated monetary policy rules. He also wondered what emerging market economies - many of which are still establishing their inflation targets—could learn from the paper. Perhaps as they gradually lower their inflation targets, he reasoned, they should stop at 3 percent, rather than 2 percent.

James Stock pushed back against focusing on either raising the inflation target or unconventional monetary policy, and not both. He noted that there are, after all, limitations to unconventional monetary policies, for example, how long the credibility of forward guidance can persist given the turnover of Federal Reserve board members and the pressures the Federal Reserve is under. In addition, there are political limits to how large the Federal Reserve's balance sheet can get. Stock argued that we should consider unconventional policies in tandem with the possibility of raising the inflation target to reduce the likelihood of hitting the zero lower bound.

David Wilcox suggested that the authors should consider using an asymmetric Taylor rule in their model, akin to the rule used by Chung and others in a recent Federal Reserve working paper, where interest rates are increased gradually during a recovery but cut rapidly in response to 
negative demand shock. ${ }^{6}$ Such an asymmetric rule is a better description of how the Federal Reserve has conducted monetary policy, Wilcox said.

Olivier Blanchard said that despite his support for the idea of a 4 percent inflation target to counteract the 2 percentage point decline in $r^{*}$ over the past several decades, a comment made by Stanley Fisher at this year's Sintra conference raised a relevant issue. Fisher said that when he was considering raising the inflation target to 4 percent in Israel he was told by the unions that they would respond by demanding wage indexation. Blanchard recognized that people do not care much about inflation when it is at 2 percent but they might care when inflation is 4 percent. This might lead them to react more to actual inflation than they do today, changing again the nature of the Phillips curve relation and complicating the task of the central bank. Blanchard also agreed with Shambaugh that it is important to discuss using fiscal policy to help counteract the zero lower bound and said he would be interested in papers that explore the effectiveness of fiscal policy in an analytical framework similar to the authors' paper.

Philippe Andrade thanked the discussants and audience for their insightful comments. He said that many of the comments are addressed in the paper's robustness checks. He noted that adjusting the labor and goods markets in the model and accounting for parameter uncertaintyfor instance, uncertainty about the slope of the Phillips curve-raises the model's optimal inflation target and does not weaken its relationship with $r^{*}$. He also emphasized that the model uses an inertial Taylor rule which already implies a lot of forward guidance.

Andrade acknowledged Kiley's suggestion that deviating from the model's assumption of rational expectations would make zero lower bound episodes less costly and therefore reduce the necessity of a higher inflation target. However, he pointed out that deviating from rational expectations would also make alternatives to raising the inflation target-like forward guidance-less effective, strengthening the argument for a higher inflation target. So the effect of relaxing the rational expectations assumption could go either way.

6. Hess Chung, Etienne Gagnon, Taisuke Nakata, Matthias Paustian, Bernd Schlusche, James Trevino, Diego Vilán, and Wei Zheng, "Monetary Policy Options at the Effective Lower Bound: Assessing the Federal Reserve's Current Policy Toolkit," Working Paper no. 2019-003 (Washington, DC: Board of Governors of the Federal Reserve System, 2019), https://www.federalreserve.gov/econres/feds/files/2019003pap.pdf. 
In response to comments that argued for changing the monetary policy strategy rather than the inflation target, Andrade accepted that in practice it might be difficult to convince the public of the central bank's commitment to a new target. But he countered that because of the frequency of zero lower bound episodes at the current inflation target, inflation might undershoot 2 percent for long periods, bringing the central bank's commitment to the current 2 percent target into question as well. While he agreed that it might be difficult to build a consensus behind a higher inflation target, he argued that if such a consensus could be achieved, central banks would find it easier to explain than changing the monetary policy rule. This would also be more credible than committing to time-inconsistent policy rules. $\mathrm{He}$ therefore believes that there are credibility arguments that both support and counter increasing the inflation target.

In response to comments suggesting a price level target or a similar monetary policy rule to counteract the zero lower bound, Hervé Le Bihan pointed out that such policies imply some overshooting of inflation with respect to the target following a period of below target inflation. He argued that commenters who raised concerns about a higher inflation target triggering an inflationary spiral should have similar concerns about alternative policies that imply some overshooting of inflation.

Le Bihan also addressed concerns about the model's pricing mechanism. He acknowledged that the authors' choice of Calvo pricing was partially motivated by convenience. But he noted a paper by Blanco suggests that alternatives, like a menu-cost model, would make inflation less costly and strengthen the authors' results. ${ }^{7}$ Le Bihan also reemphasized that they had been careful to test the robustness of their results to changes in the model.

On the issue raised by Luminita Stevens of estimating of the probability of zero or effective lower bound (ELB) Le Bihan concurred that it was difficult to provide reliable estimates given the current historical record of very rare and long events of ELB. For instance, in the euro area, the relevant policy rate has been negative since 2014 and is currently expected to remain negative for more than seven years according to market-implied data. Such facts however point to the relevance of the ELB constraint and to the need for adjusting the monetary policy strategy.

Jordi Galí took a step back from the specifics of the model and built on the sentiment in Friedman's comment. When central banks chose a 2 percent inflation target several years ago their beliefs about $r^{*}$ were a key

7. Andrés Blanco, "Optimal Inflation Target in an Economy with Menu Costs and Zero Lower Bound," Working Paper. https://sites.google.com/a/umich.edu/andres-blanco/. 
component in that choice. Now that $r^{*}$ has decreased, perhaps permanently, he commented, it makes sense to revisit that choice. Indeed, the decline in $r^{*}$ necessitates either a change in the inflation target or a change in monetary policy strategy, perhaps combined with fiscal policy, Galí argued. Sticking with a business as usual approach is untenable and is inconsistent with a view of a monetary policy framework built in a more rational, more systematic way, over twenty years ago.

Galí concluded by thanking both the discussants and the audience for their great comments. 